\title{
Synthesis of isoxazolines by the electrophilic chalcogenation of $\beta, \gamma-$ unsaturated oximes: fishing novel anti-inflammatory agents
}

Eric Francis Lopes, ${ }^{a}$ Filipe Penteado, ${ }^{a}$ Samuel Thurow, ${ }^{a}$ Mikaela Pinz, ${ }^{b}$ Angelica Reis, ${ }^{b}$ Ethel Wilhelm, ${ }^{\mathrm{b}}$ Cristiane Luchese, ${ }^{\mathrm{b}}$ Thiago Barcellos, ${ }^{\mathrm{c}}$ Bianca Dalberto ${ }^{\mathrm{a}}$ Diego Alves, ${ }^{\mathrm{a}}$ Marcio S. da Silva ${ }^{a}$ and Eder João Lenardãoa,*

a Laboratório de Síntese Orgânica Limpa - LASOL - CCQFA - Universidade Federal de Pelotas UFPel - P.O. Box 354 - 96010-900, Pelotas, RS, Brazil.

b Laboratório de Pesquisa em Farmacologia Bioquímica (LaFarBio), Grupo de Pesquisa em Neurobiotecnologia - GPN -CCQFA, Universidade Federal de Pelotas - UFPel - P.O. Box 354 96010-900, Pelotas, RS, Brazil.

c Laboratory of Biotechnology of Natural and Synthetic Products, Universidade de Caxias do Sul UCS, 95070-560, Caxias do Sul, RS, Brazil.

\section{Contents:}

Mechanism studies through monitoring of short-live intermediates by HRMS

Figure S1

Figure S2.

Figure S3.

Figure S4 


\section{Mechanism studies through monitoring of short-live intermediates by HRMS}

For mechanism studies, the formation of short-live intermediates was analyzed by HRMS. The aliquots were sampled directly from the reaction experiments, immediately dissolved in MeCN and injected into the APCI source at a constant flow rate of $3.0 \mu \mathrm{L} / \mathrm{min}$. The presence of the selenium atom in the intermediates was confirmed by its characteristic isotope pattern, which comprises six stable and abundant isotopes.

Experimental Procedure \#1: Oxime 1f $(0.1 \mathrm{mmol})$ was added to $1 \mathrm{~mL}$ of acetonitrile, followed by the addition of phenylselenyl chloride $2 \mathbf{a}(0.1 \mathrm{mmol})$. As soon as the solution became homogeneous, a $50 \mu \mathrm{L}$ aliquot was collected, diluted in $\mathrm{MeCN}$ and injected into the APCI source. 


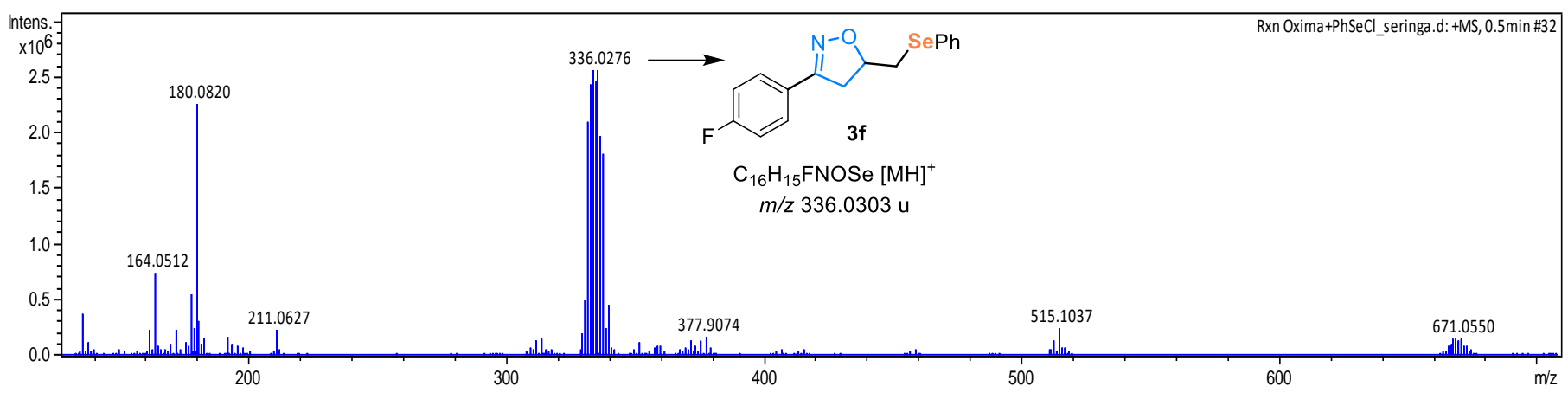

Figure S1. Full HRMS spectrum (APCl source), from 0 to $700 \mathrm{~m} / \mathrm{z}$, obtained from the experiment \#1.

(A)

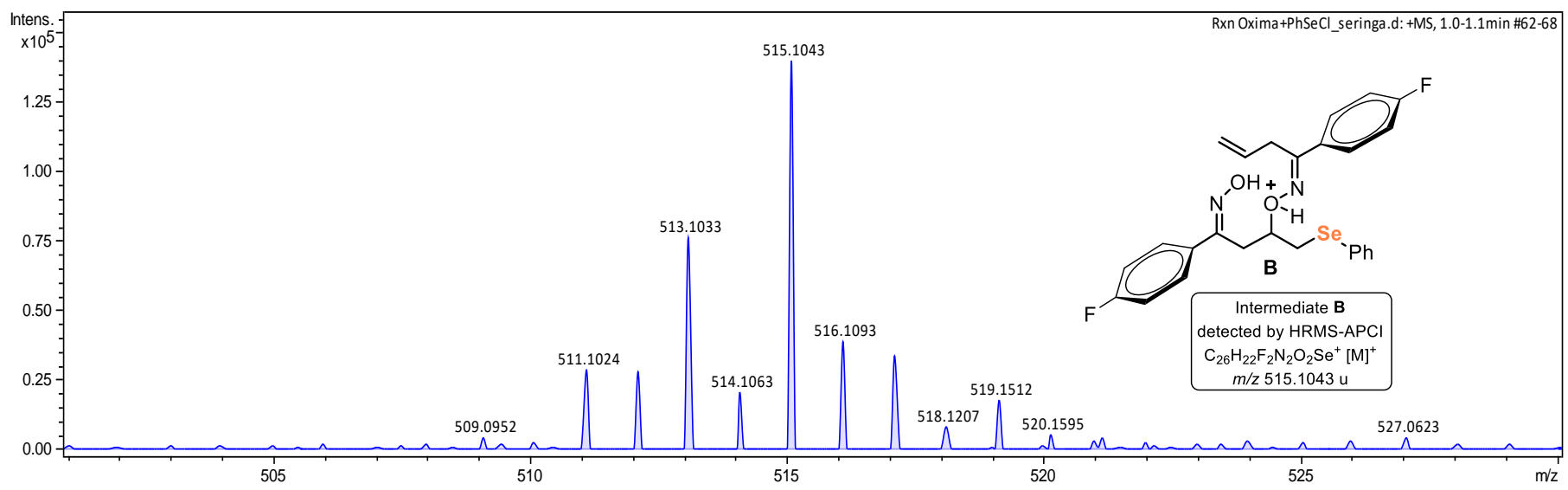

(B)

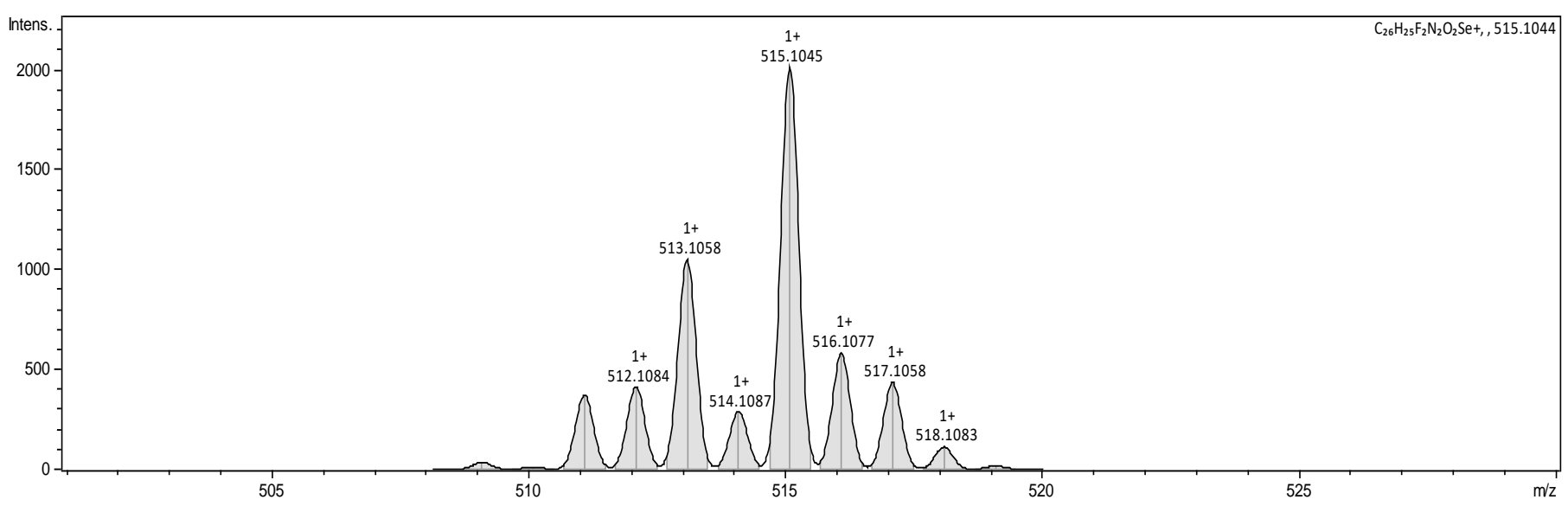

Figure S2. Expanded region of the spectrum of experiment \#1 (Figure S1) showing the peak with $\mathrm{m} / \mathrm{z}$ 515.1043 attributed to the intermediate $\mathbf{B}(A)$, and the simulated $\mathrm{m} / \mathrm{z}$ and isotope partner for the molecular formula $\mathrm{C}_{26} \mathrm{H}_{22} \mathrm{~F}_{2} \mathrm{~N}_{2} \mathrm{O}_{2} \mathrm{Se}^{+}[\mathrm{H}]^{+}(\mathrm{B})$. 
(A)

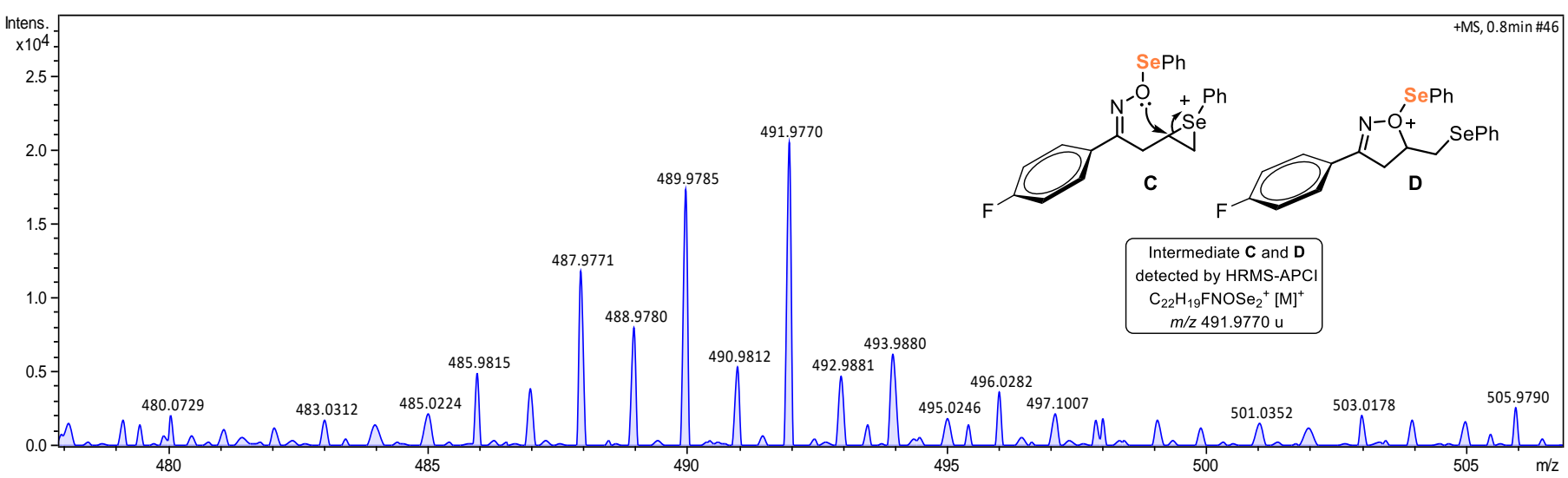

(B)

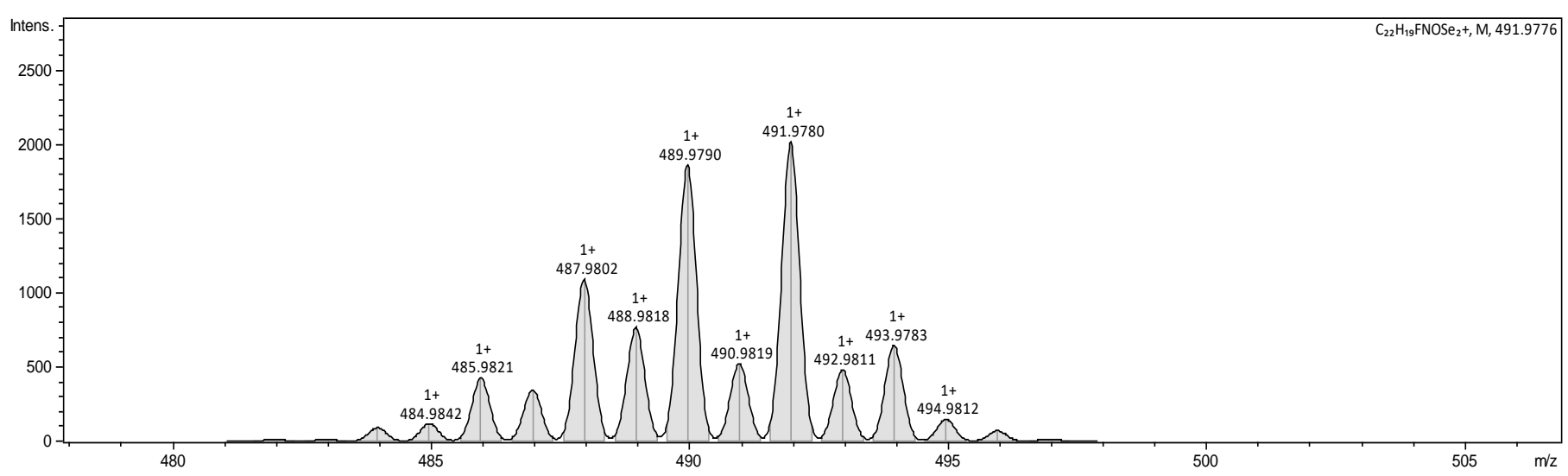

Figure S3. Expanded region of the spectrum of experiment \#1 (Figure S1) showing the peak with $\mathrm{m} / \mathrm{z}$ 491.9770 attributed to the intermediate $\mathbf{C}$ and $\mathbf{D}(\mathbf{A})$, and the simulated $\mathrm{m} / \mathrm{z}$ and isotope partner for the molecular formula $\mathrm{C}_{22} \mathrm{H}_{19} \mathrm{FNOSe}^{+}[\mathrm{H}]^{+}(\mathrm{B})$. 

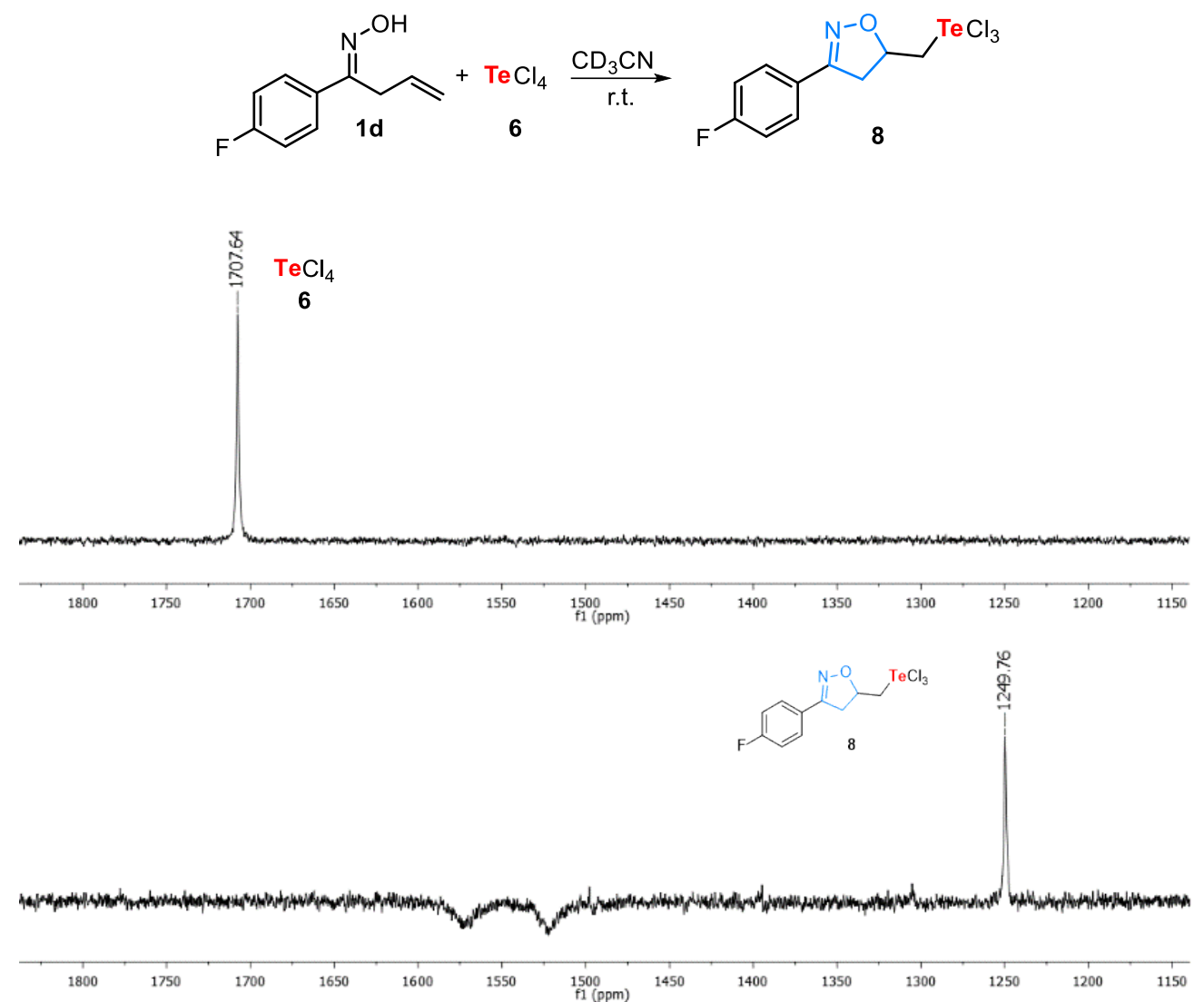

(A)

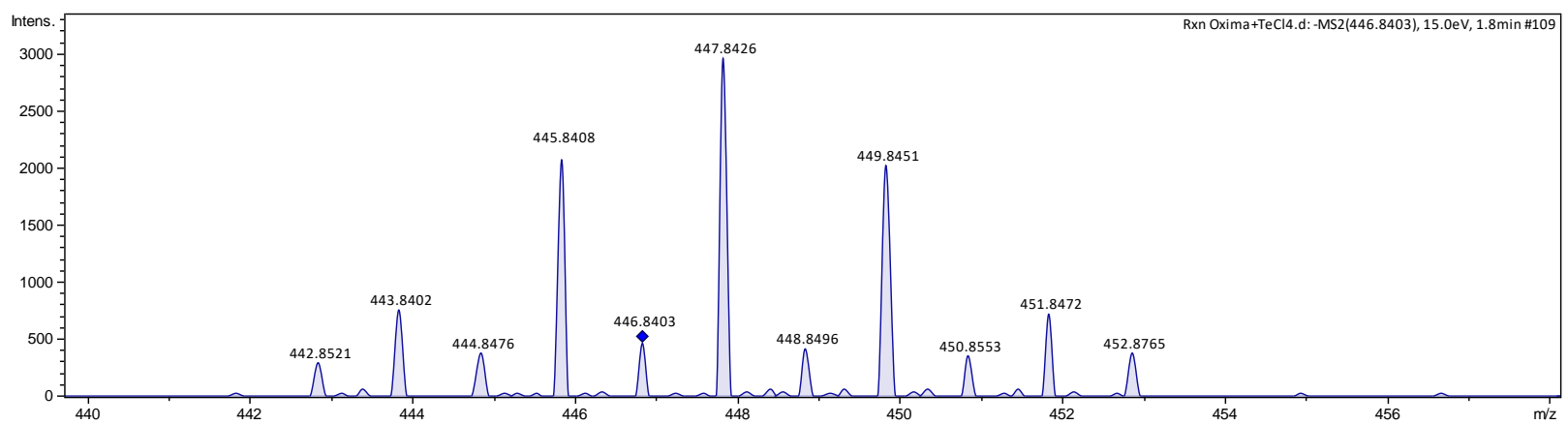

(B)

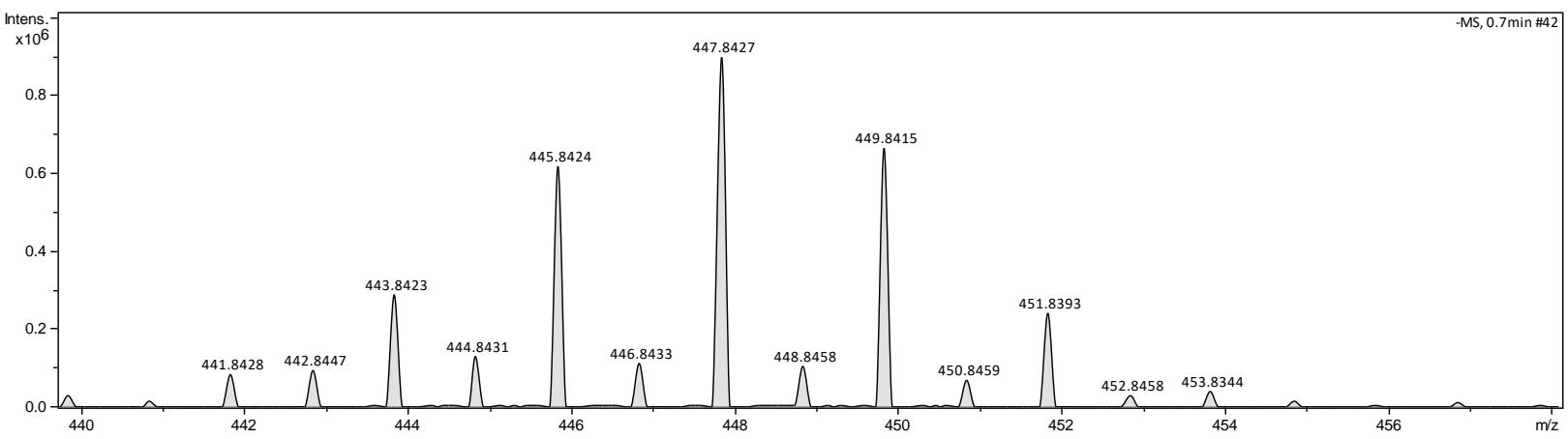

Figure S4. ${ }^{125}$ Te NMR spectrum and HRMS data of the reaction between tellurium tetrachloride 6 and $\beta, Y-$ unsaturated oxime 1d. Showing the peak with $\mathrm{m} / \mathrm{z} 447.8426$ attributed to the intermediate $8(\mathrm{~A})$, and the simulated $\mathrm{m} / \mathrm{z}$ and isotope partner for the molecular formula $\left.\mathrm{C}_{10} \mathrm{H}_{9} \mathrm{Cl}_{4} \mathrm{FNOTe}^{-[\mathrm{H}}\right]^{-}(\mathrm{B})$. 


\section{Bioassays - Statistical analysis}

Data were analyzed by Graphpad Prism $^{\circledR} 5$ and the normality of data was evaluated by the D'Agostino and Pearson omnibus normality test. Statistical analysis was performed using one-way analysis of variance (ANOVA) followed by the Newman- Keuls' test when appropriated. For acute toxicity assay, the data were analyzed using a non-paired t-test. Probability values less than 0.05 $(p<0.05)$ were considered statistically significant. Data were expressed as mean \pm S.E.M.

Table S1. Effect of a single administration of PPSEI45 $(300 \mathrm{mg} / \mathrm{kg})$ on the plasmatic biochemical markers in mice.

\begin{tabular}{lll}
\hline & Control & PPSEI45 \\
\hline AST (U/L) & $55 \pm 9$ & $61 \pm 6$ \\
ALT (U/L) & $62 \pm 13$ & $49 \pm 32$ \\
Urea (mg/dL) & $70 \pm 20$ & $49 \pm 1$ \\
\hline
\end{tabular}

Data are reported as mean \pm standard error of the mean (SEM) of three animals per group. Statistical analysis was performed using a non-paired t test. Abbreviations: Aspartate (AST) and alanine (ALT) aminotransferases, 3-phenyl-5-((phenylselanyl) methyl)-4,5dihydroisoxazole 3a (PPSEI45).

Table S2. Effect of a single oral administration of PPSEI45 (300 mg/kg) on $\delta$-ALA-D activity in liver, kidney and brain of mice.

\begin{tabular}{ccc}
\hline & Control & PPSEI45 \\
\hline Liver (nmol PBG/mg protein/h) & $39 \pm 4$ & $30 \pm 3$ \\
Kidney (nmol PBG/mg protein/h) & $4 \pm 1$ & $4 \pm 1$ \\
Brain (nmol PBG/mg protein/h) & $3 \pm 1$ & $1 \pm 1$
\end{tabular}

Data are reported as mean \pm standard error of the mean (SEM) of three animals per group. Statistical analysis was performed using a nonpaired t test. Abbreviations: 3-phenyl-5-((phenylselanyl)methyl)-4,5dihydroisoxazole 3a (PPSEI45), $\delta$-aminolevulinate dehydratase ( $\delta$-ALAD). 


\section{Selected NMR spectra}

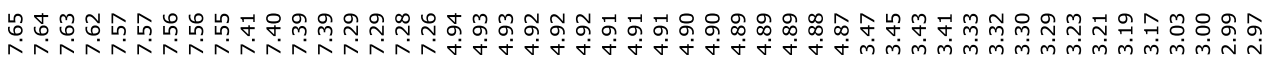<smiles>c1ccc(CSc2ccccc2)cc1</smiles>
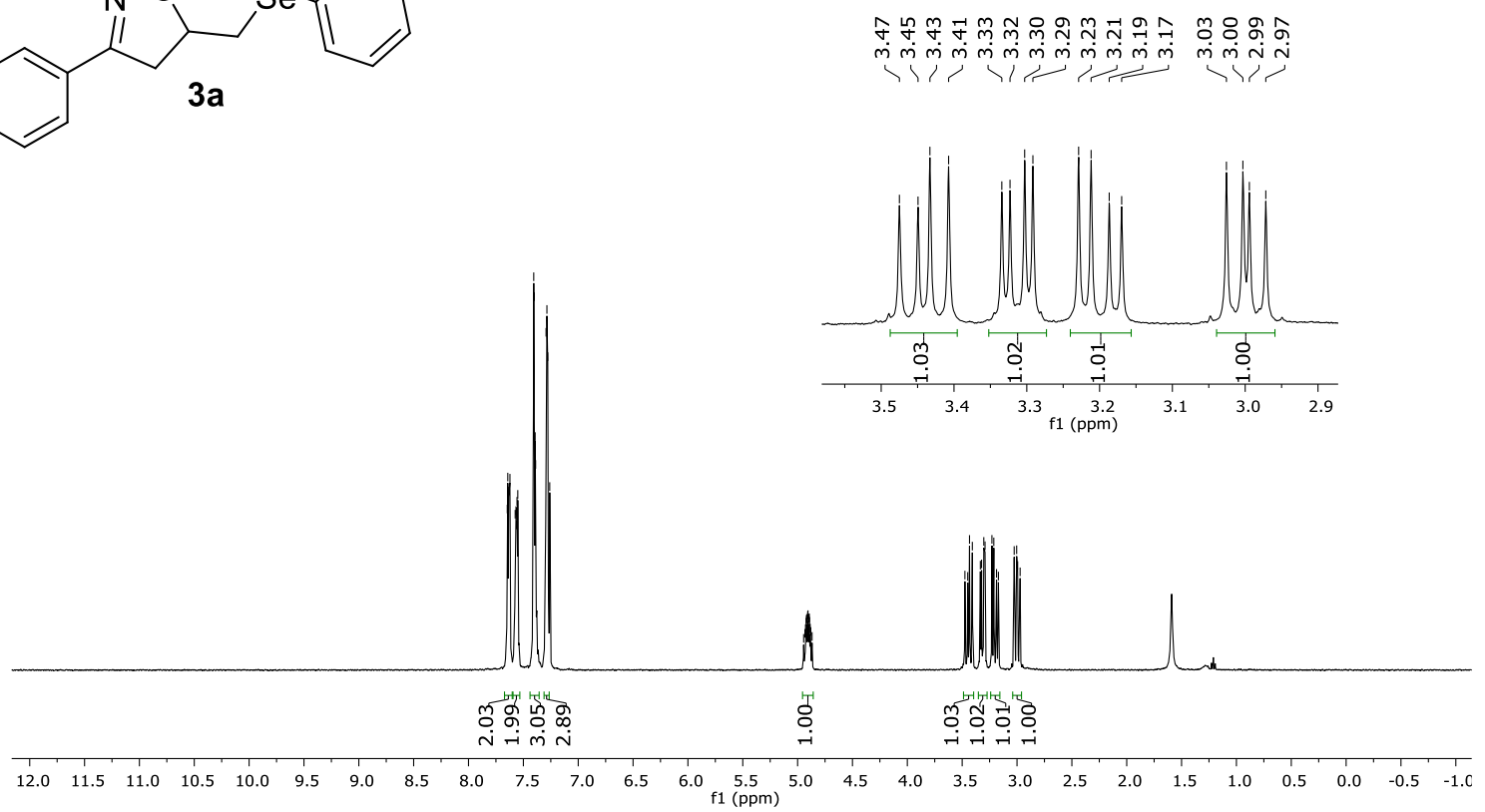

${ }^{1} \mathrm{H}$ NMR $\left(400 \mathrm{MHz}, \mathrm{CDCl}_{3}\right)$ spectrum of $\mathbf{3 a}$.

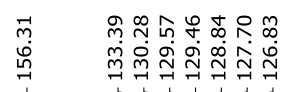

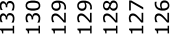

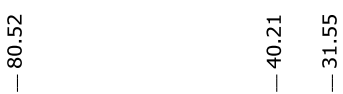
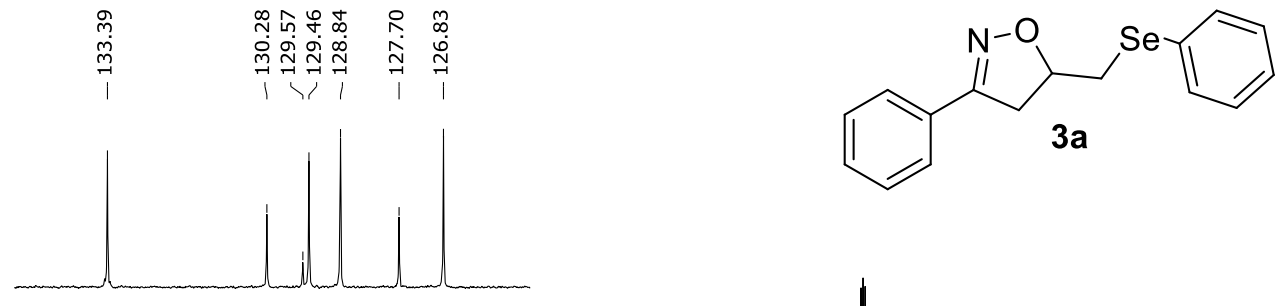

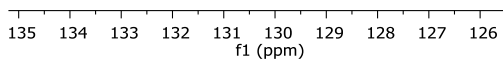

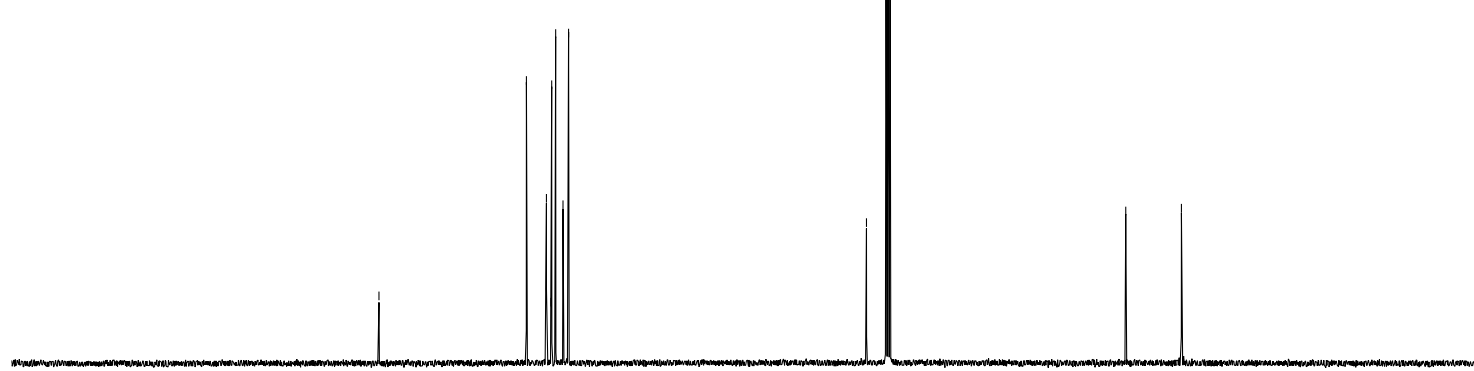

$\begin{array}{llllllllllllllllllllllll}1210 & 200 & 190 & 180 & 170 & 160 & 150 & 140 & 130 & 120 & 110 & 100 & 10 & 80 & 70 & 60 & 50 & 40 & 30 & 20 & 10 & 0 & -10\end{array}$

${ }^{13} \mathrm{C}$ NMR $\left(100 \mathrm{MHz}, \mathrm{CDCl}_{3}\right)$ spectrum of $\mathbf{3} \mathbf{a}$. 
<smiles>Brc1ccc(C2=NOC(C[Se]c3ccccc3)C2)cc1</smiles>
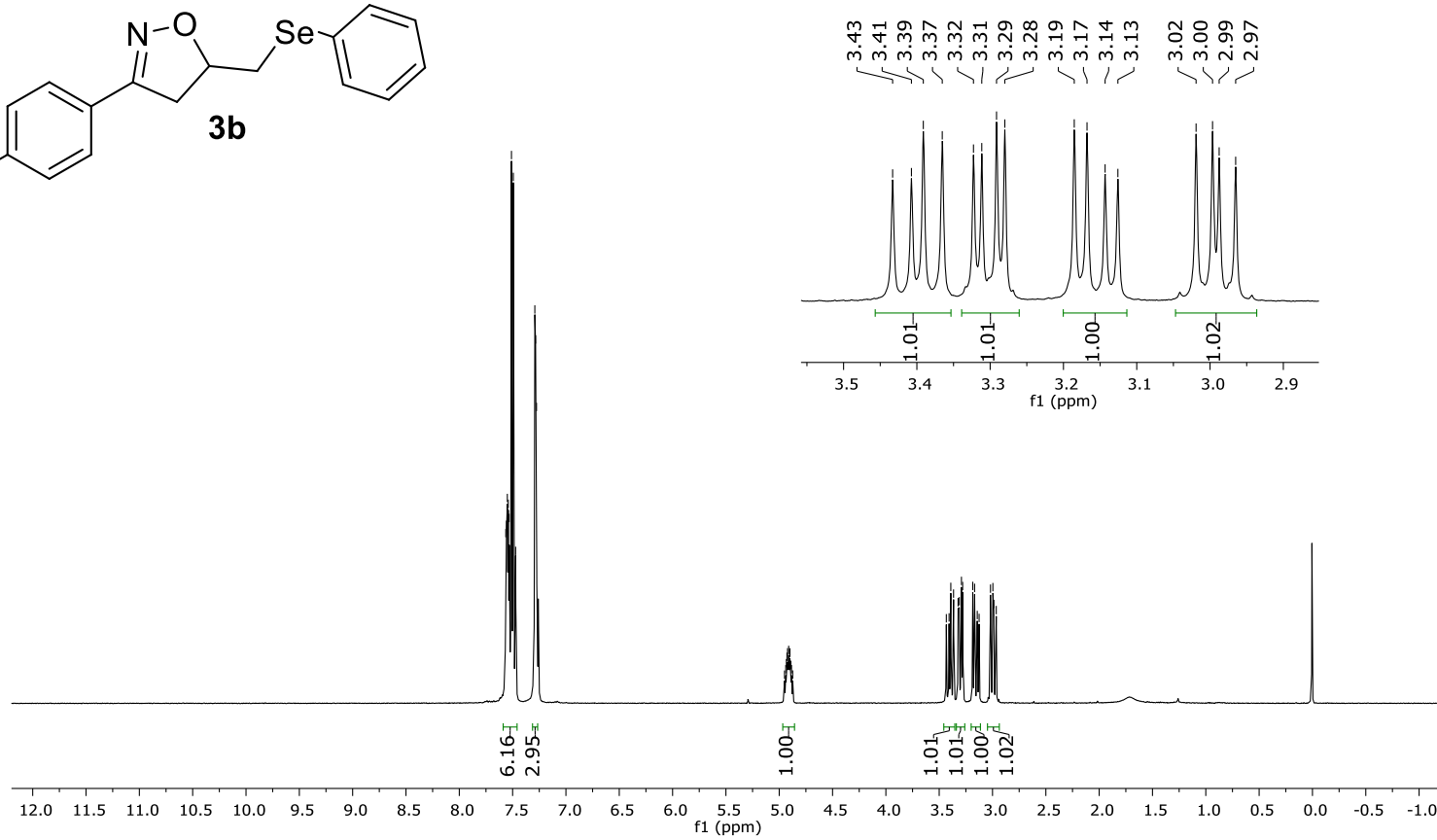

${ }^{1} \mathrm{H}$ NMR $\left(400 \mathrm{MHz}, \mathrm{CDCl}_{3}\right)$ spectrum of $\mathbf{3 b}$.

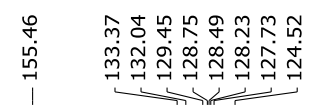

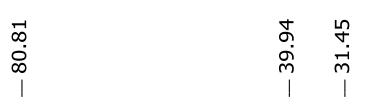

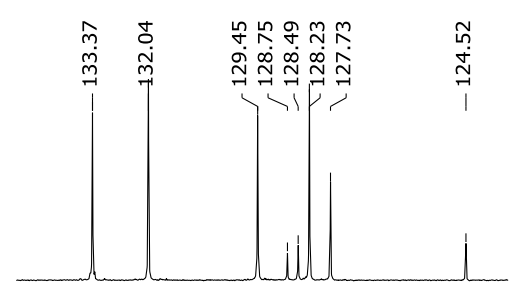

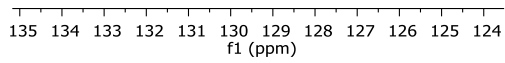<smiles>Brc1ccc(C2=NOC(C[Se]c3ccccc3)C2)cc1</smiles>

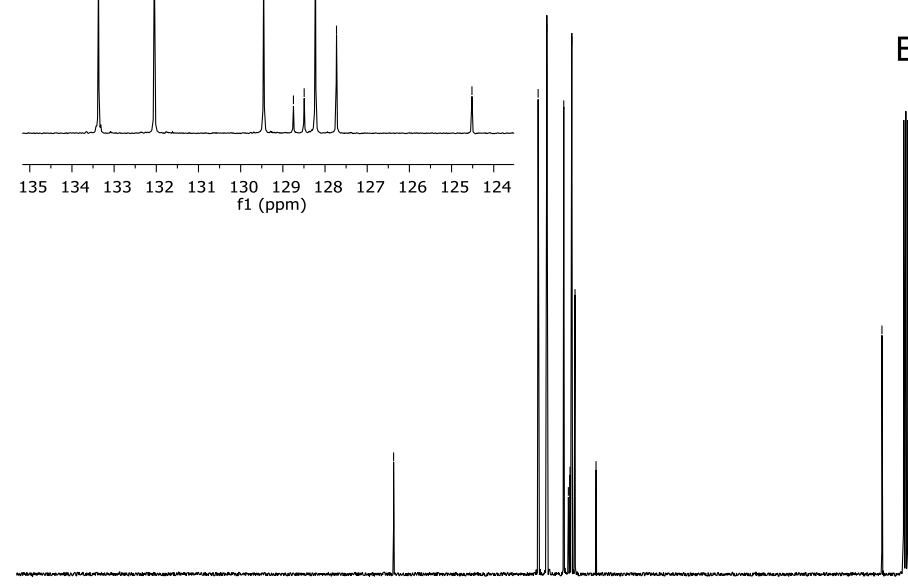

$\begin{array}{lllll}210 & 200 & 190 & 180 & 170\end{array}$

${ }^{13} \mathrm{C}$ NMR $\left(100 \mathrm{MHz}, \mathrm{CDCl}_{3}\right)$ spectrum of $\mathbf{3 b}$. 


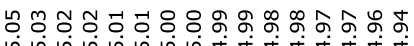

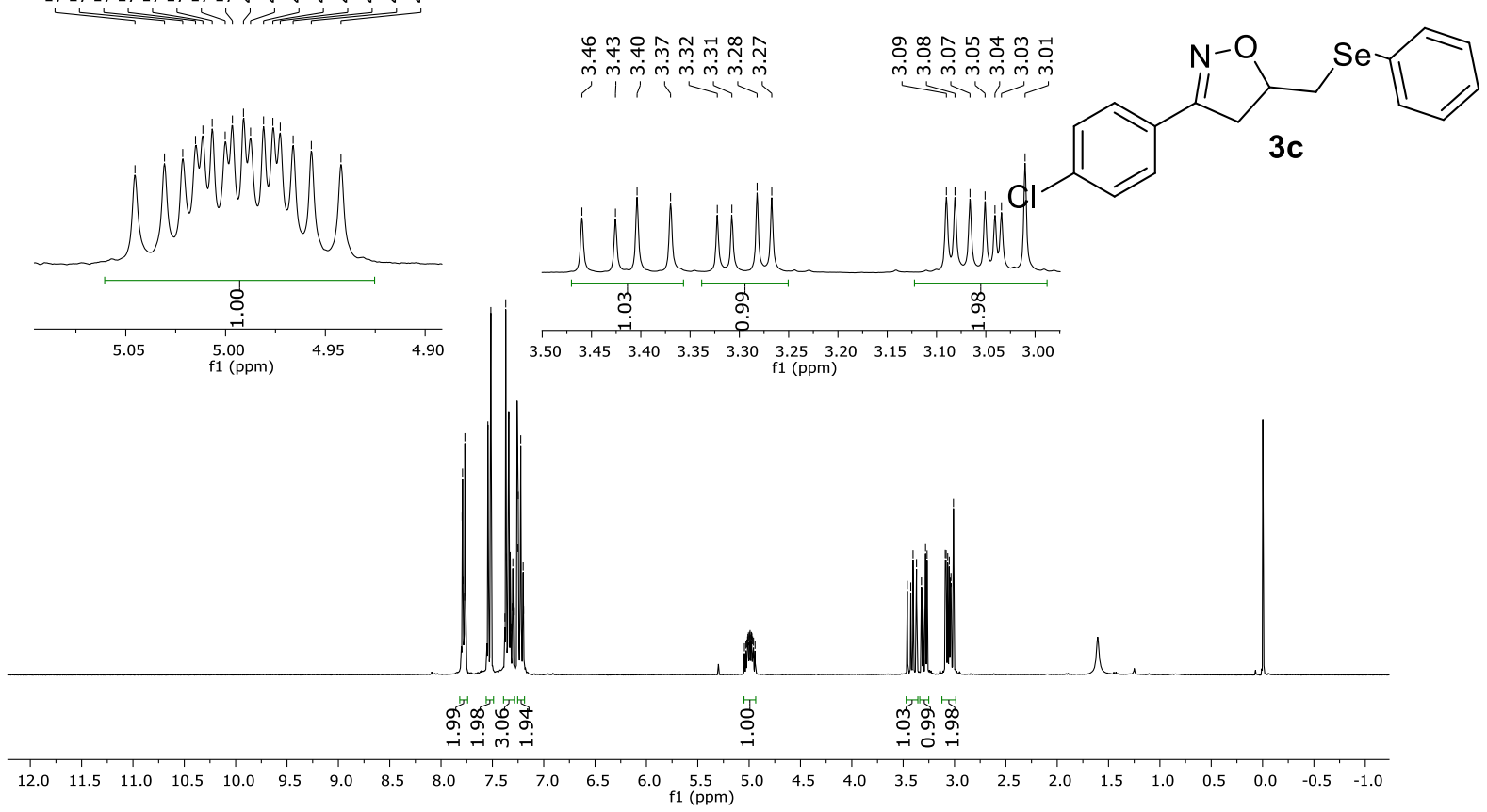

${ }^{1} \mathrm{H}$ NMR $\left(300 \mathrm{MHz}, \mathrm{CDCl}_{3}\right)$ spectrum of $\mathbf{3 c}$.

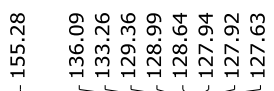

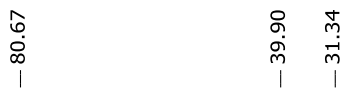

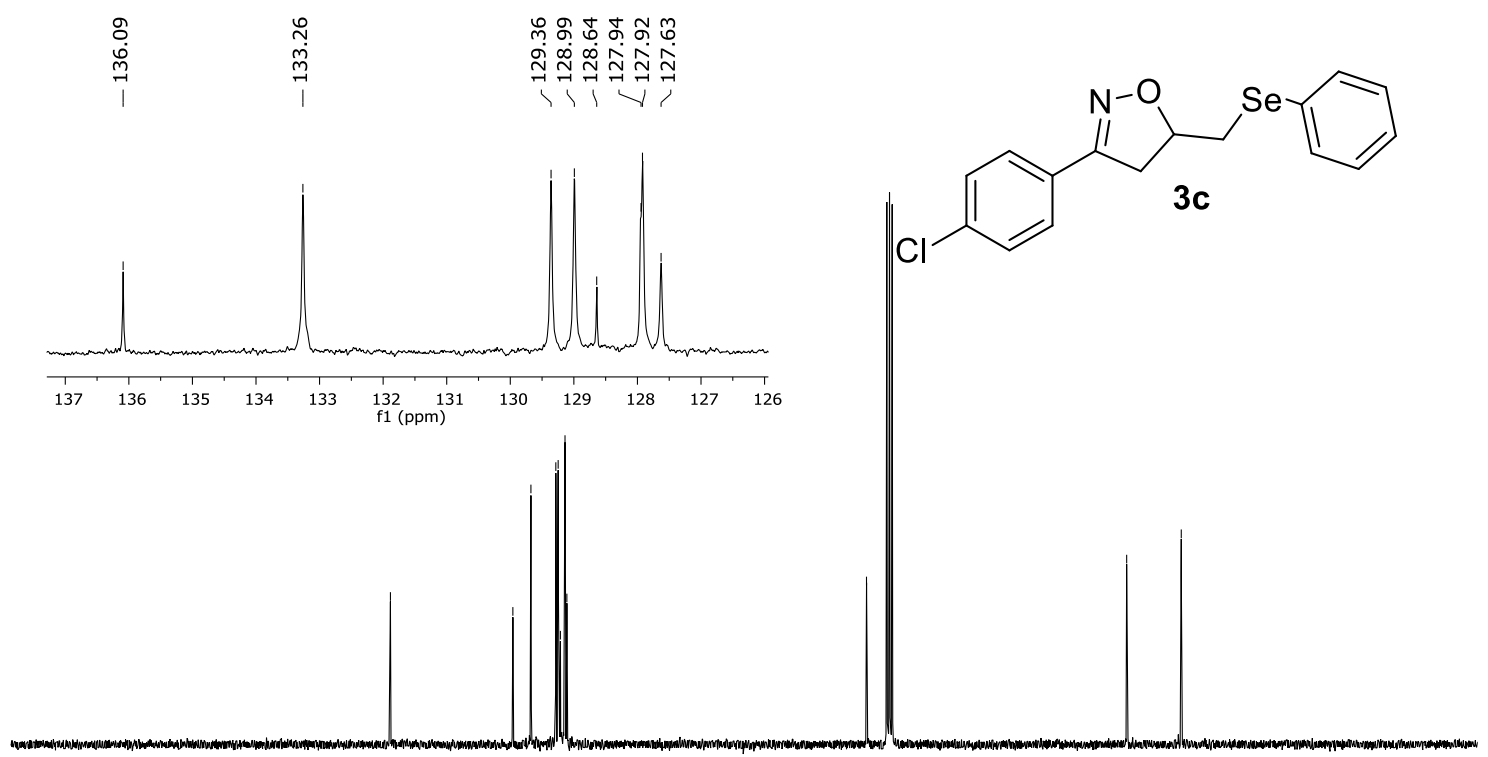

$\begin{array}{llllllllllllllllllllllllllllllll}210 & 200 & 190 & 180 & 170 & 160 & 150 & 140 & 130 & 120 & 110 & 100 & 90 & 80 & 70 & 60 & 50 & 40 & 30 & 20 & 10 & 0 & -10\end{array}$

${ }^{13} \mathrm{C}$ NMR $\left(75 \mathrm{MHz}, \mathrm{CDCl}_{3}\right)$ spectrum of $3 \mathrm{c}$. 


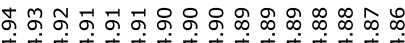

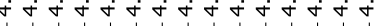

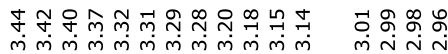
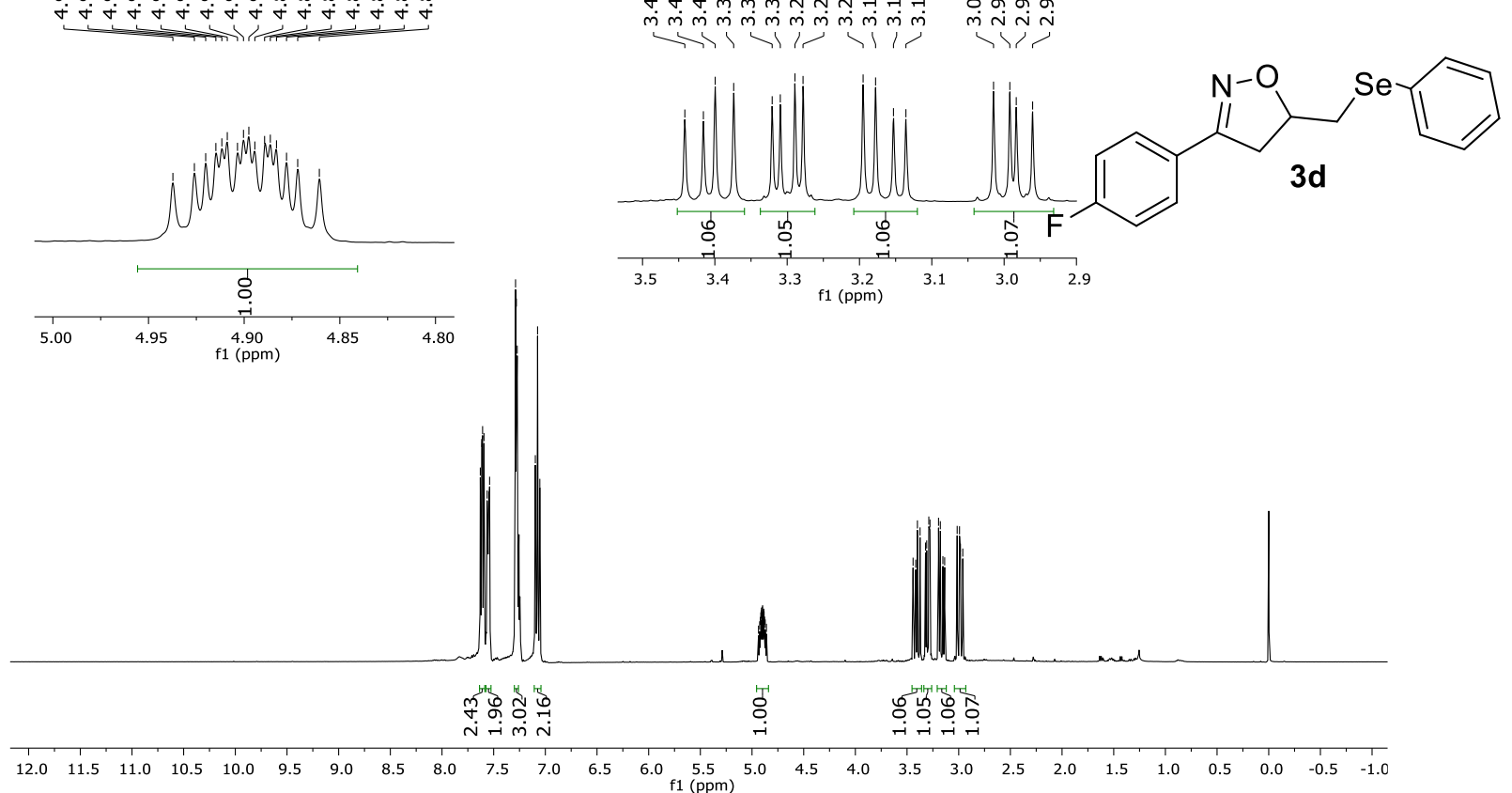

${ }^{1} \mathrm{H}$ NMR $\left(400 \mathrm{MHz}, \mathrm{CDCl}_{3}\right)$ spectrum of $\mathbf{3 d}$
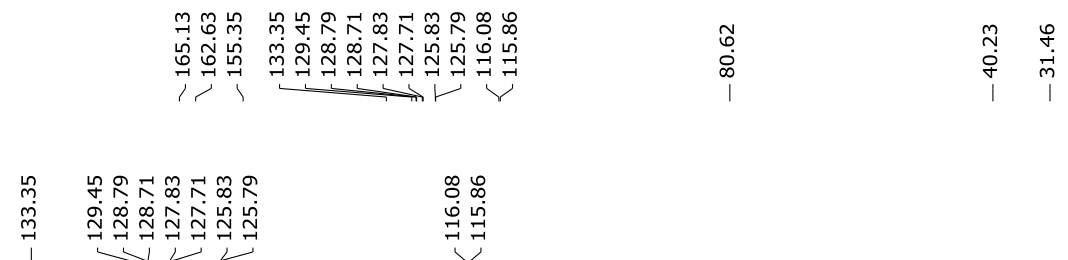

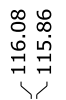
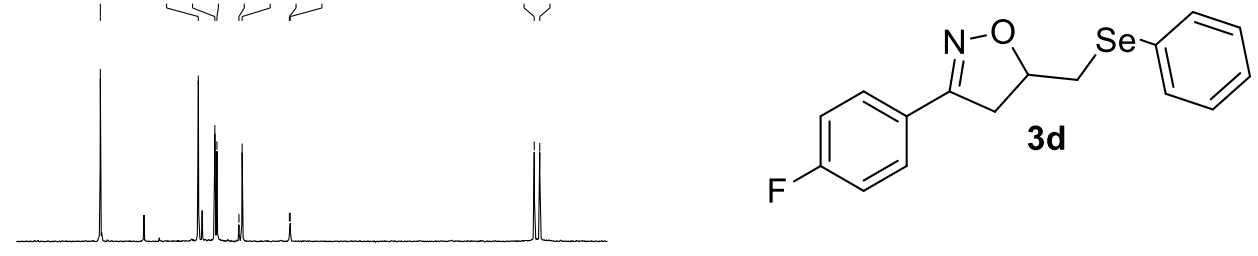

$\begin{array}{llllllllllllllll}136 & 134 & 132 & 130 & 128 & 126 & 124 & 122 & 120 & 118 & 116 & 114\end{array}$

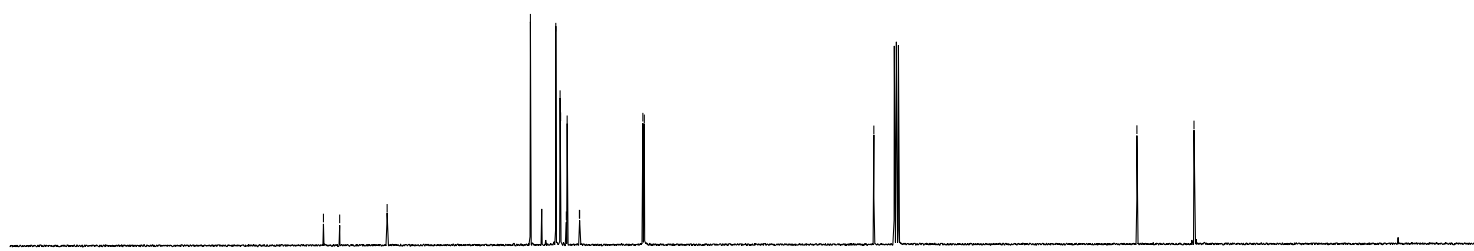

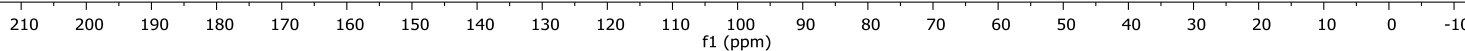
${ }^{13} \mathrm{C}$ NMR $\left(100 \mathrm{MHz}, \mathrm{CDCl}_{3}\right)$ spectrum of $\mathbf{3 d}$. 

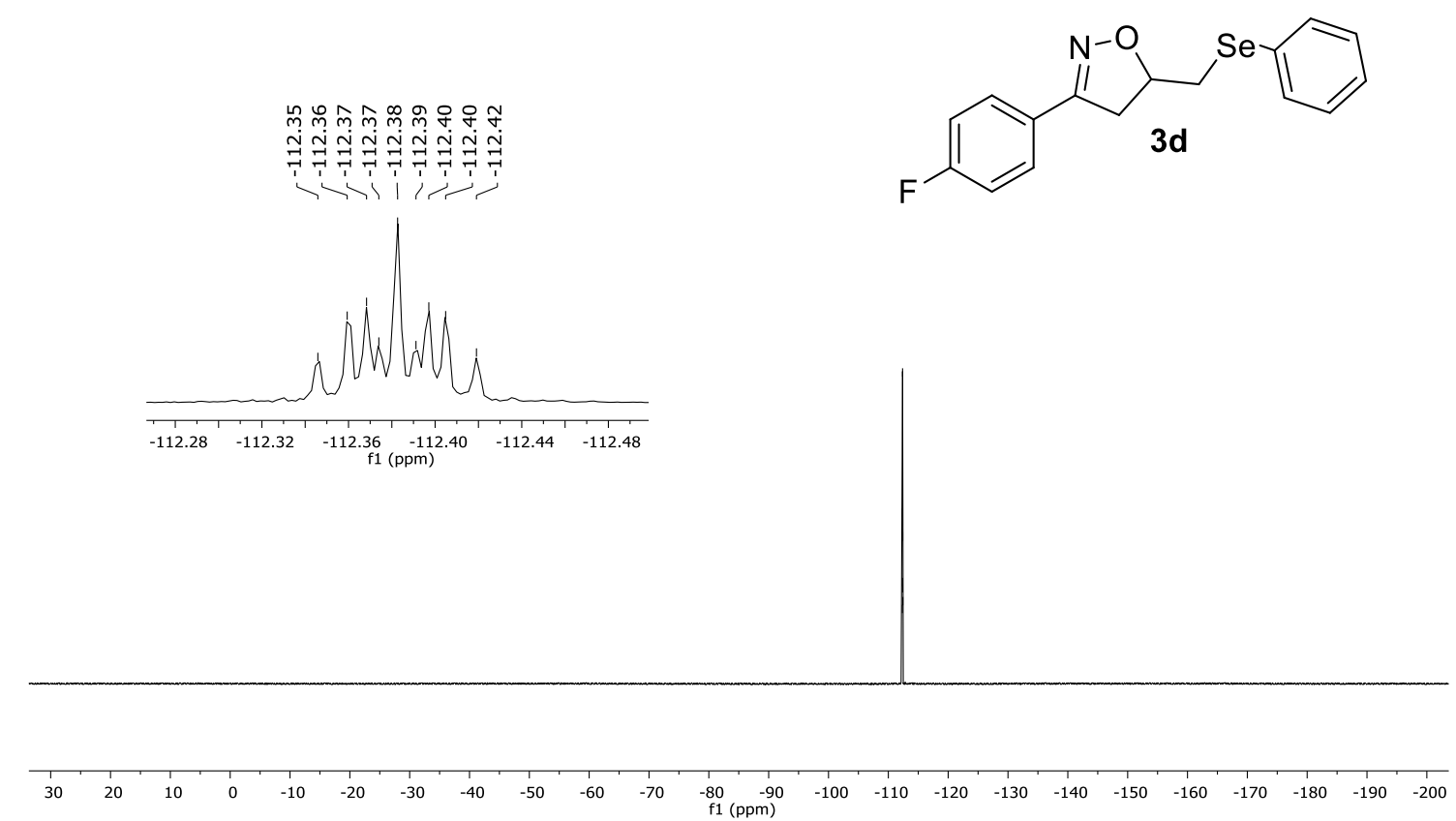

${ }^{19} \mathrm{~F}$ NMR (376 $\left.\mathrm{MHz}, \mathrm{CDCl}_{3}\right)$ spectrum of $\mathbf{3 d}$.
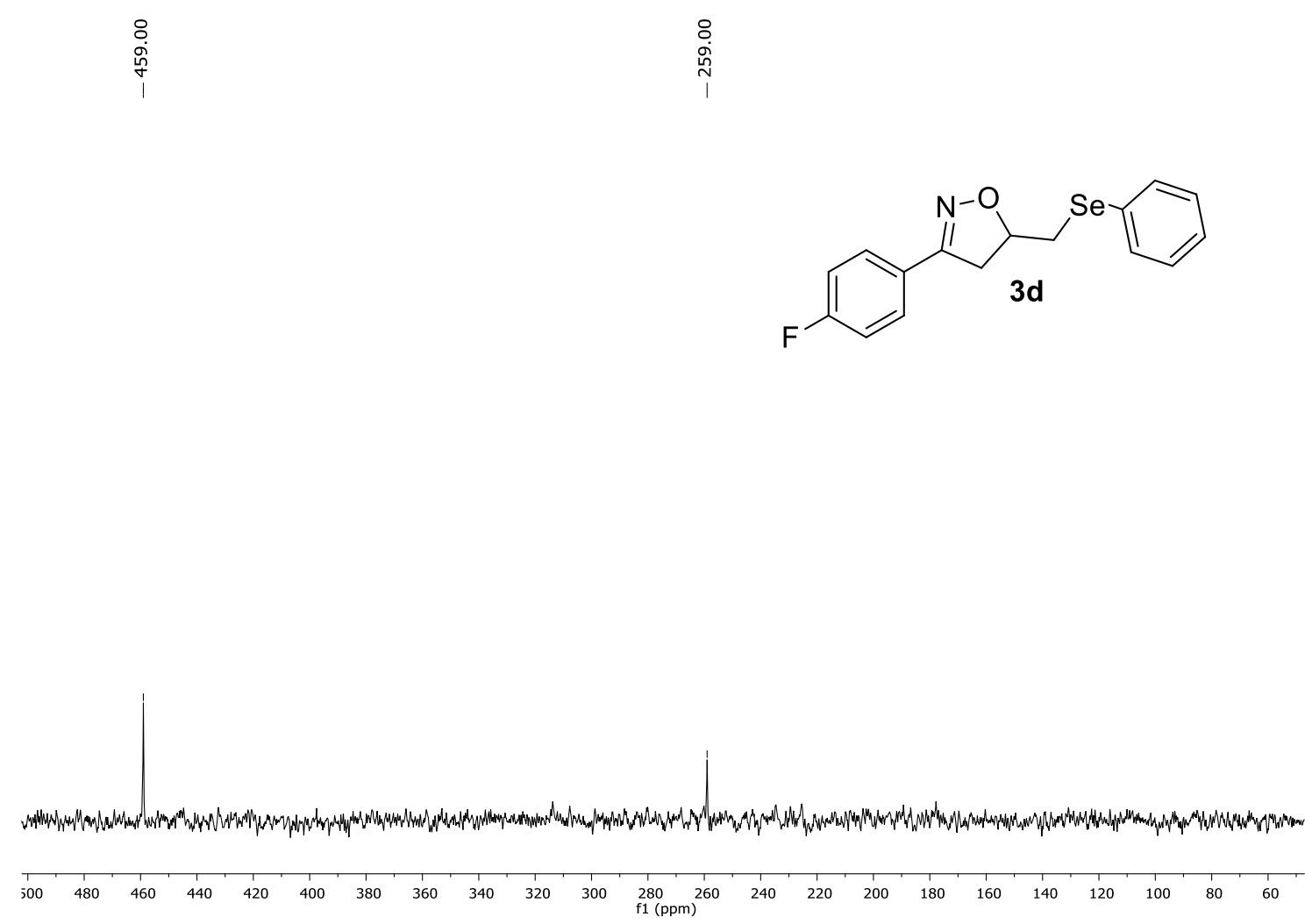

${ }^{77} \mathrm{Se} \mathrm{NMR} \mathrm{(76} \mathrm{MHz,} \mathrm{CDCl}_{3},(\mathrm{PhSe})_{2}$ as internal standard) spectrum of $\mathbf{3 d}$. 

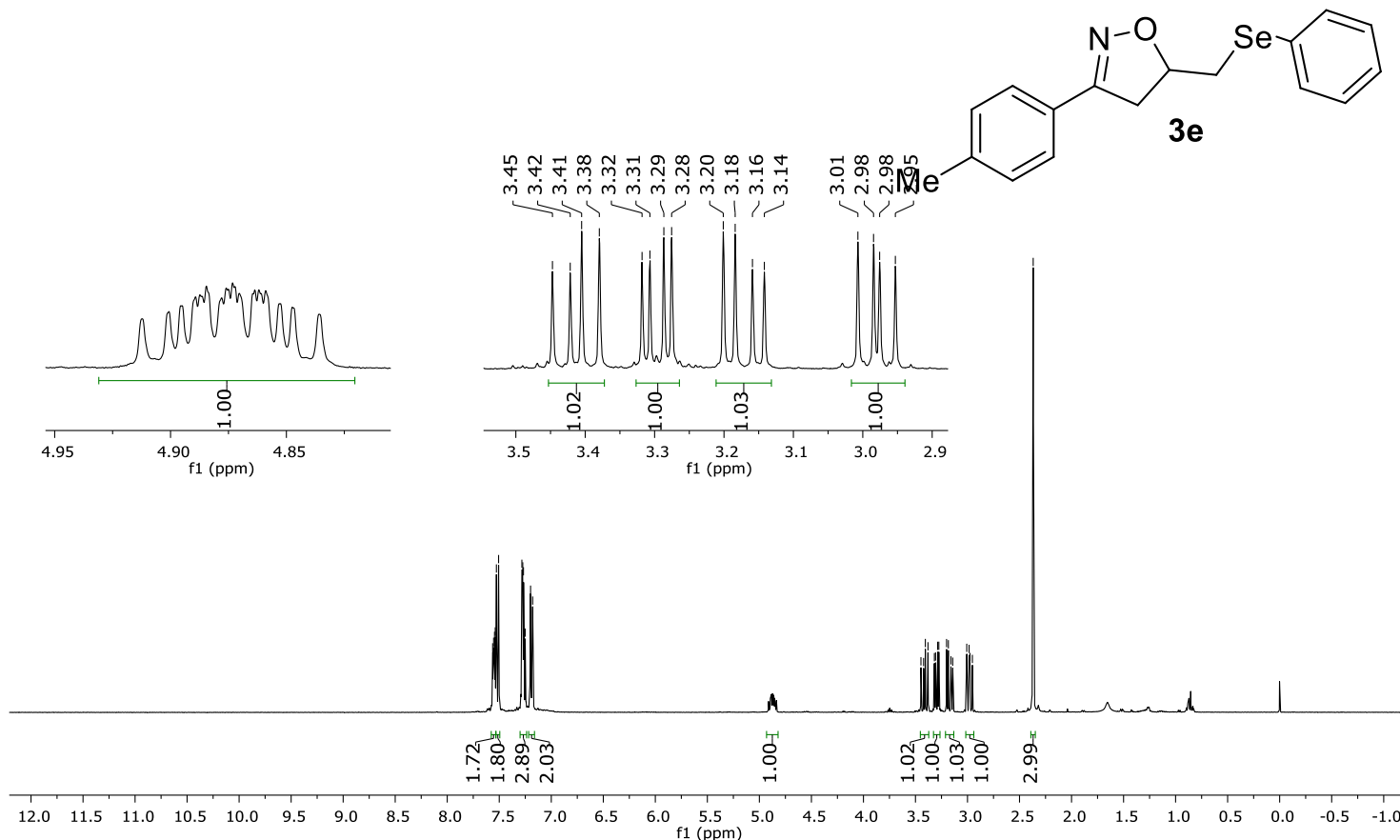

${ }^{1} \mathrm{H}$ NMR $\left(400 \mathrm{MHz}, \mathrm{CDCl}_{3}\right)$ spectrum of $\mathbf{3 e}$.

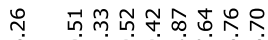

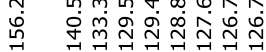

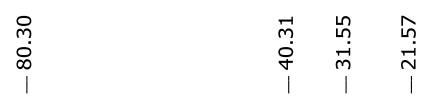<smiles>Cc1ccc(C2=NOC(C[Se]c3ccccc3)C2)cc1</smiles>

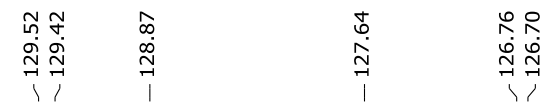

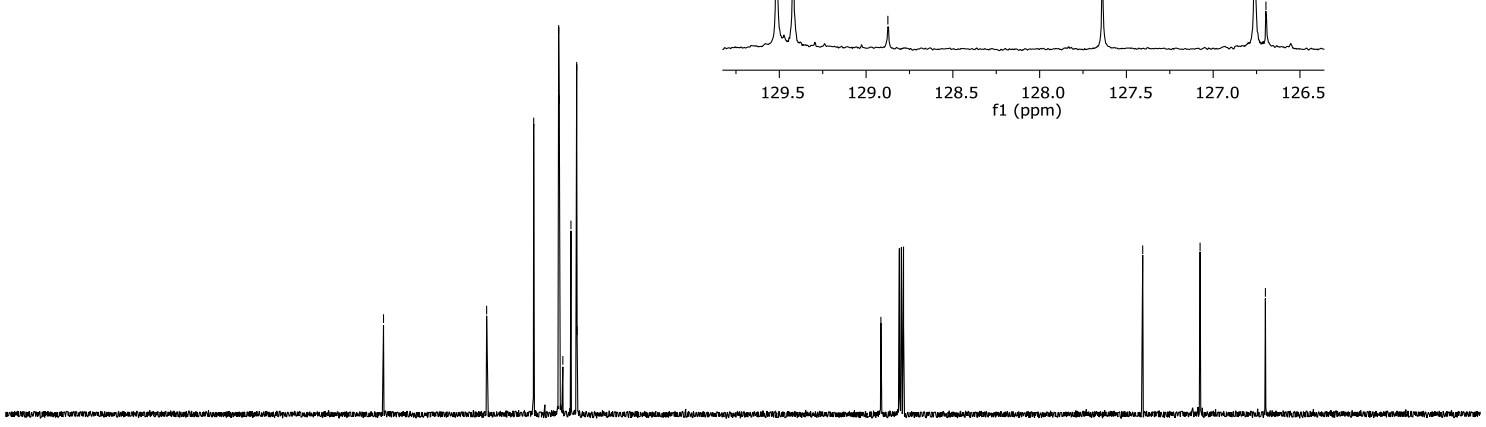

$\begin{array}{lllllllllllllllllllllllllll}1 & 210 & 200 & 190 & 180 & 170 & 160 & 150 & 140 & 130 & 120 & 110 & 100 & 90 & 80 & 70 & 60 & 50 & 40 & 30 & 20 & 10 & 0 & -11\end{array}$

${ }^{13} \mathrm{C}$ NMR $\left(100 \mathrm{MHz}, \mathrm{CDCl}_{3}\right)$ spectrum of $3 \mathbf{e}$ 
<smiles>Cc1ccc(C2=NOC(C[Se]c3ccccc3)C2)cc1</smiles>
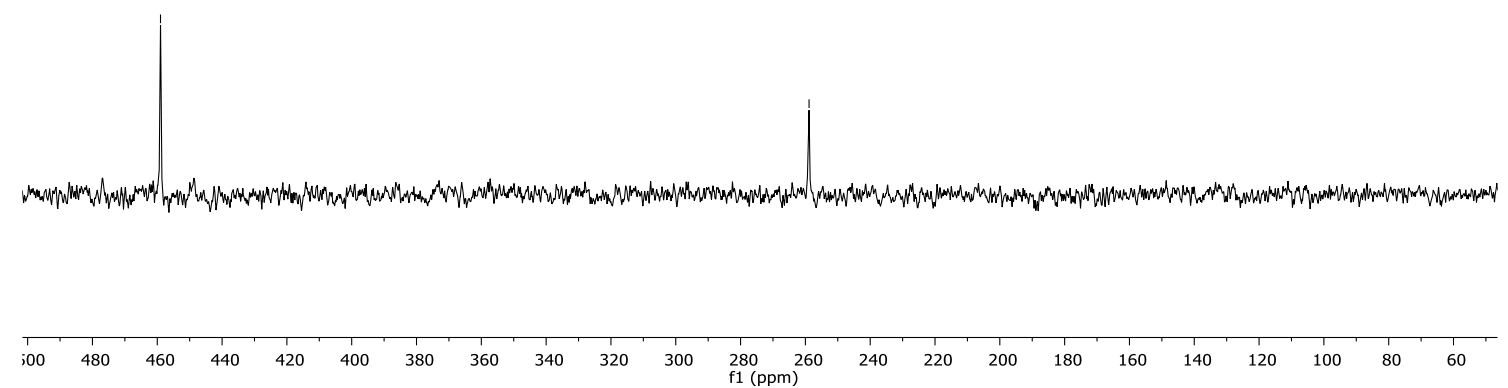

${ }^{77} \mathrm{Se} \mathrm{NMR}\left(76 \mathrm{MHz}, \mathrm{CDCl}_{3},(\mathrm{PhSe})_{2}\right.$ as internal standard) spectrum of $\mathbf{3 e}$.
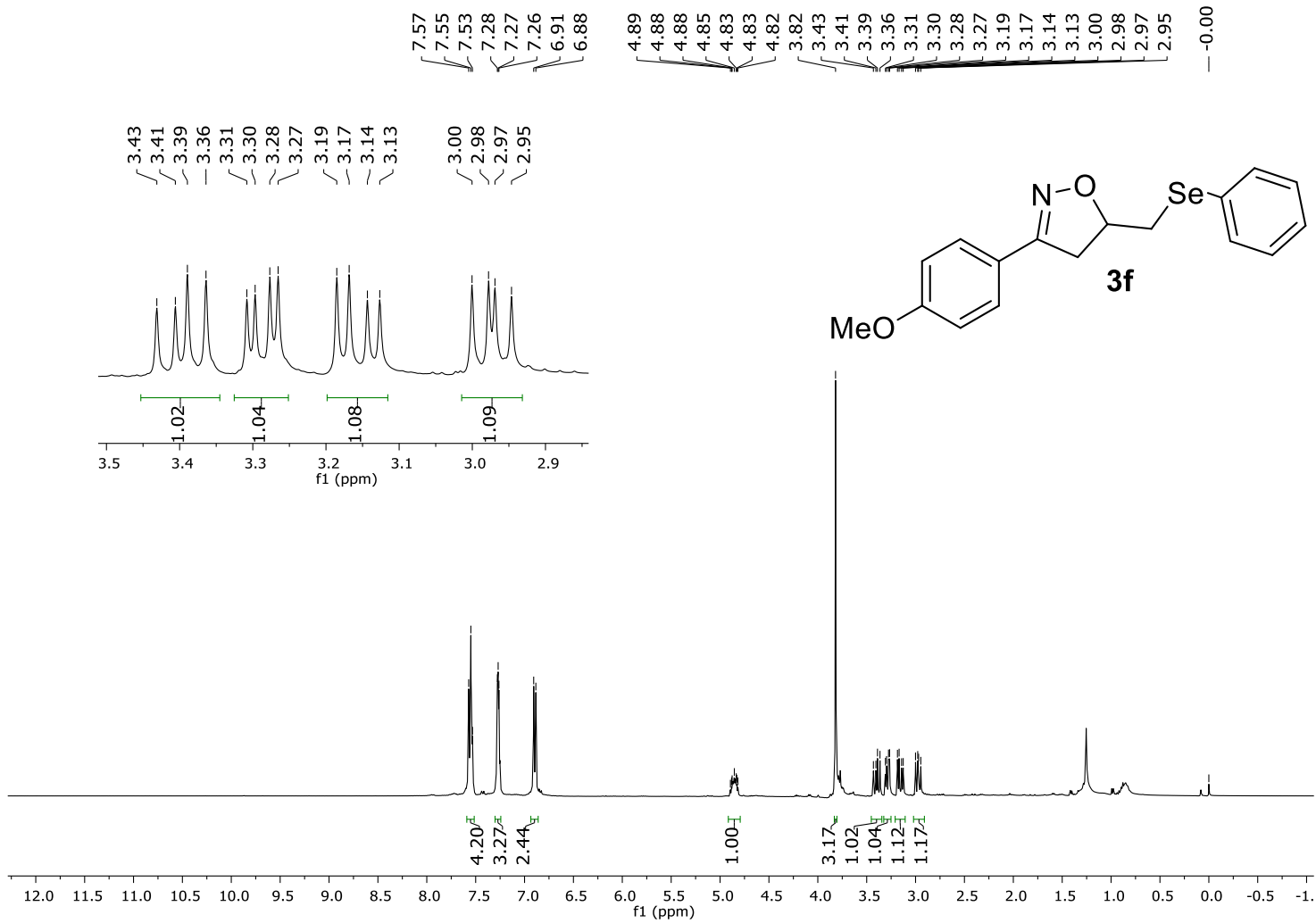

${ }^{1} \mathrm{H}$ NMR $\left(400 \mathrm{MHz}, \mathrm{CDCl}_{3}\right.$ ) spectrum of $\mathbf{3 f}$. 

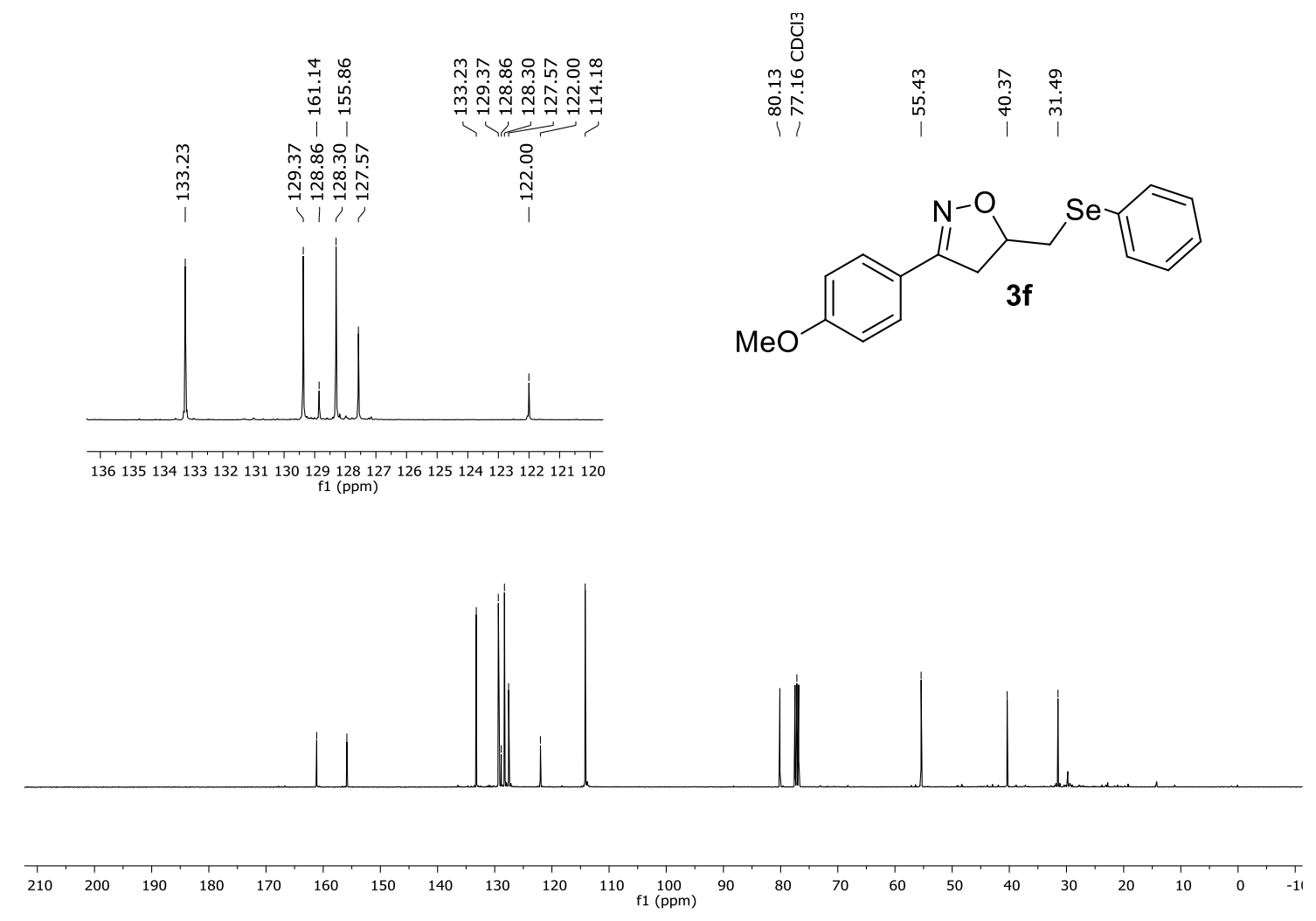

${ }^{13} \mathrm{C}$ NMR $\left(100 \mathrm{MHz}, \mathrm{CDCl}_{3}\right)$ spectrum of $\mathbf{3 f}$.

8
ơ
मे
1

ֻัฒ<smiles>COc1ccc(C2=NOC(C[Se]c3ccccc3)C2)cc1</smiles>

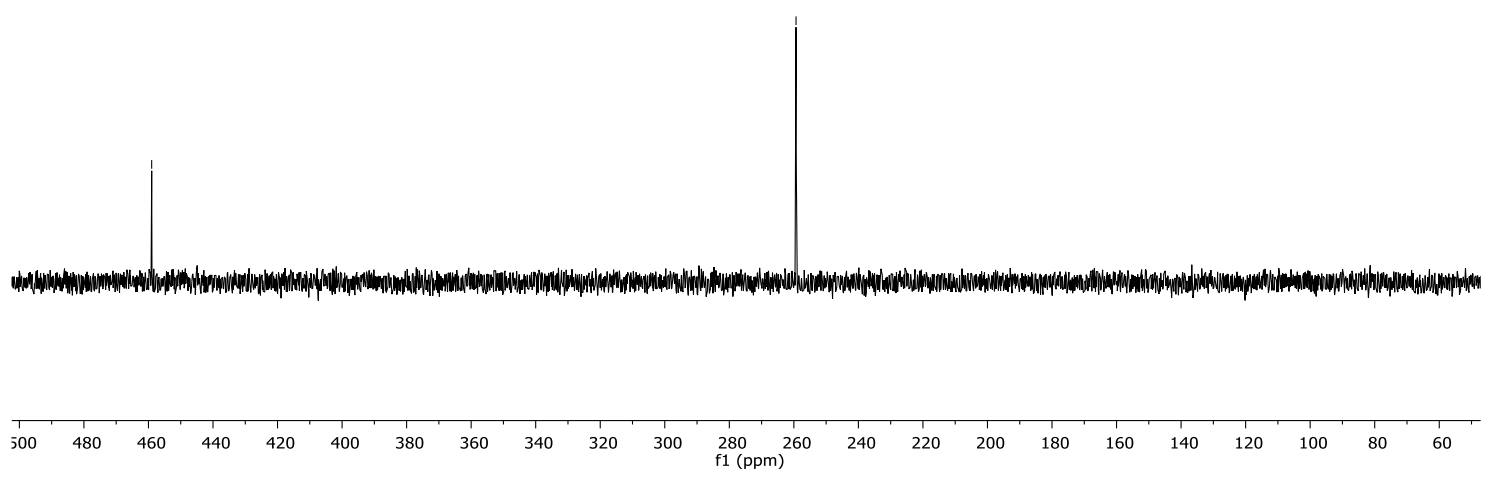

${ }^{77} \mathrm{Se} \mathrm{NMR} \mathrm{(76} \mathrm{MHz,} \mathrm{CDCl}_{3},(\mathrm{PhSe})_{2}$ as internal standard) spectrum of $\mathbf{3 f}$. 


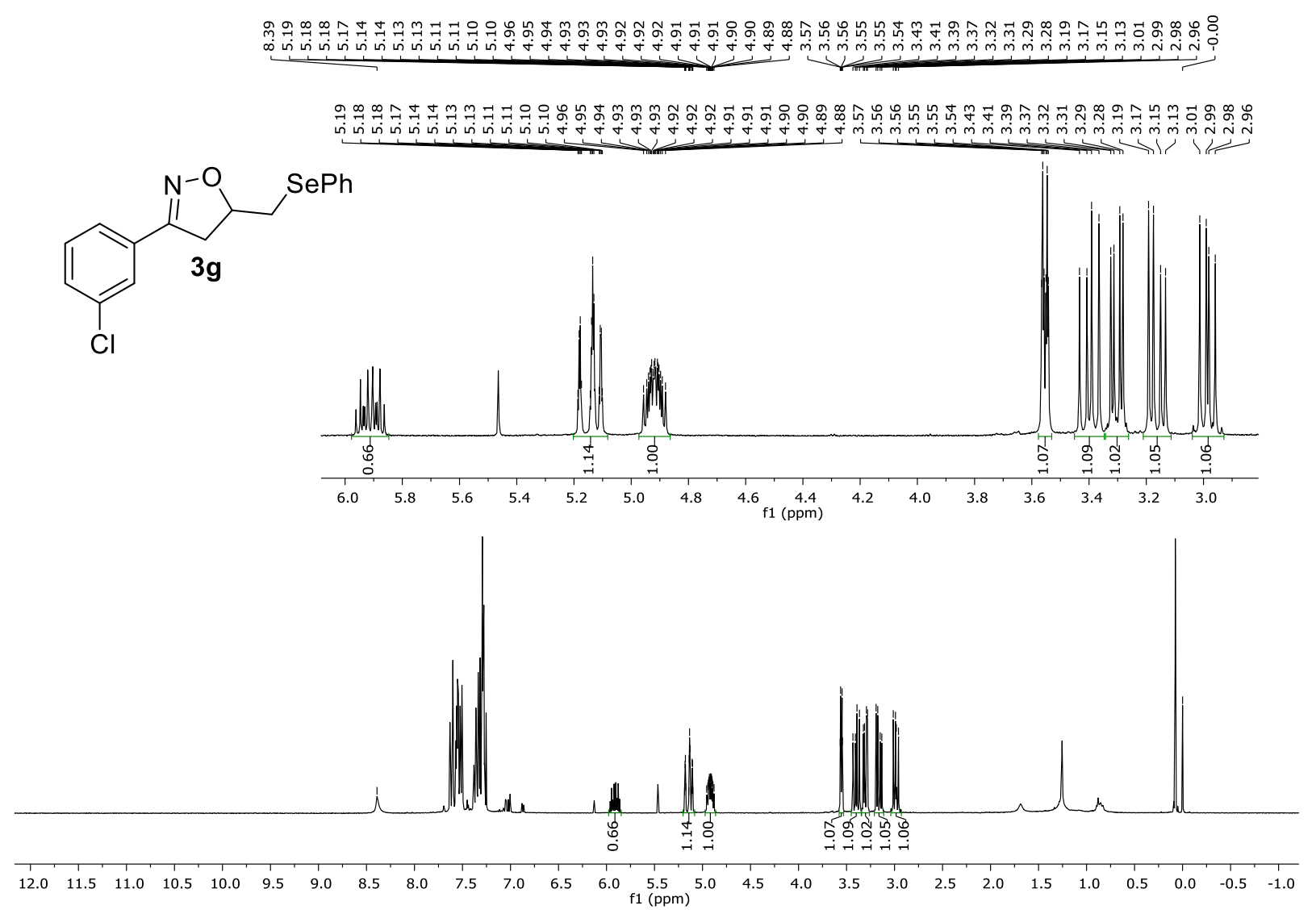

${ }^{1} \mathrm{H}$ NMR $\left(400 \mathrm{MHz}, \mathrm{CDCl}_{3}\right.$ ) spectrum of $\mathbf{3 g}$.

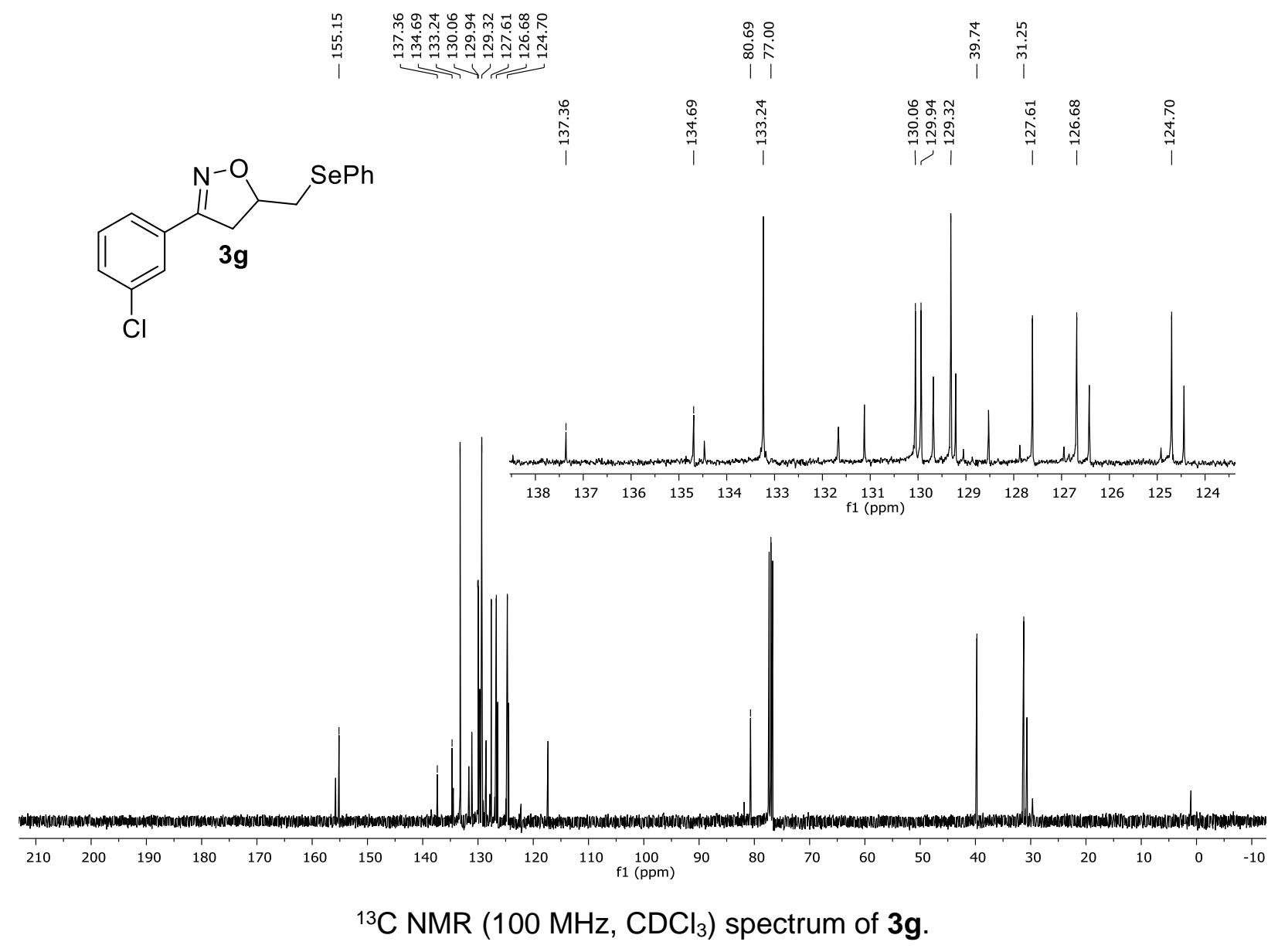




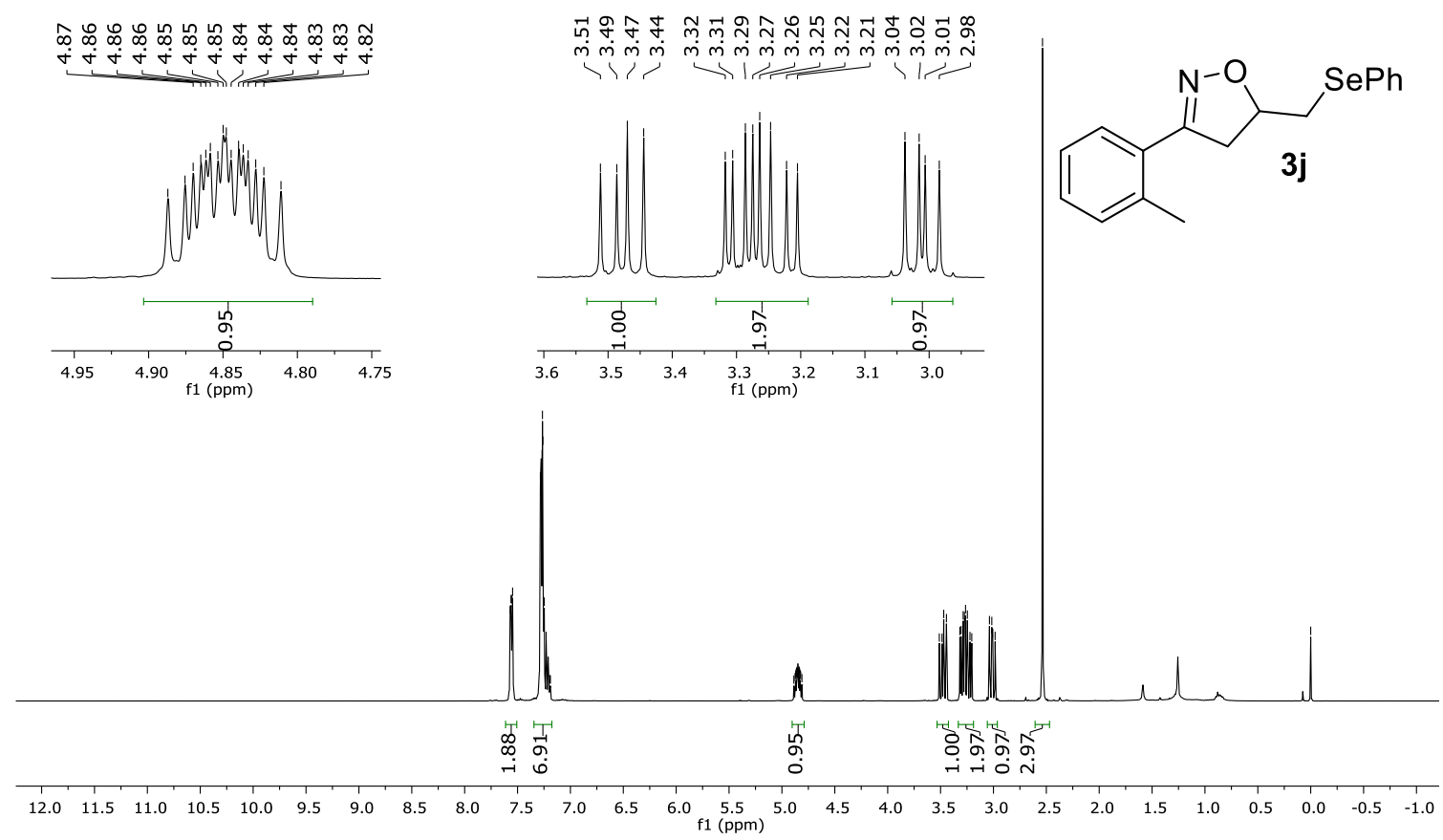

${ }^{1} \mathrm{H}$ NMR $\left(400 \mathrm{MHz}, \mathrm{CDCl}_{3}\right)$ spectrum of $\mathbf{3 i}$.

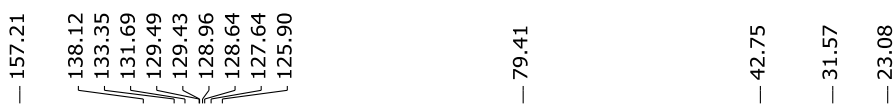

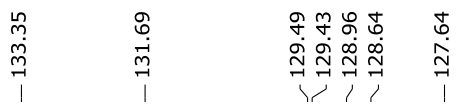
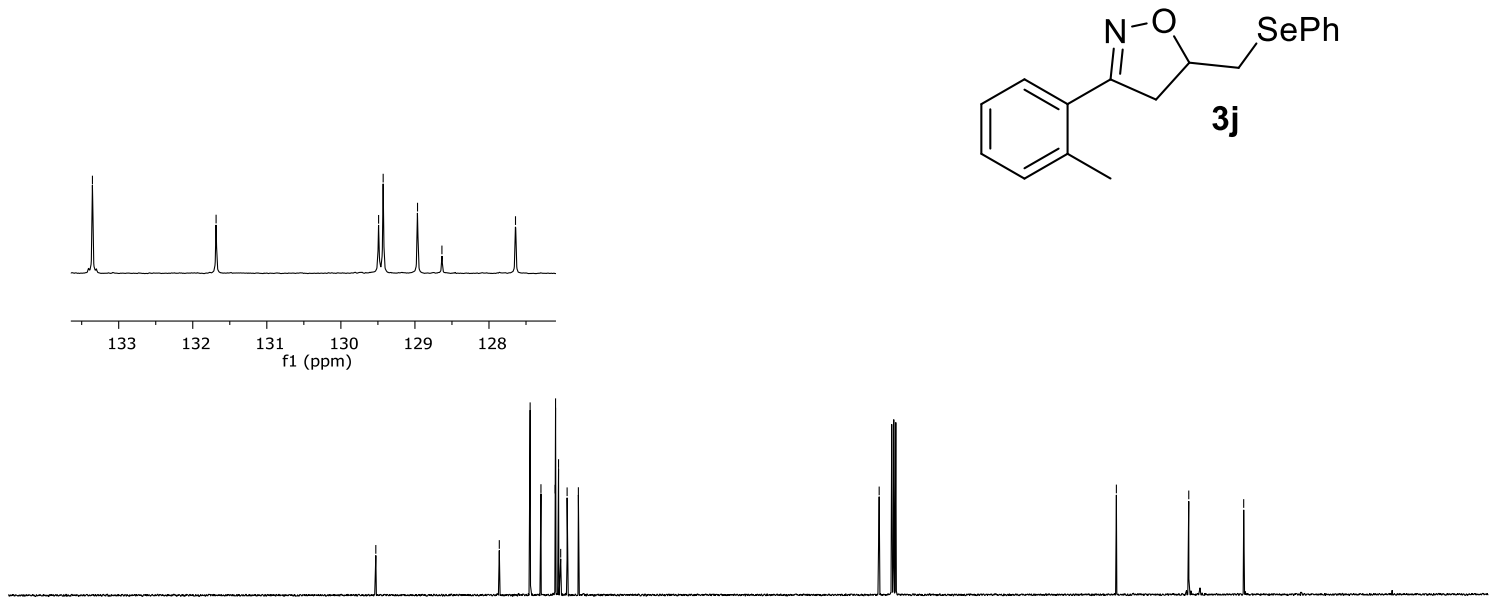

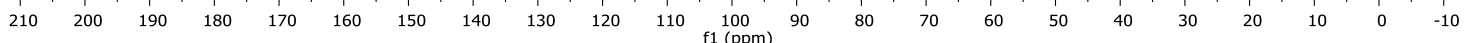

${ }^{13} \mathrm{C}$ NMR $\left(100 \mathrm{MHz}, \mathrm{CDCl}_{3}\right)$ spectrum of $\mathbf{3 i}$. 


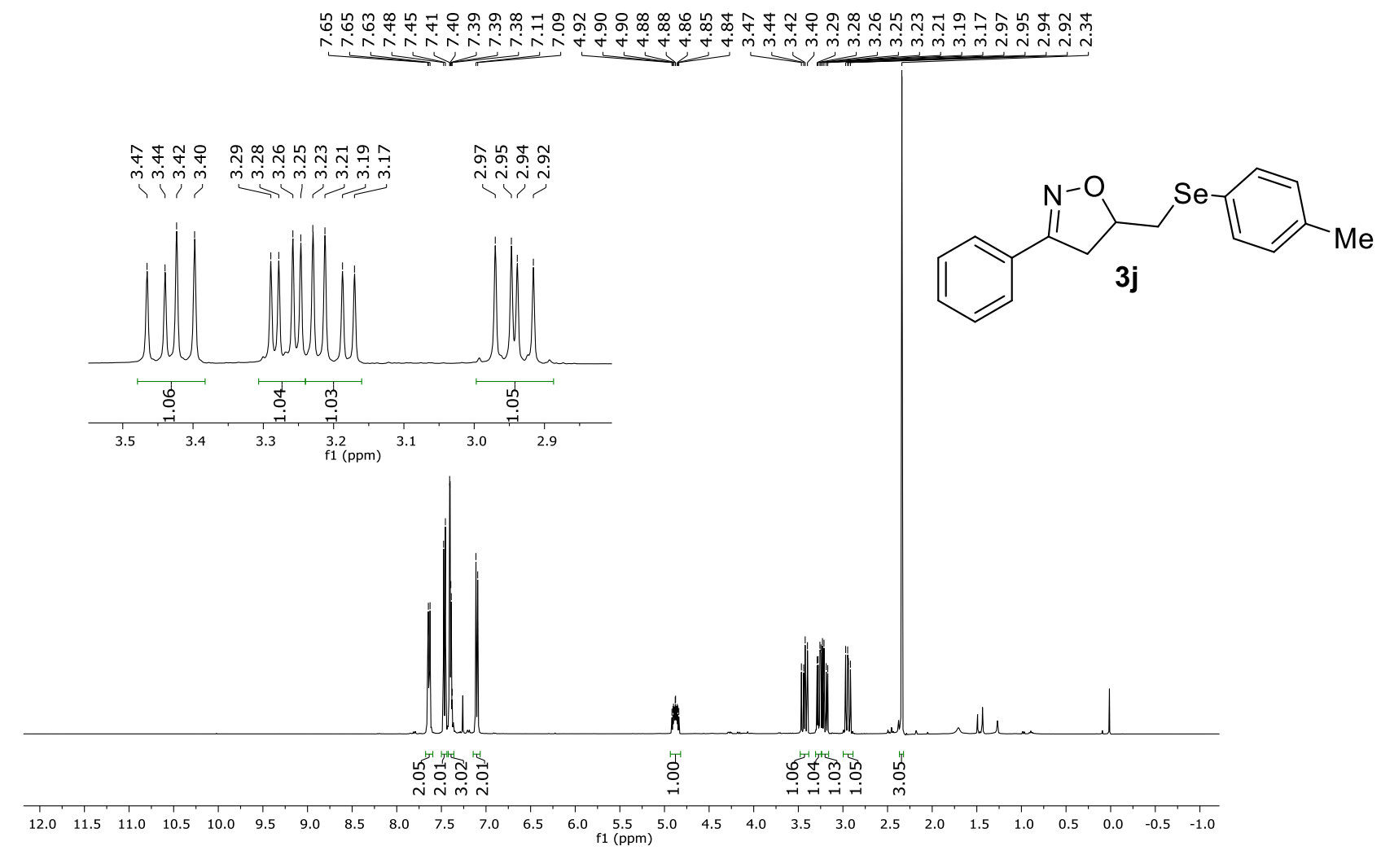

${ }^{1} \mathrm{H}$ NMR $\left(400 \mathrm{MHz}, \mathrm{CDCl}_{3}\right)$ spectrum of $\mathbf{3 j}$.

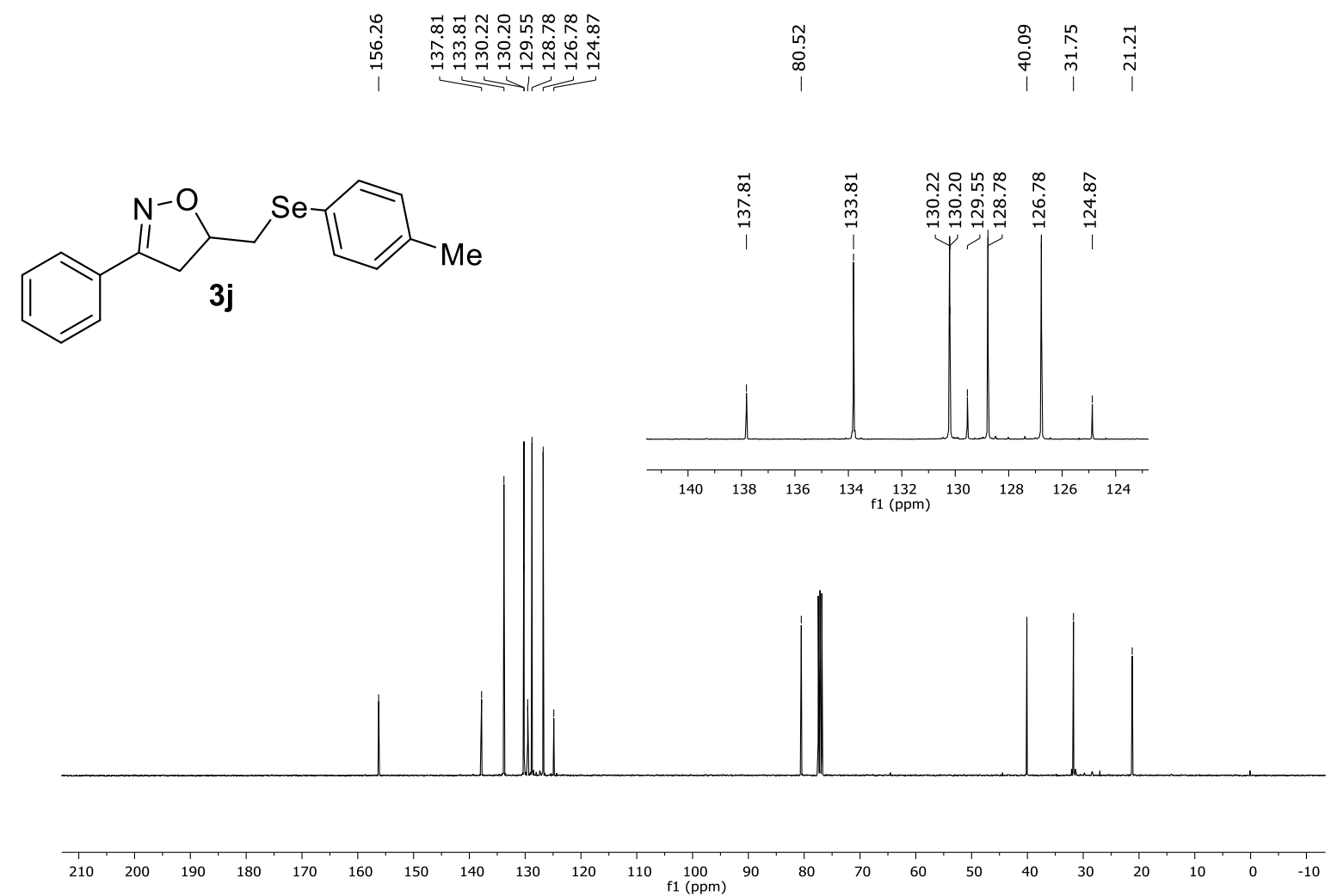

${ }^{13} \mathrm{C}$ NMR $\left(100 \mathrm{MHz}, \mathrm{CDCl}_{3}\right)$ spectrum of $\mathbf{3 j}$. 


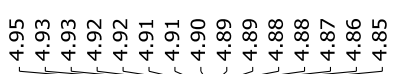

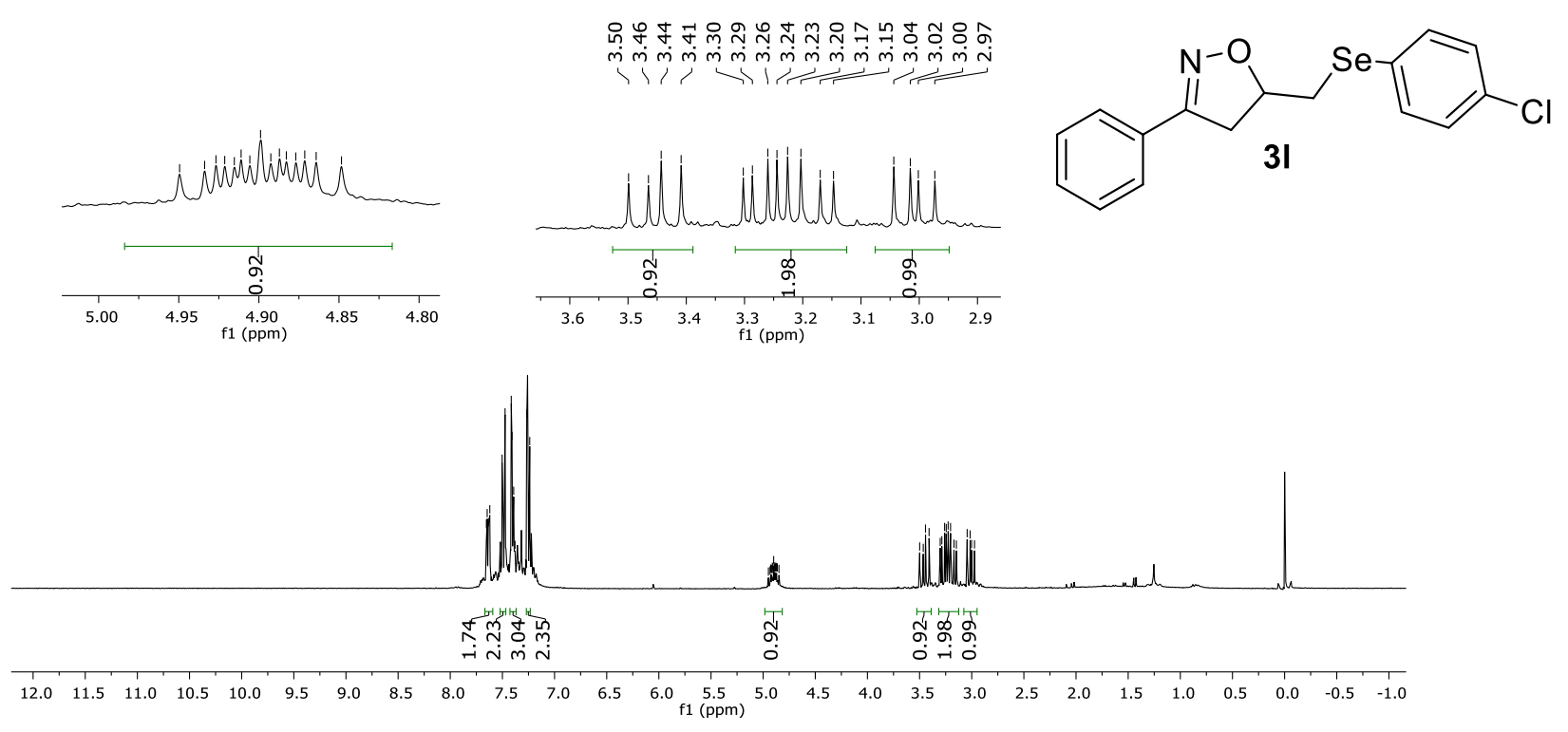

${ }^{1} \mathrm{H}$ NMR (300 MHz, $\mathrm{CDCl}_{3}$ ) spectrum of 31.

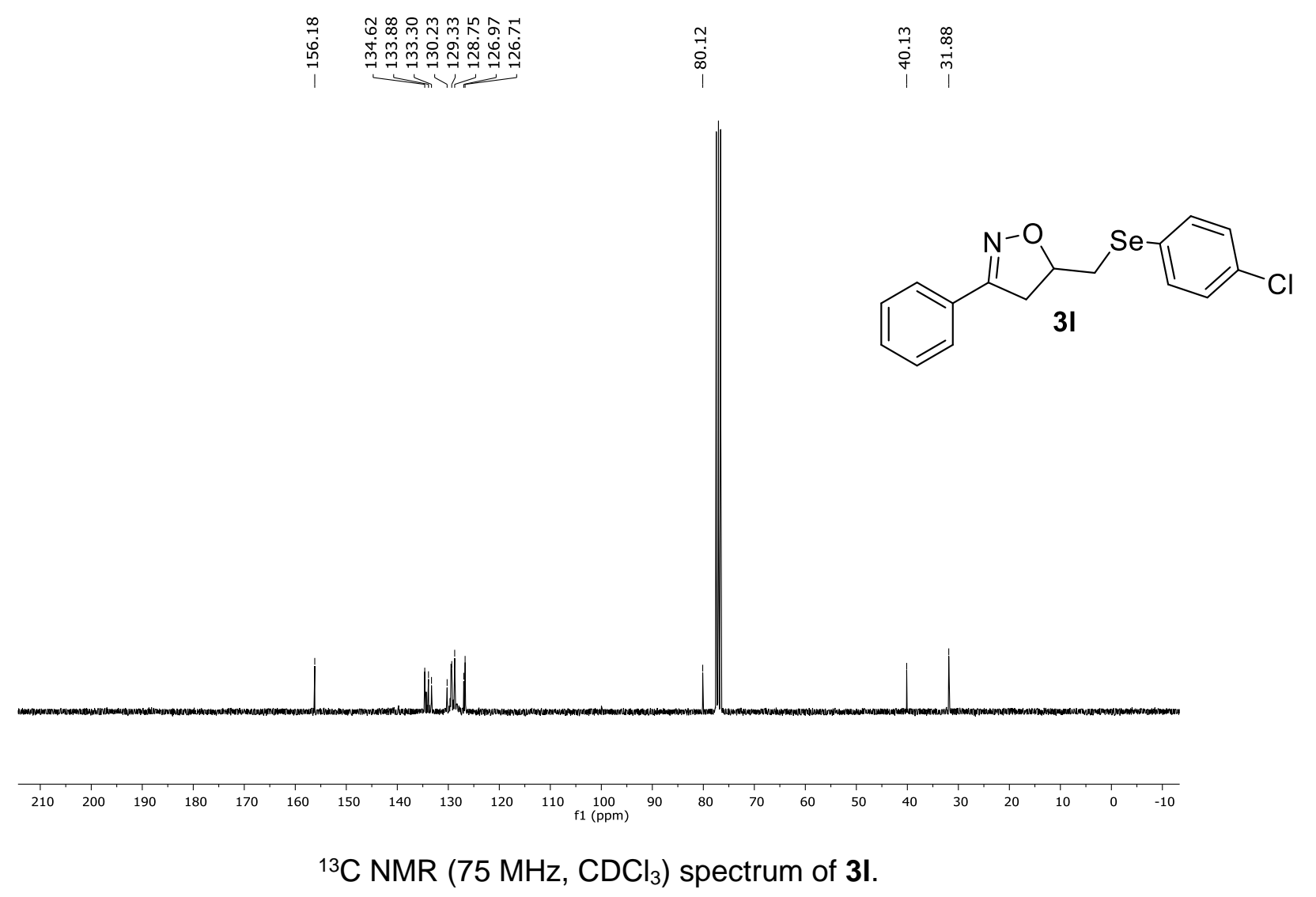




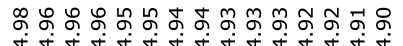<smiles>FC(F)(F)c1cccc([Se]CC2CC(c3ccccc3)=NO2)c1</smiles>

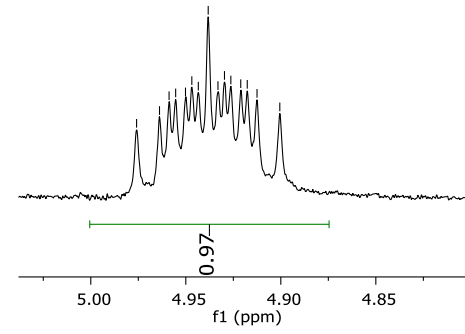
mim mim mim

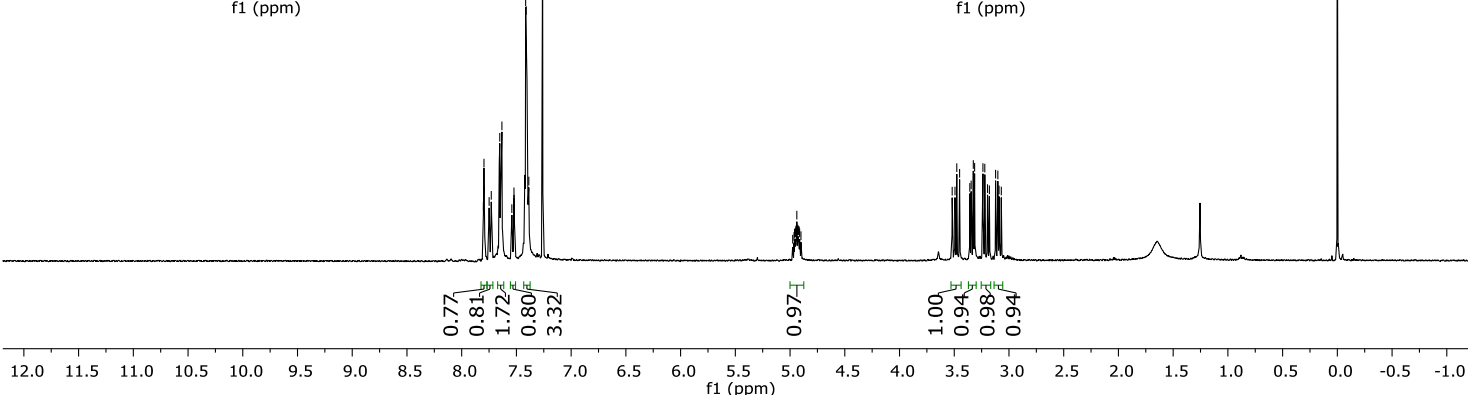

${ }^{1} \mathrm{H}$ NMR $\left(400 \mathrm{MHz}, \mathrm{CDCl}_{3}\right)$ spectrum of $3 \mathrm{~m}$.

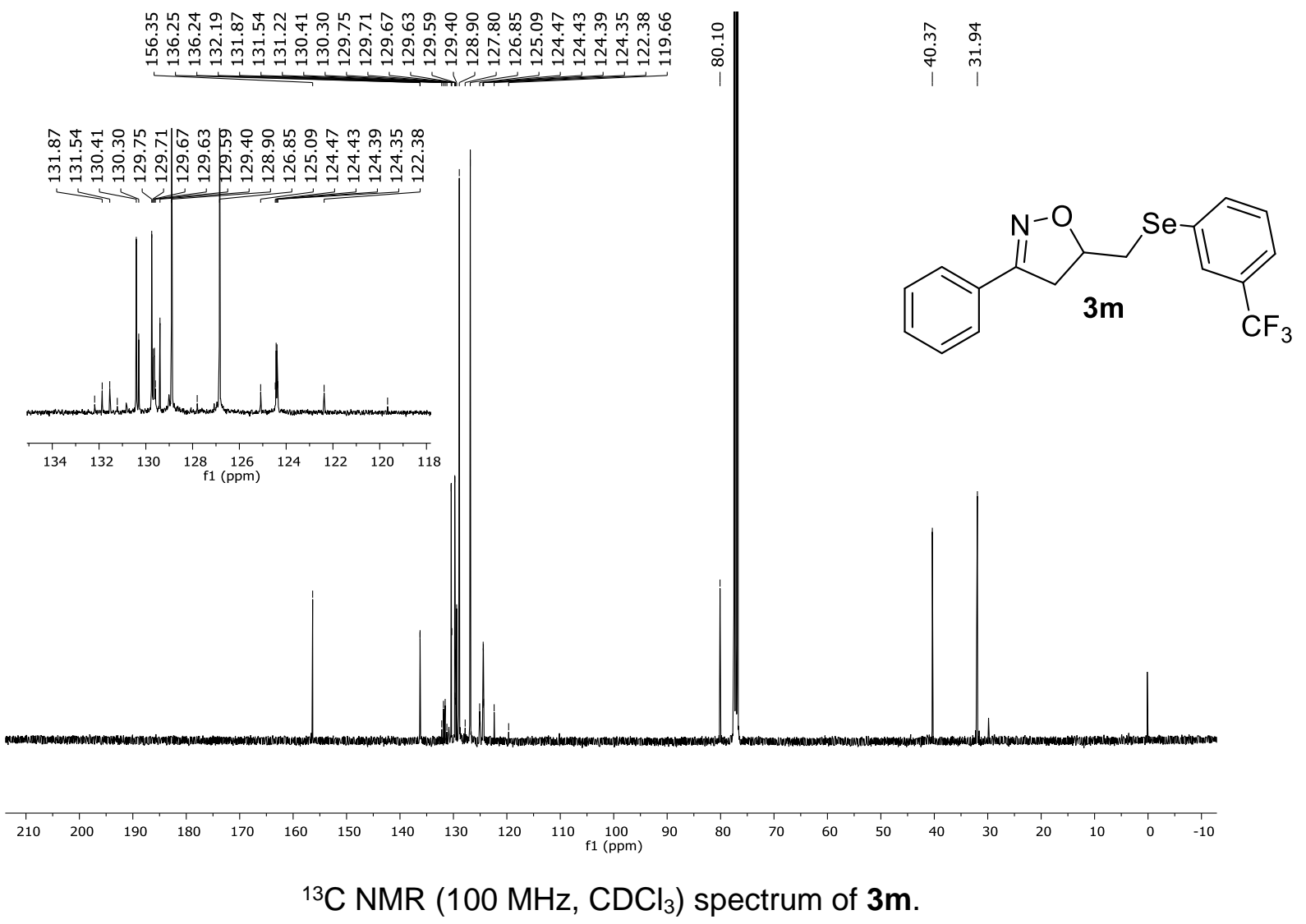




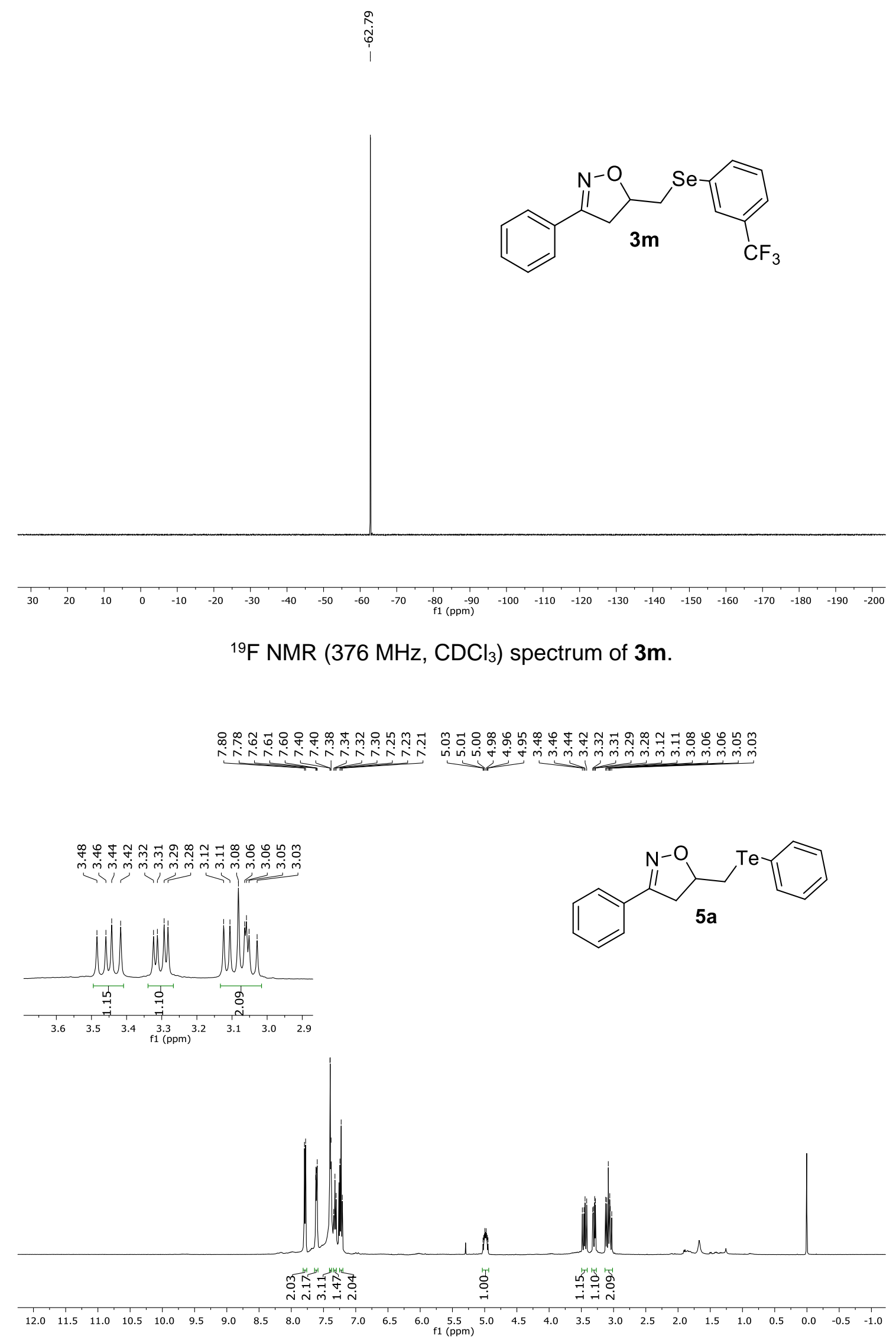

${ }^{1} \mathrm{H}$ NMR $\left(400 \mathrm{MHz}, \mathrm{CDCl}_{3}\right)$ spectrum of $\mathbf{5 a}$. 


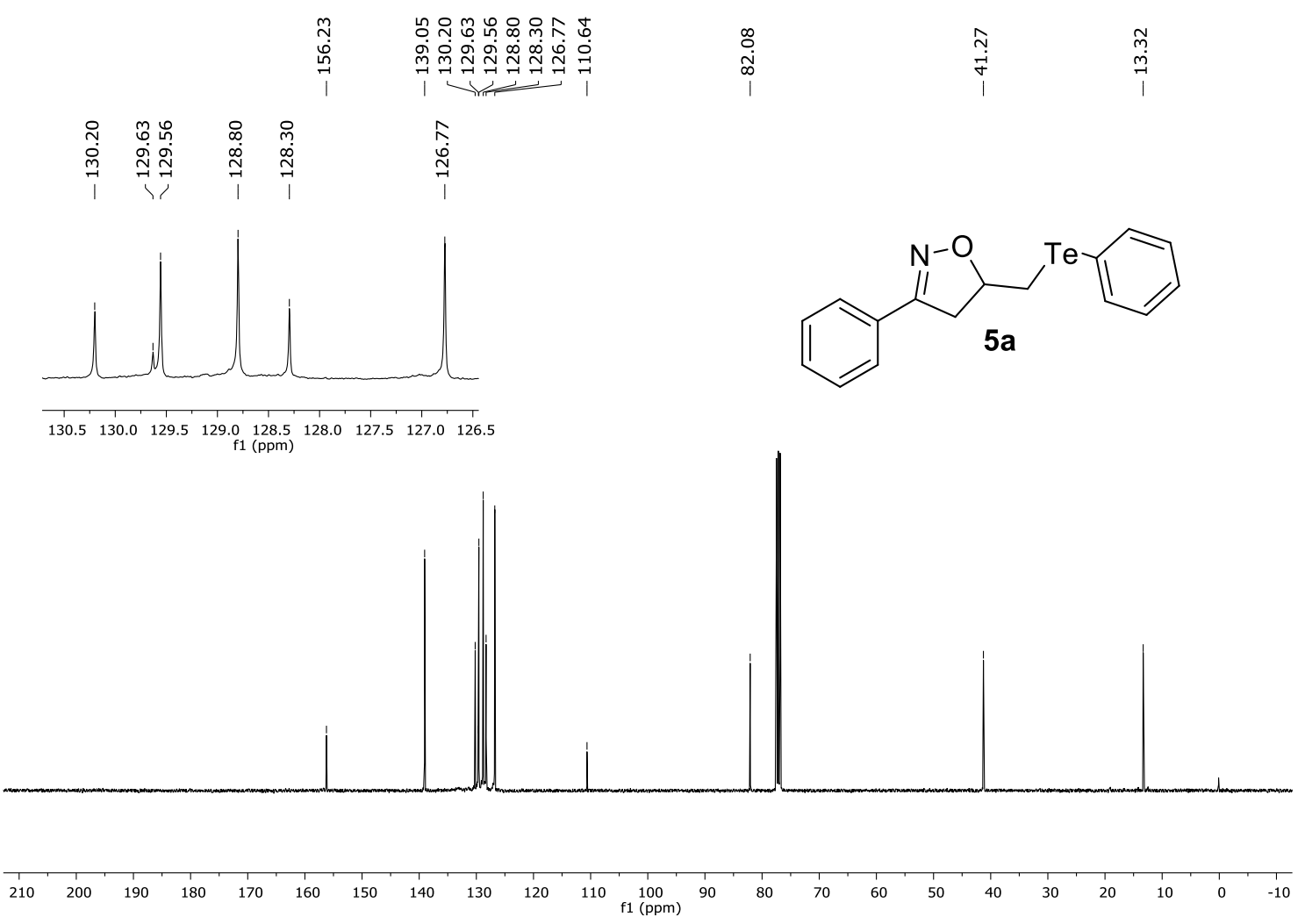

${ }^{13} \mathrm{C}$ NMR $\left(100 \mathrm{MHz}, \mathrm{CDCl}_{3}\right)$ spectrum of $5 \mathbf{a}$.

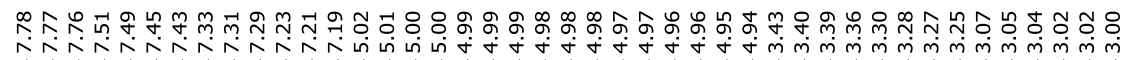

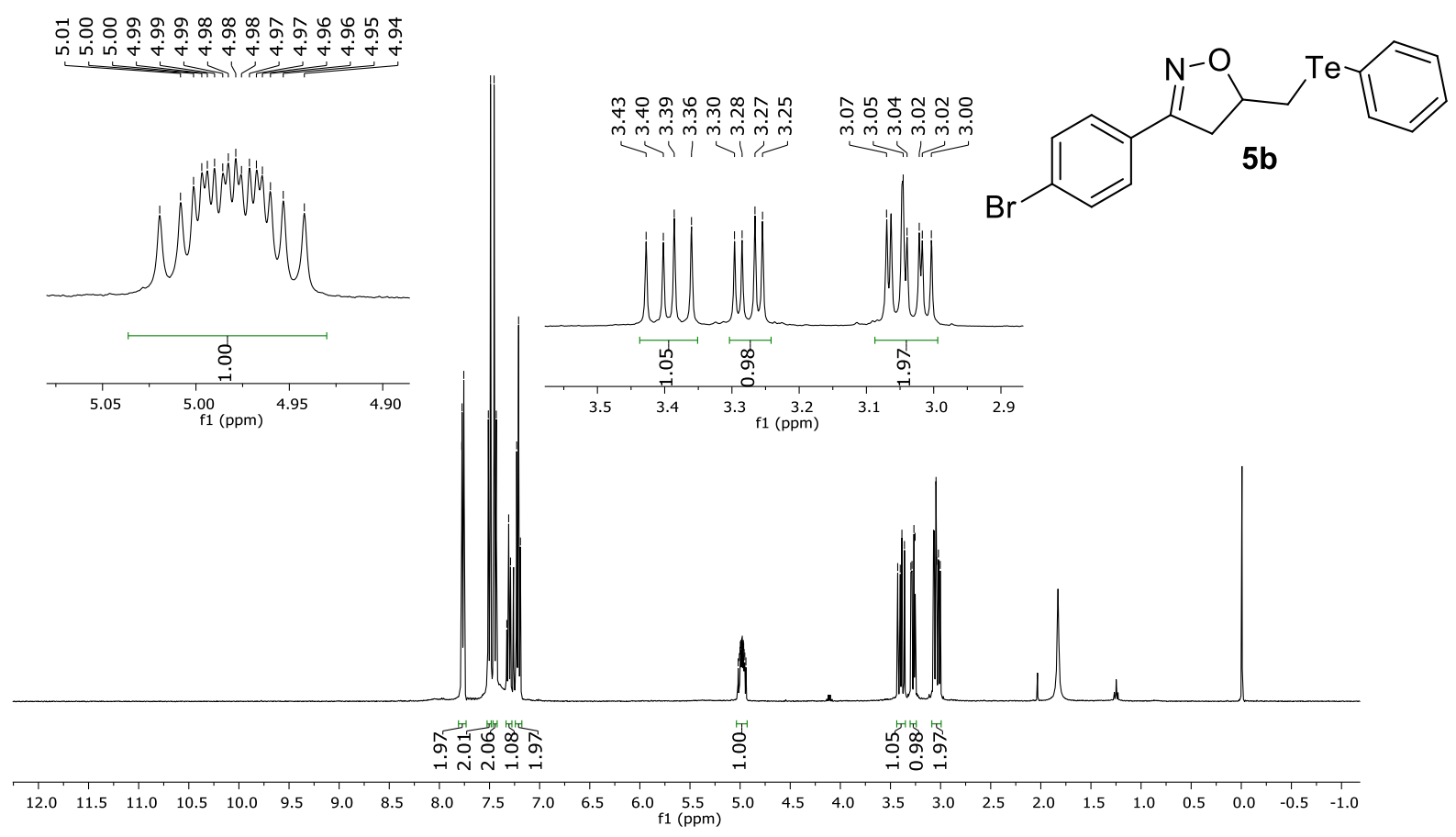

${ }^{1} \mathrm{H} \mathrm{NMR}\left(400 \mathrm{MHz}, \mathrm{CDCl}_{3}\right)$ spectrum of $5 \mathbf{b}$. 


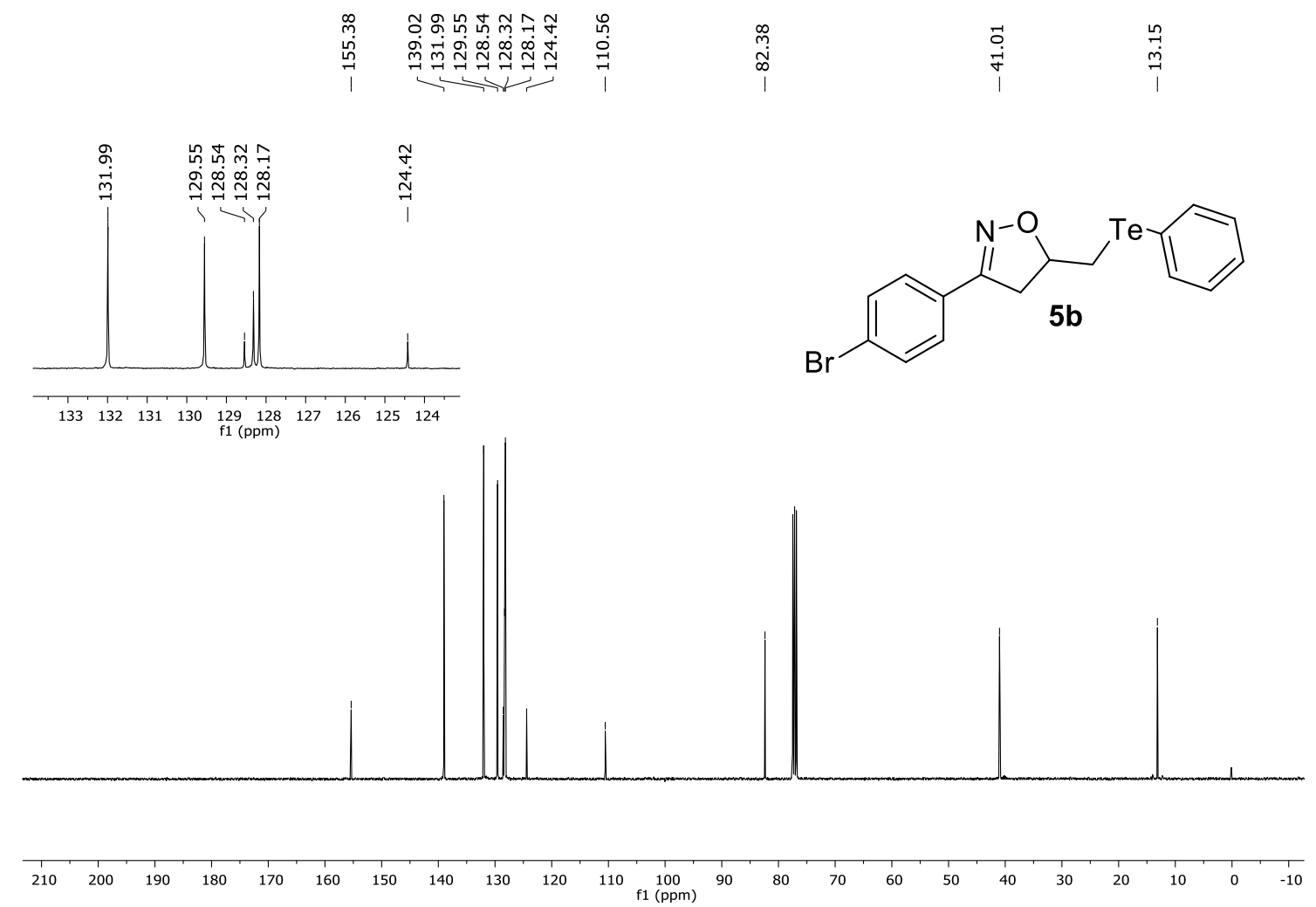

${ }^{13} \mathrm{C} \mathrm{NMR}\left(100 \mathrm{MHz}, \mathrm{CDCl}_{3}\right)$ spectrum of $\mathbf{5 b}$.

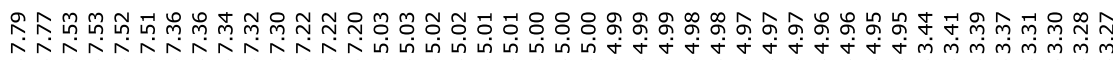

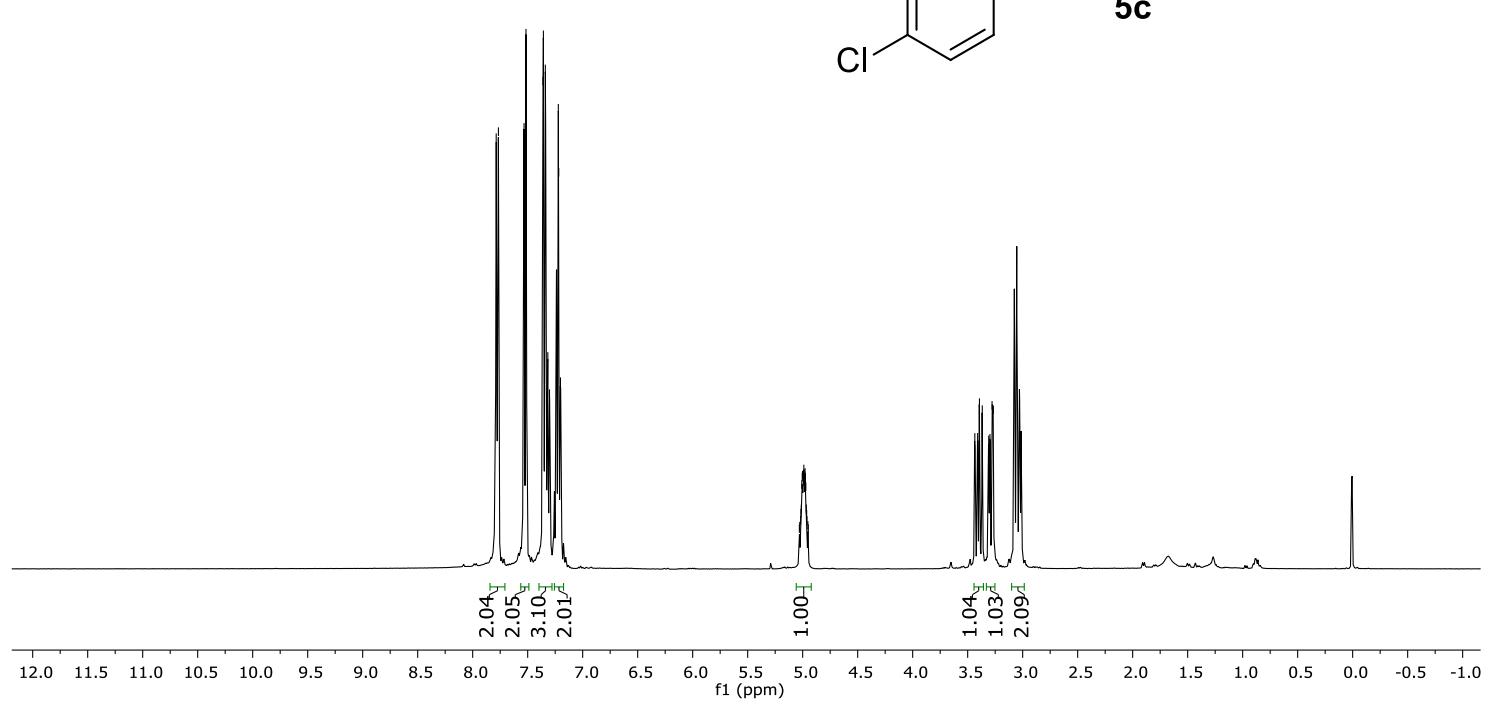<smiles>Clc1ccc(C2=NOC(C[Te]c3ccccc3)C2)cc1</smiles>

${ }^{1} \mathrm{H}$ NMR $\left(400 \mathrm{MHz}, \mathrm{CDCl}_{3}\right)$ spectrum of $5 \mathbf{c}$. 

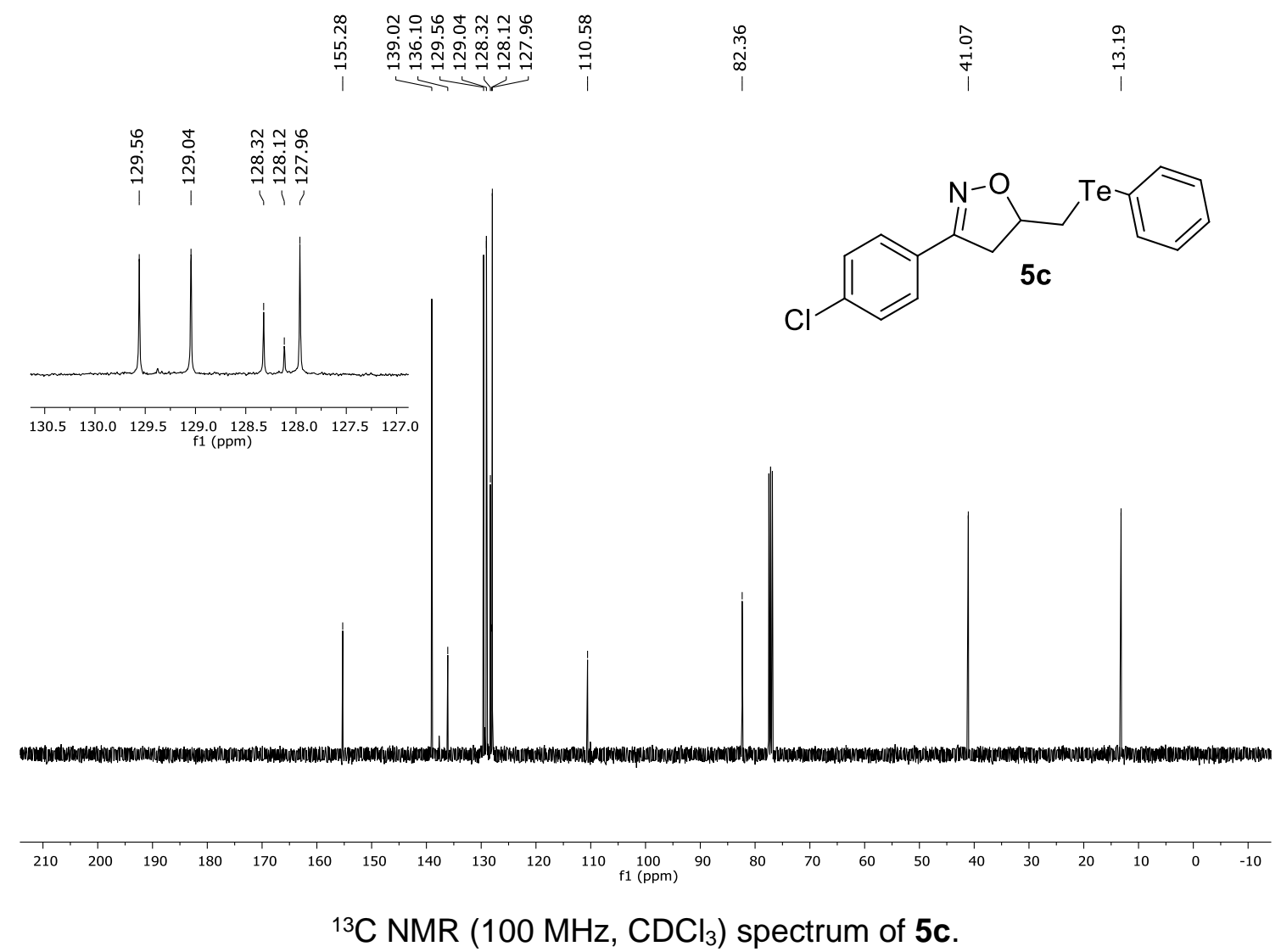

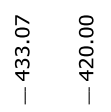
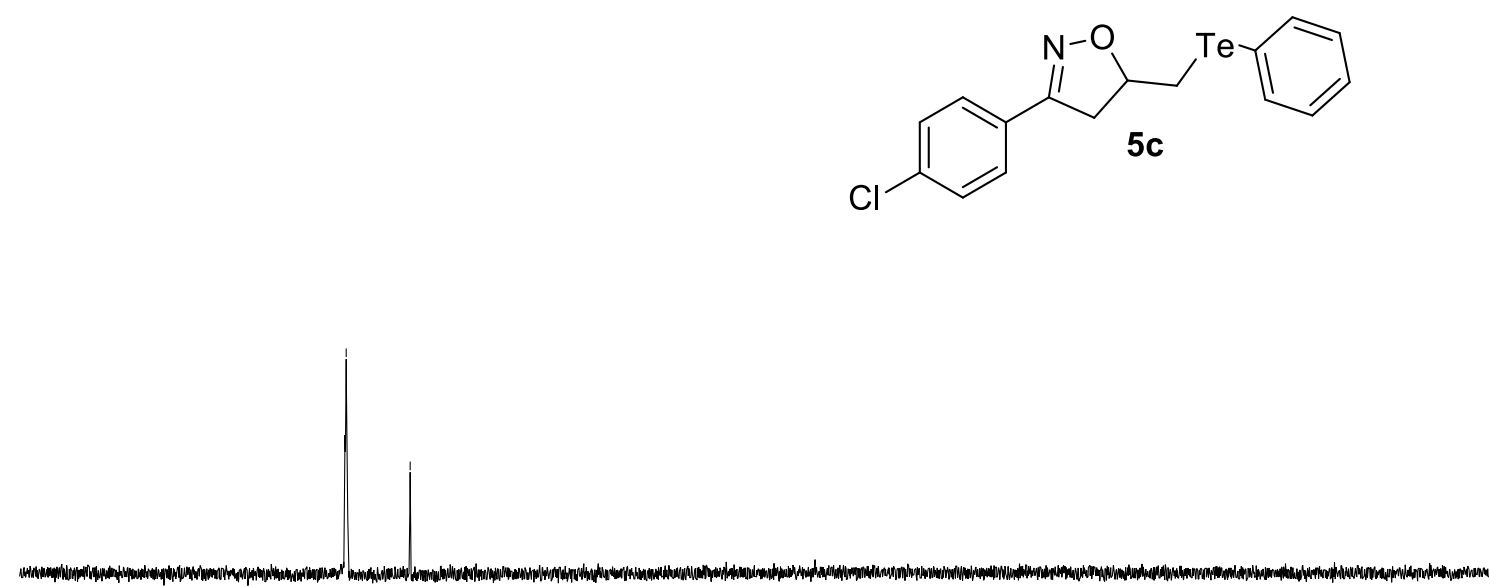

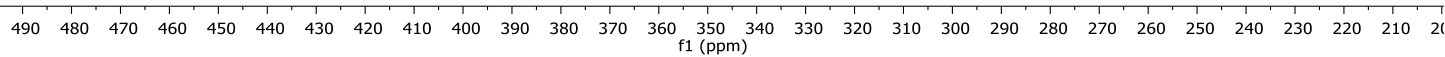

${ }^{125} \mathrm{Te} \mathrm{NMR}\left(126 \mathrm{MHz}, \mathrm{CDCl}_{3},(\mathrm{PhTe})_{2}\right.$ as internal standard) spectrum of $\mathbf{5 c}$. 


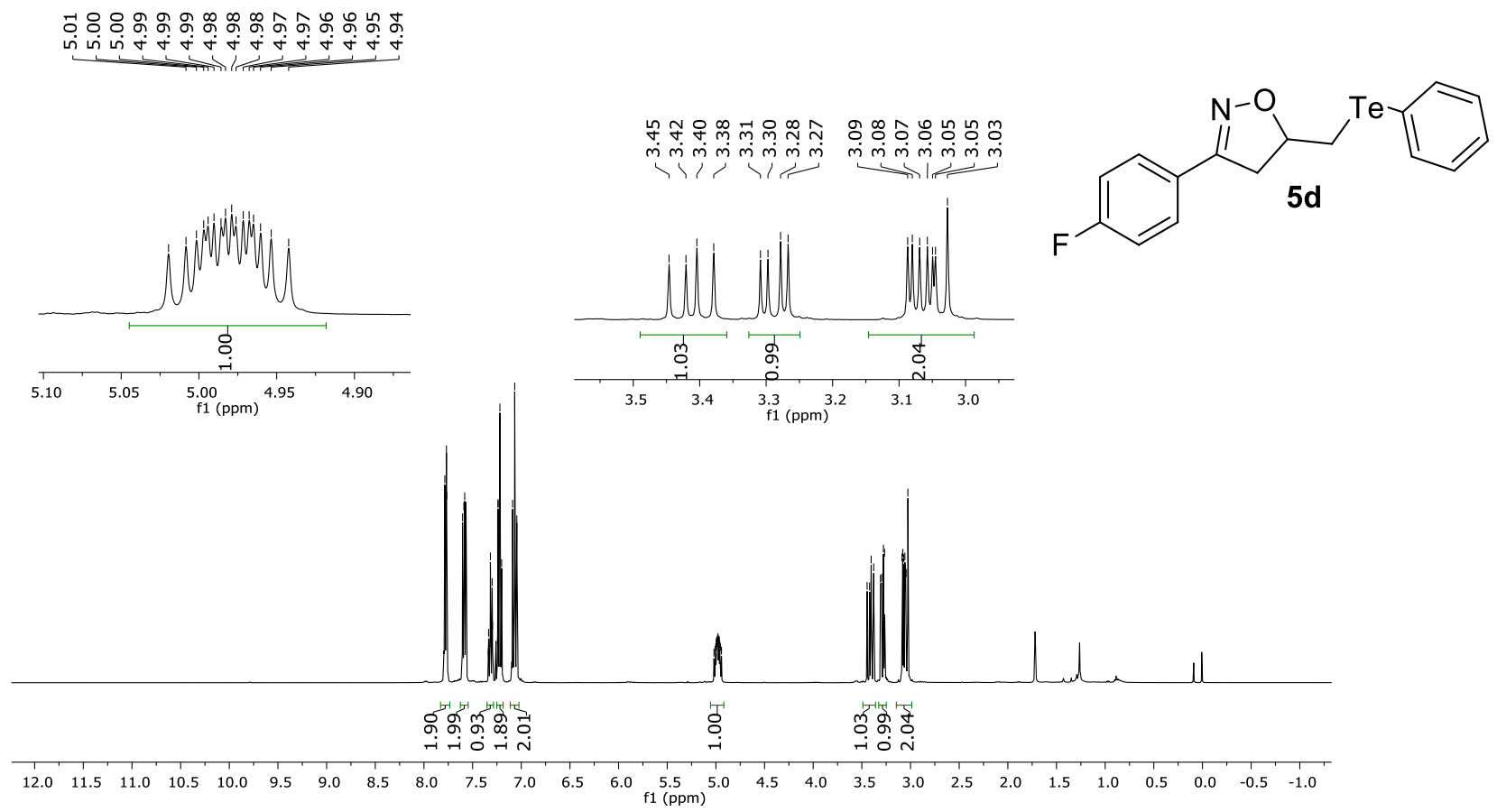

${ }^{1} \mathrm{H}$ NMR $\left(400 \mathrm{MHz}, \mathrm{CDCl}_{3}\right)$ spectrum of $5 \mathbf{d}$.

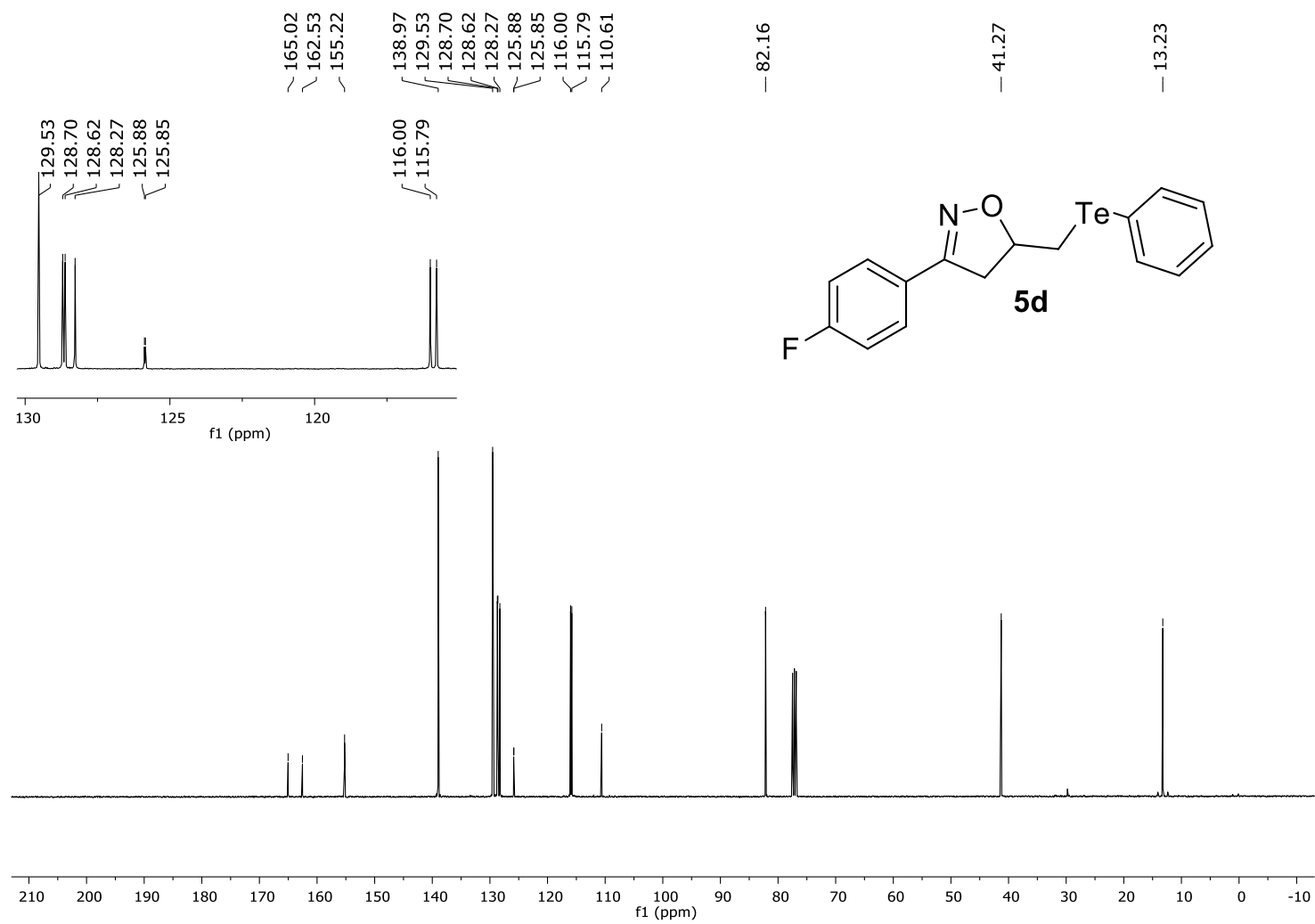

${ }^{13} \mathrm{C}$ NMR $\left(100 \mathrm{MHz}, \mathrm{CDCl}_{3}\right)$ spectrum of $\mathbf{5 d}$. 

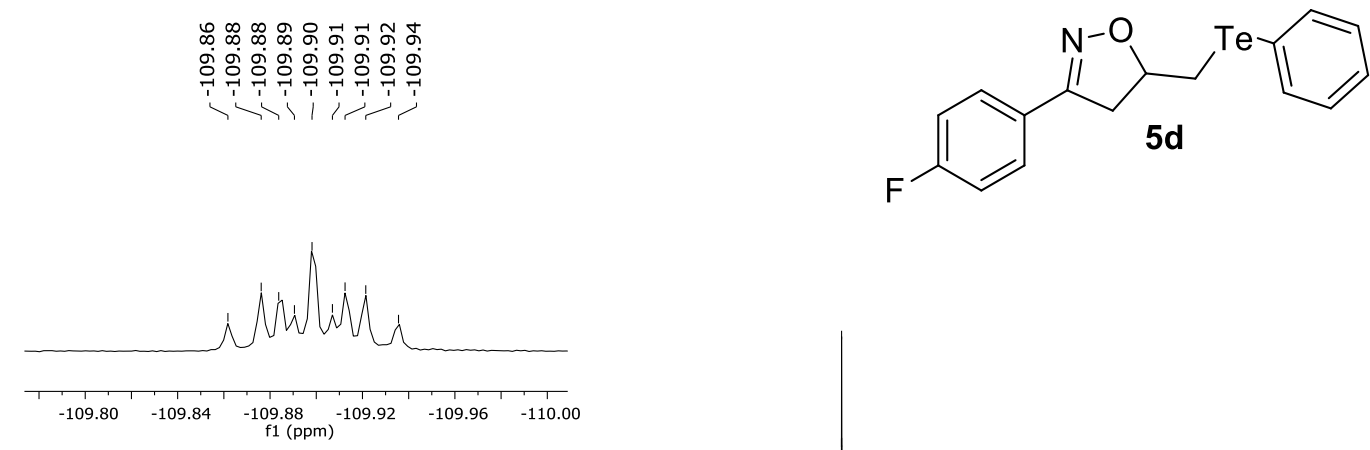

$\mathrm{F}$

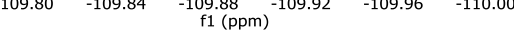

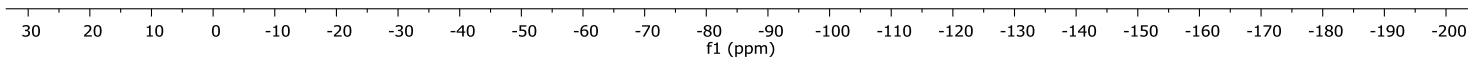

${ }^{19} \mathrm{~F} \mathrm{NMR}\left(376 \mathrm{MHz}, \mathrm{CDCl}_{3}\right)$ spectrum of $\mathbf{5 d}$.

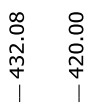<smiles>Fc1ccc(C2=NOC(C[Te]c3ccccc3)C2)cc1</smiles>

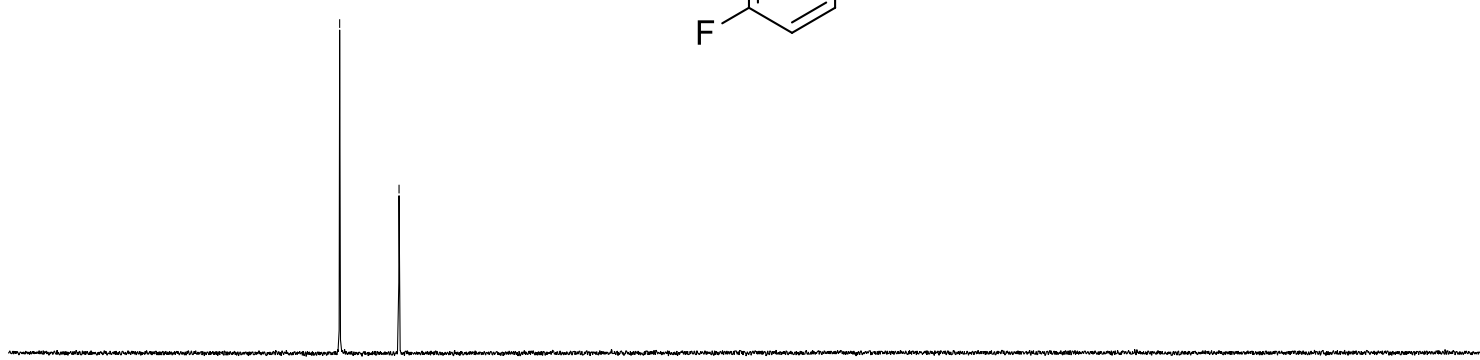

$\begin{array}{llllllllllllllllllllllllllllllllllllllllll}490 & 480 & 470 & 460 & 450 & 440 & 430 & 420 & 410 & 400 & 390 & 380 & 370 & 360 & 350 & 340 & 330 & 320 & 310 & 300 & 290 & 280 & 270 & 260 & 250 & 240 & 230 & 220 & 210 & 26\end{array}$ ${ }^{125} \mathrm{Te}$ NMR (126 MHz, $\mathrm{CDCl}_{3}$, (PhTe) $)_{2}$ as internal standard) spectrum of $\mathbf{5 d}$. 


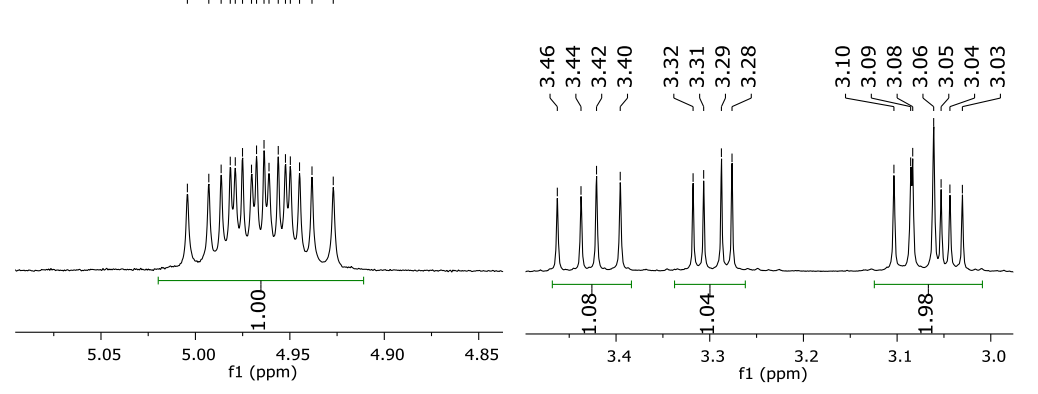<smiles>Cc1ccc(C2=NOC(C[Te]c3ccccc3)C2)cc1</smiles>

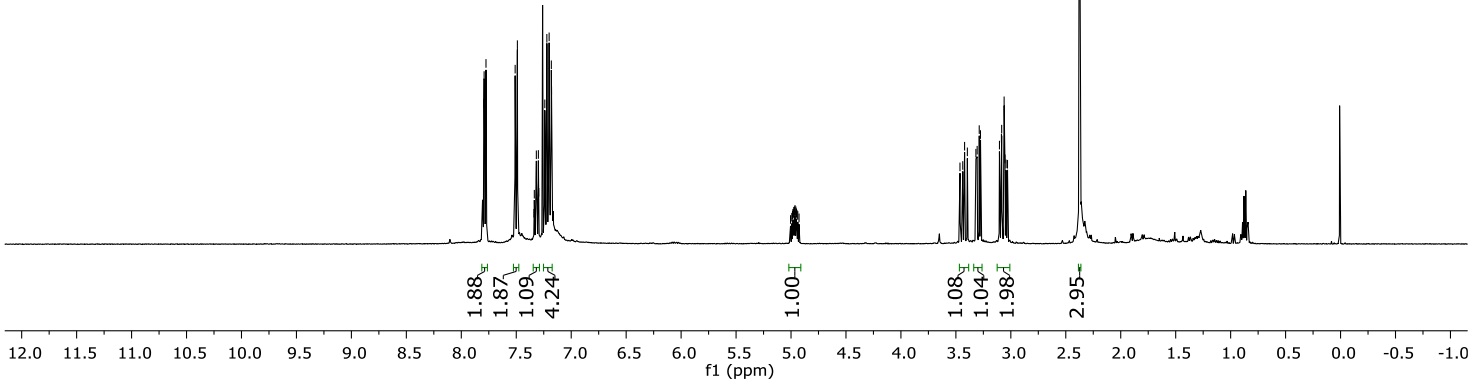

${ }^{1} \mathrm{H} \mathrm{NMR}\left(400 \mathrm{MHz}, \mathrm{CDCl}_{3}\right)$ spectrum of $5 \mathrm{e}$.

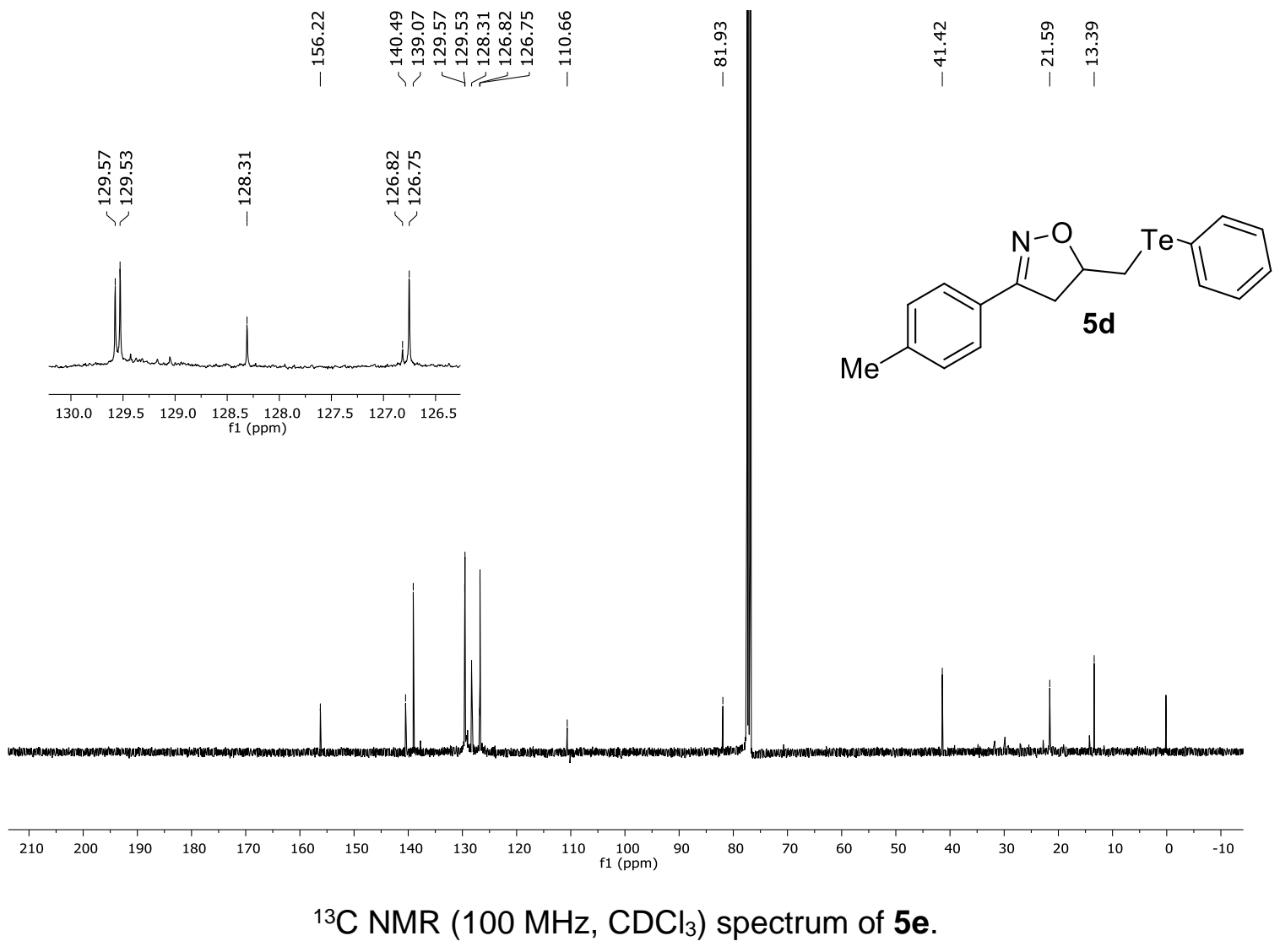




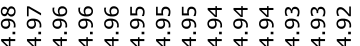

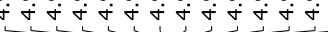

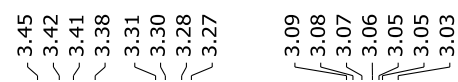
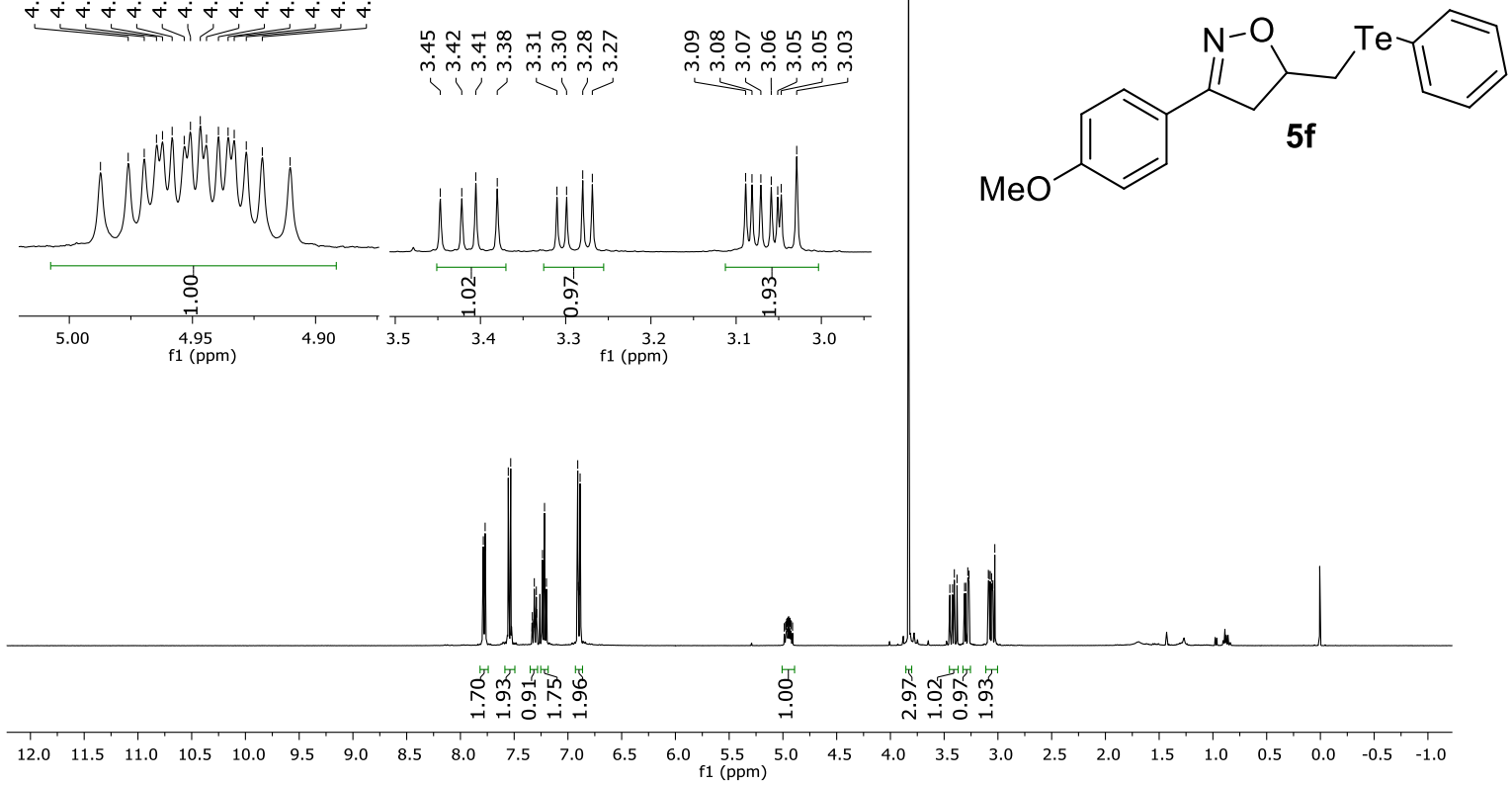

${ }^{1} \mathrm{H}$ NMR $\left(400 \mathrm{MHz}, \mathrm{CDCl}_{3}\right)$ spectrum of $\mathbf{5 f}$.

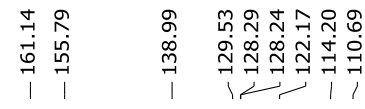

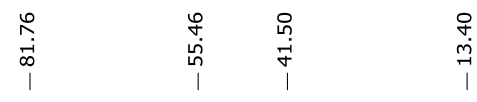

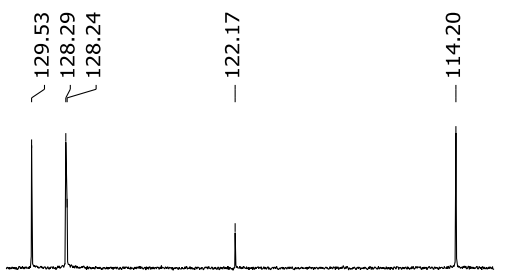

$\begin{array}{lllllllll}130 & 128 & 126 & 124 & 122 & 120 & 118 & 116 & 114\end{array}$
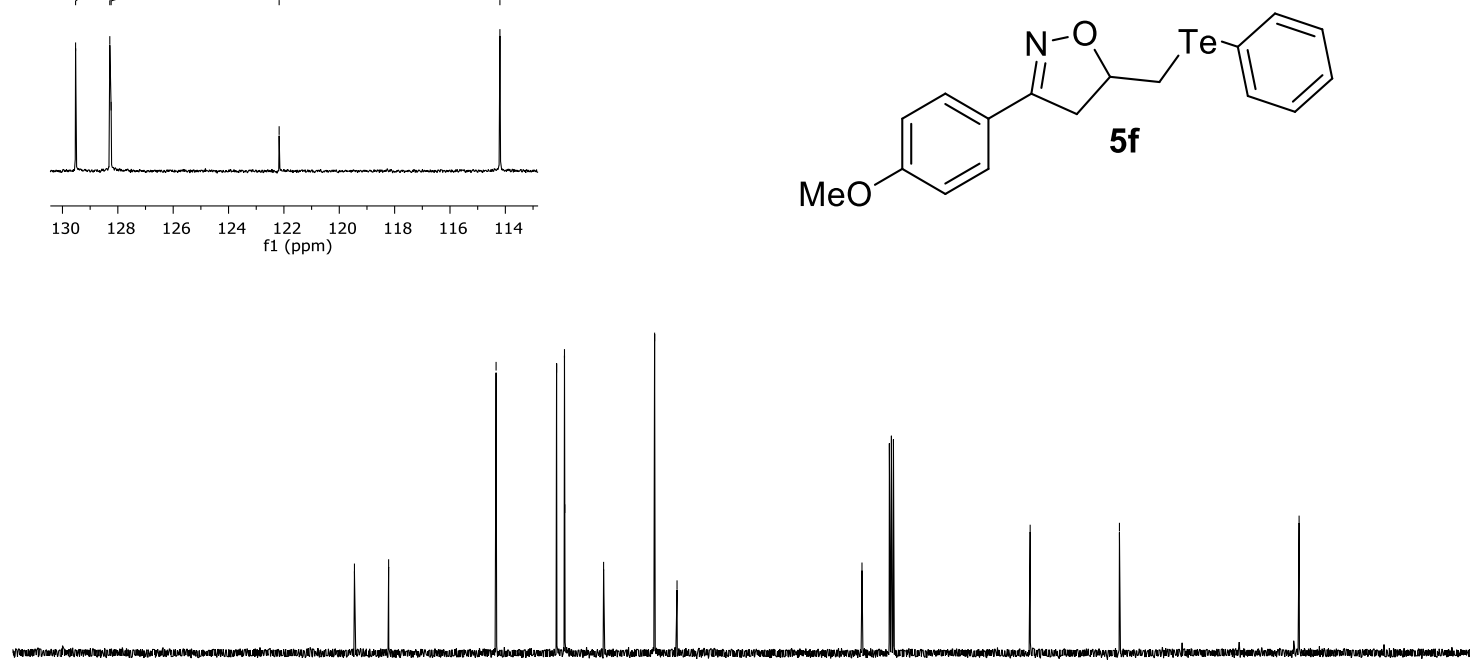

$\begin{array}{llllllllllllllllllllllllll}210 & 200 & 190 & 180 & 170 & 160 & 150 & 140 & 130 & 120 & 110 & 100 & 90 & 80 & 70 & 60 & 50 & 40 & 30 & 20 & 10 & 0 & -10\end{array}$

${ }^{13} \mathrm{C}$ NMR $\left(100 \mathrm{MHz}, \mathrm{CDCl}_{3}\right)$ spectrum of $5 \mathbf{f}$. 
<smiles>COc1ccc(C2=NOC(C[Te]c3ccccc3)C2)cc1</smiles>

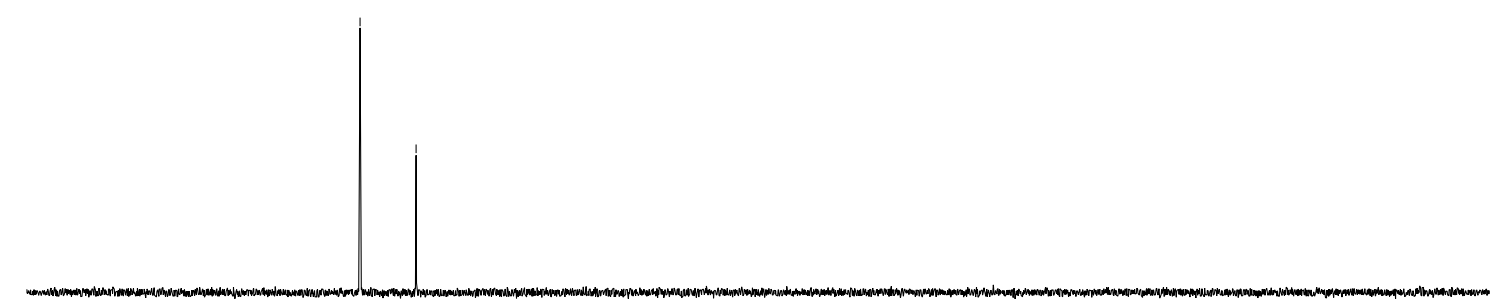

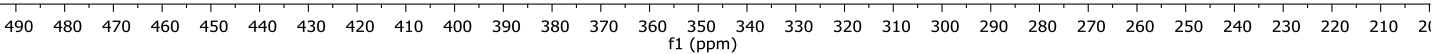

${ }^{125} \mathrm{Te} \mathrm{NMR}\left(126 \mathrm{MHz}, \mathrm{CDCl}_{3},(\mathrm{PhTe})_{2}\right.$ as internal standard) spectrum of $\mathbf{5 f}$.

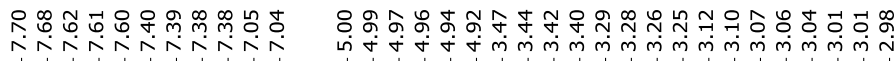
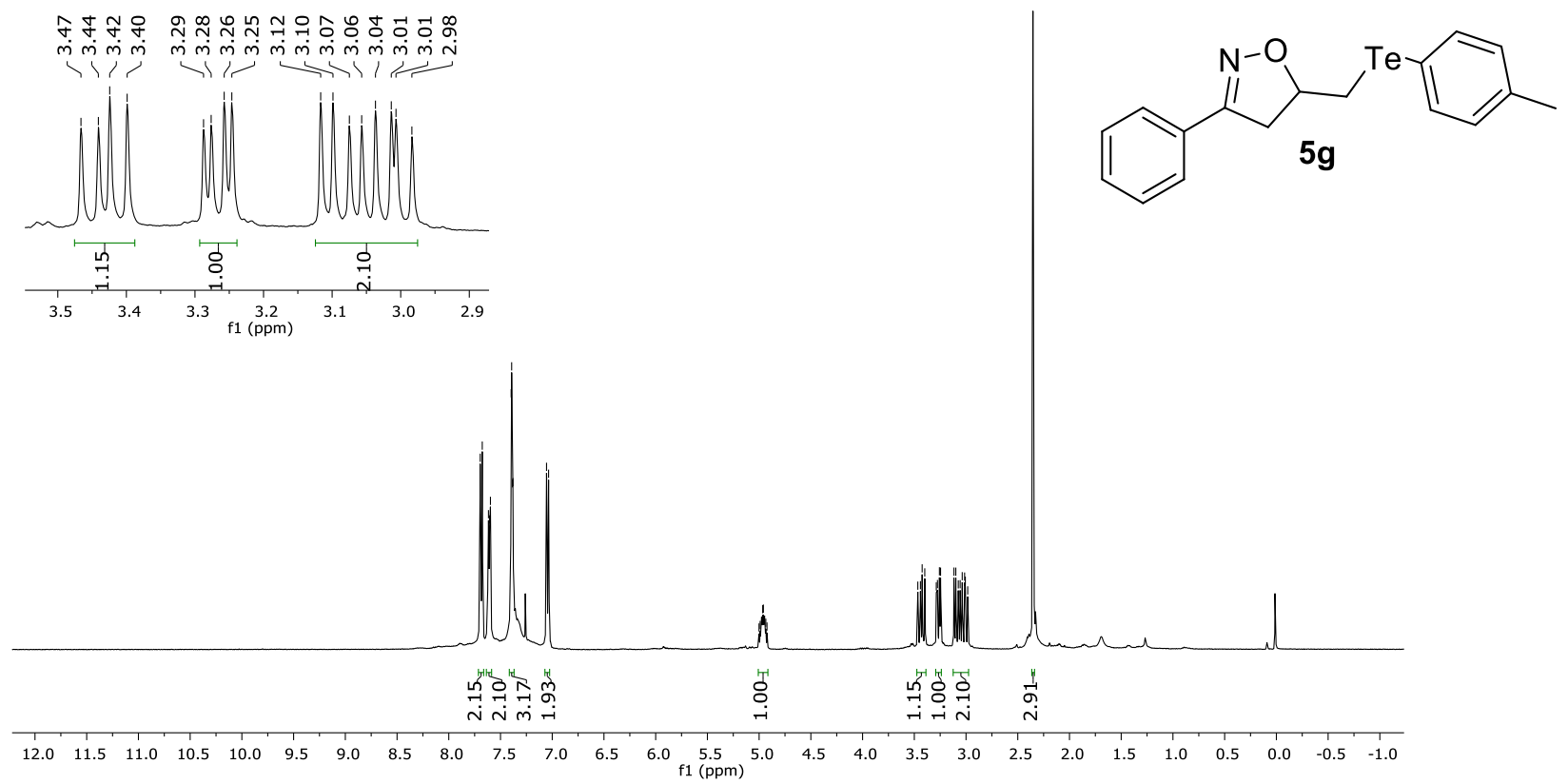

${ }^{1} \mathrm{H}$ NMR $\left(400 \mathrm{MHz}, \mathrm{CDCl}_{3}\right)$ spectrum of $\mathbf{5 g}$. 

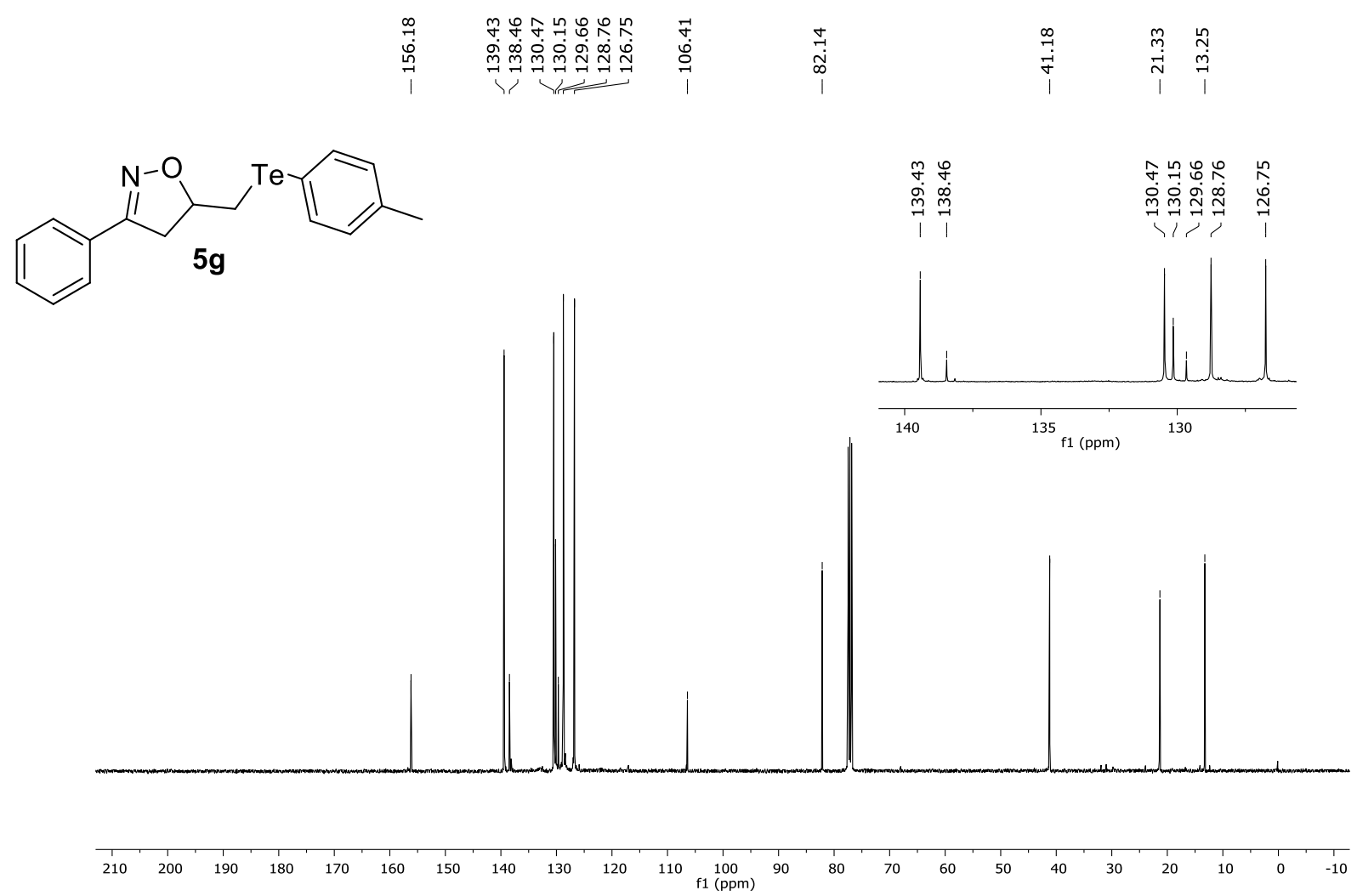

${ }^{13} \mathrm{C}$ NMR $\left(100 \mathrm{MHz}, \mathrm{CDCl}_{3}\right)$ spectrum of $\mathbf{5 g}$.

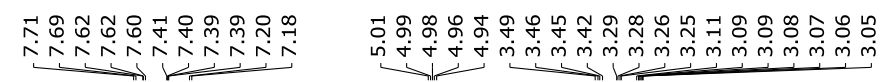

$\overbrace{5 i}$

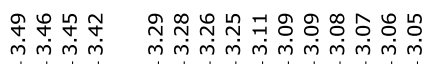

mimim mimim

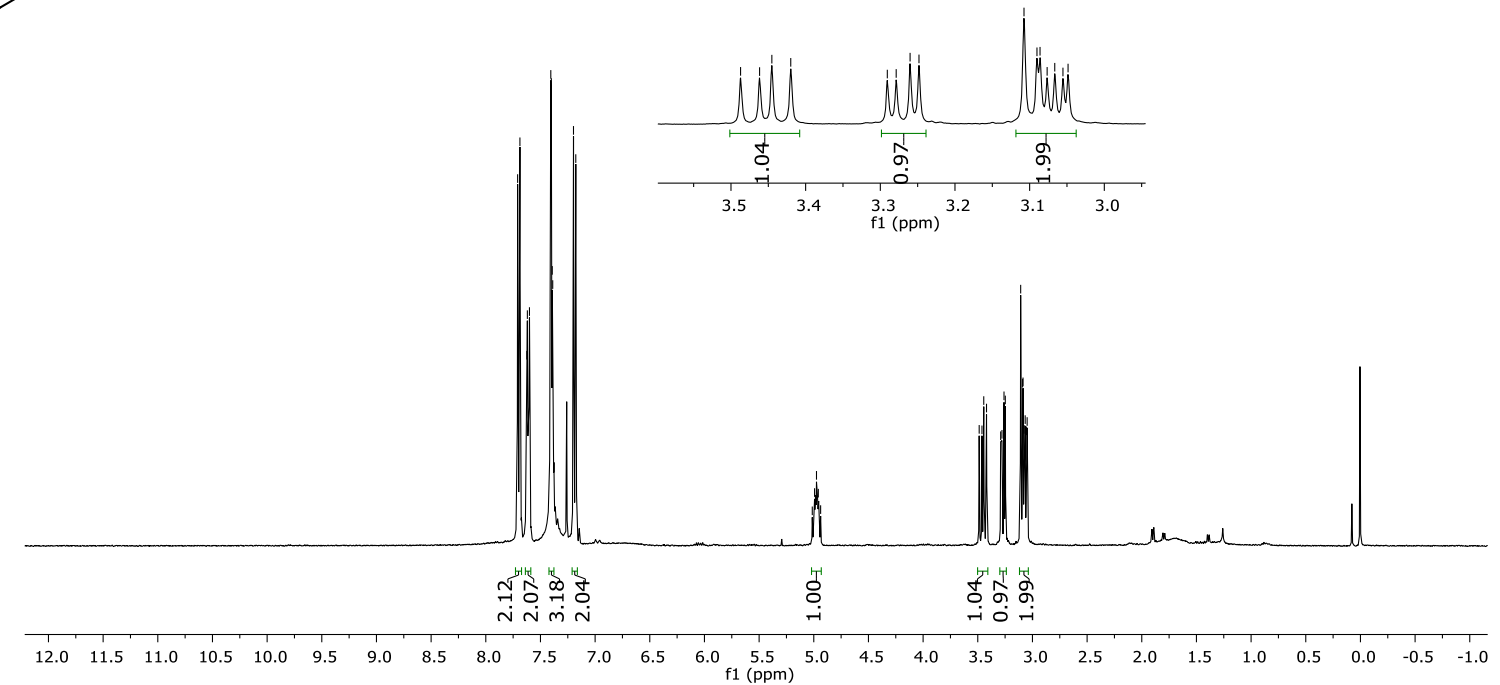

${ }^{1} \mathrm{H}$ NMR $\left(400 \mathrm{MHz}, \mathrm{CDCl}_{3}\right)$ spectrum of $\mathbf{5 i}$. 


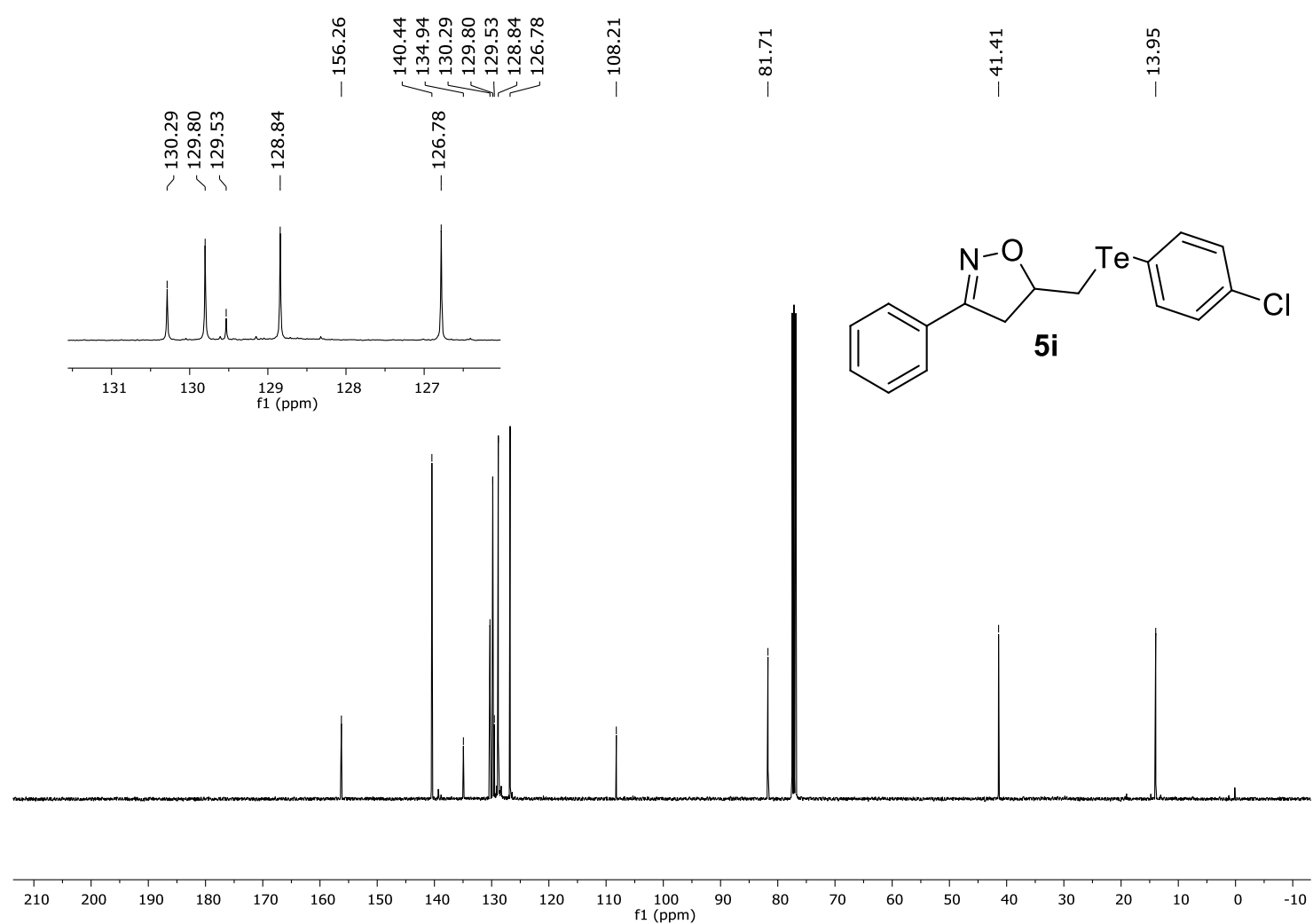

${ }^{13} \mathrm{C}$ NMR $\left(100 \mathrm{MHz}, \mathrm{CDCl}_{3}\right)$ spectrum of $\mathbf{5 i}$.

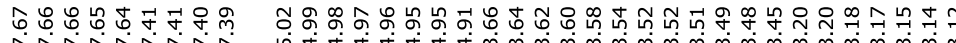 \\ мं लें}
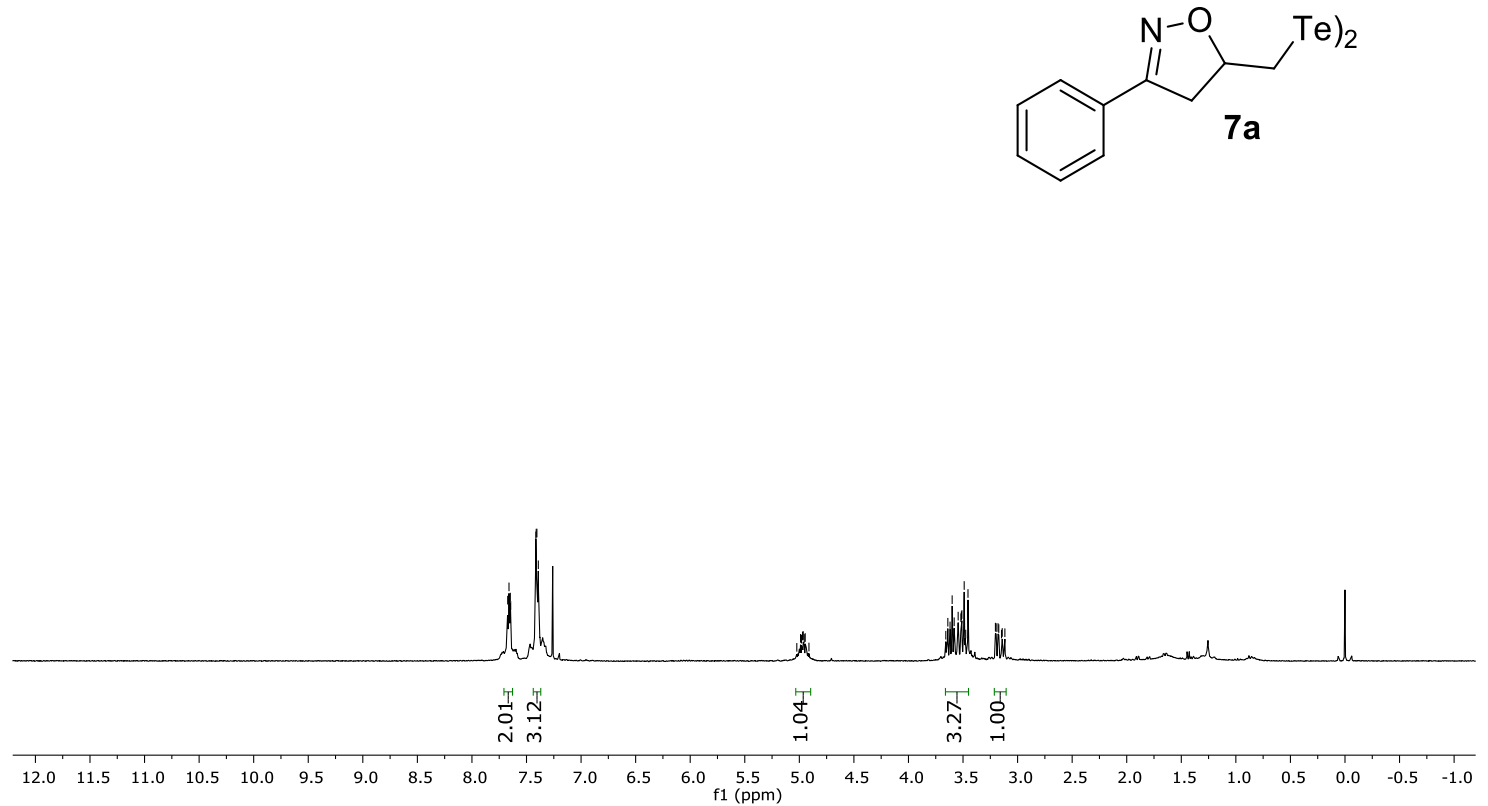

${ }^{1} \mathrm{H}$ NMR $\left(300 \mathrm{MHz}, \mathrm{CDCl}_{3}\right)$ spectrum of $7 \mathbf{a}$. 


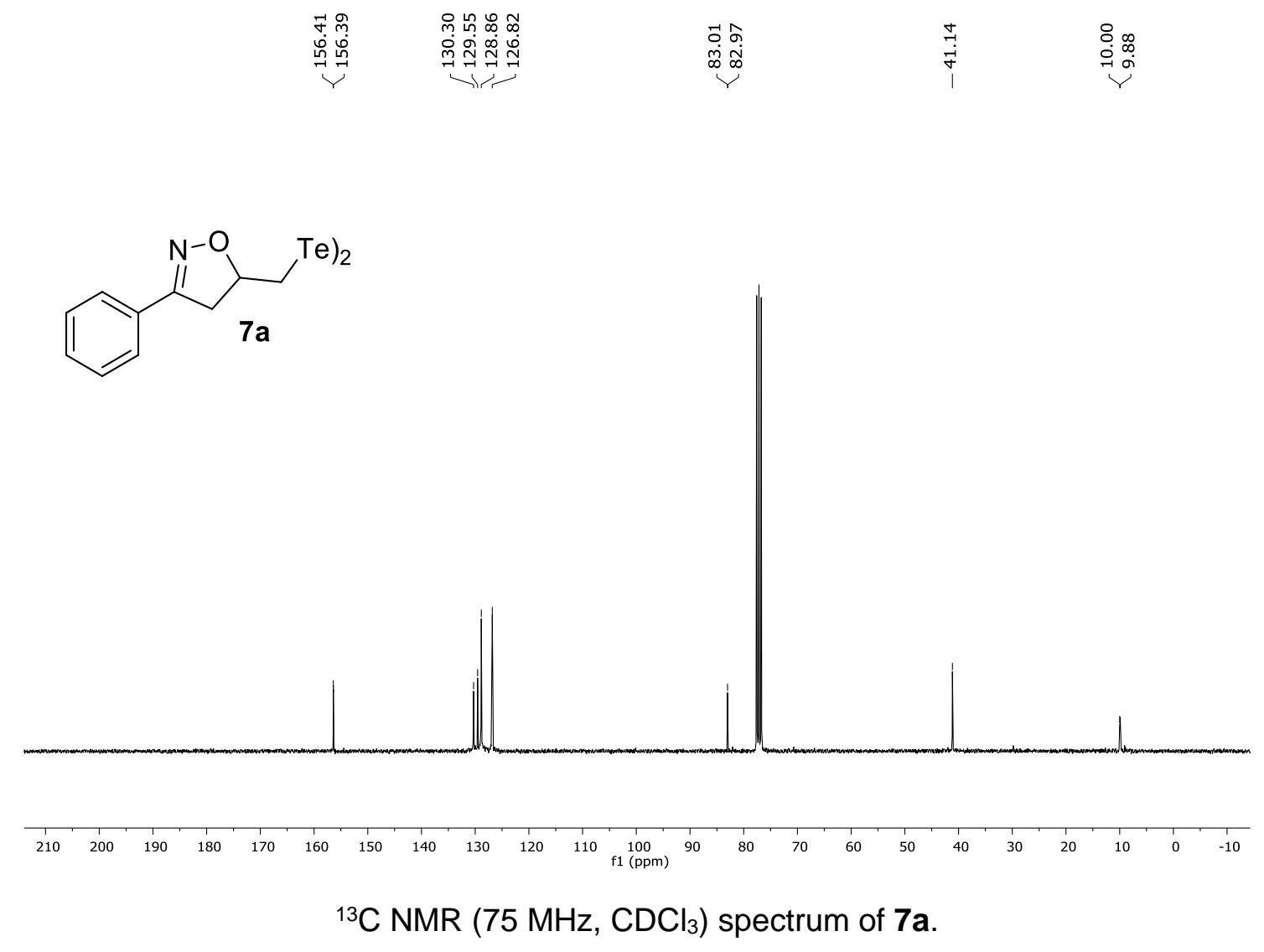

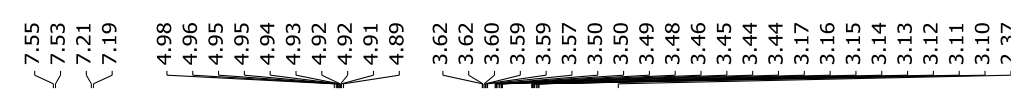
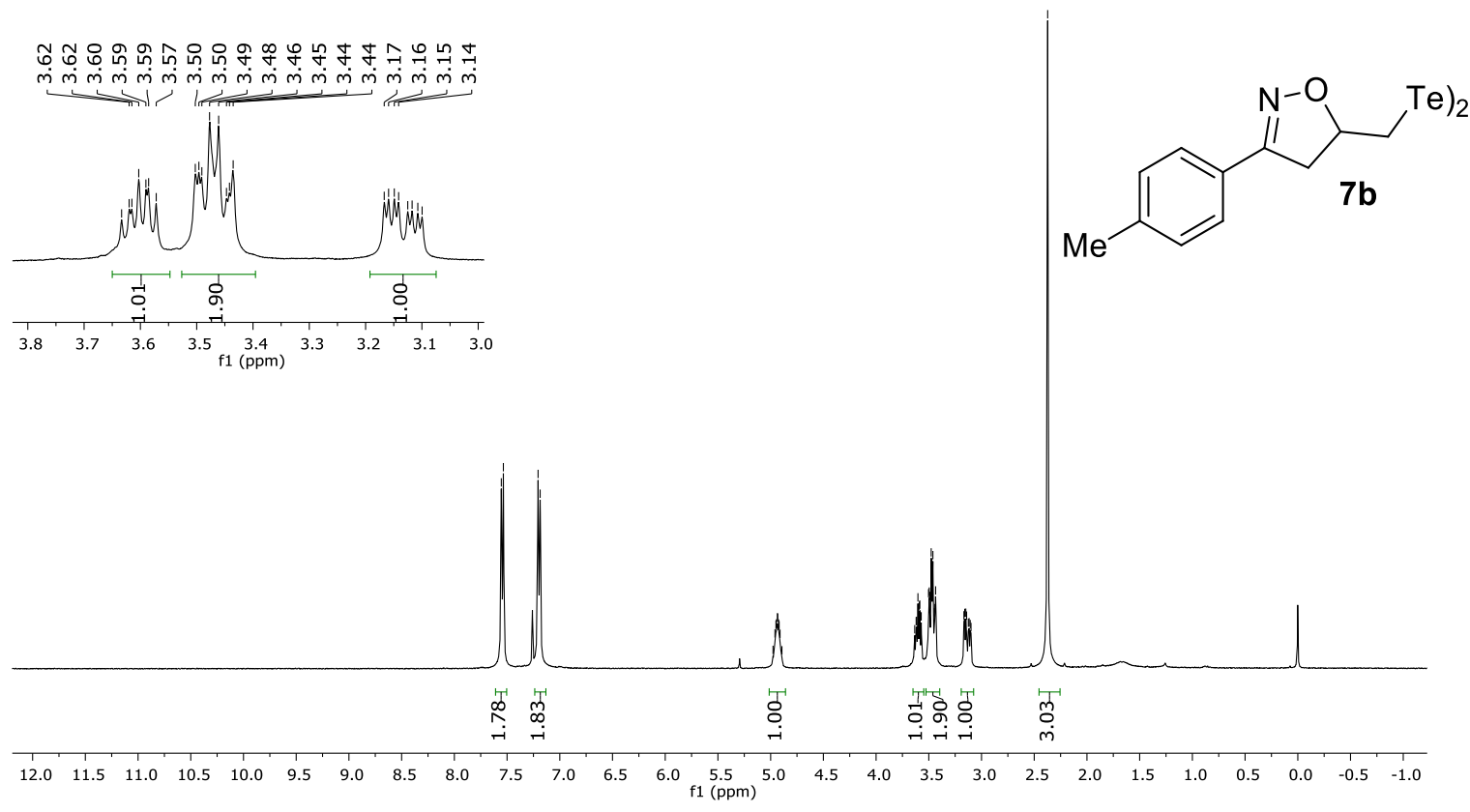

${ }^{1} \mathrm{H}$ NMR $\left(400 \mathrm{MHz}, \mathrm{CDCl}_{3}\right)$ spectrum of $\mathbf{7 b}$. 

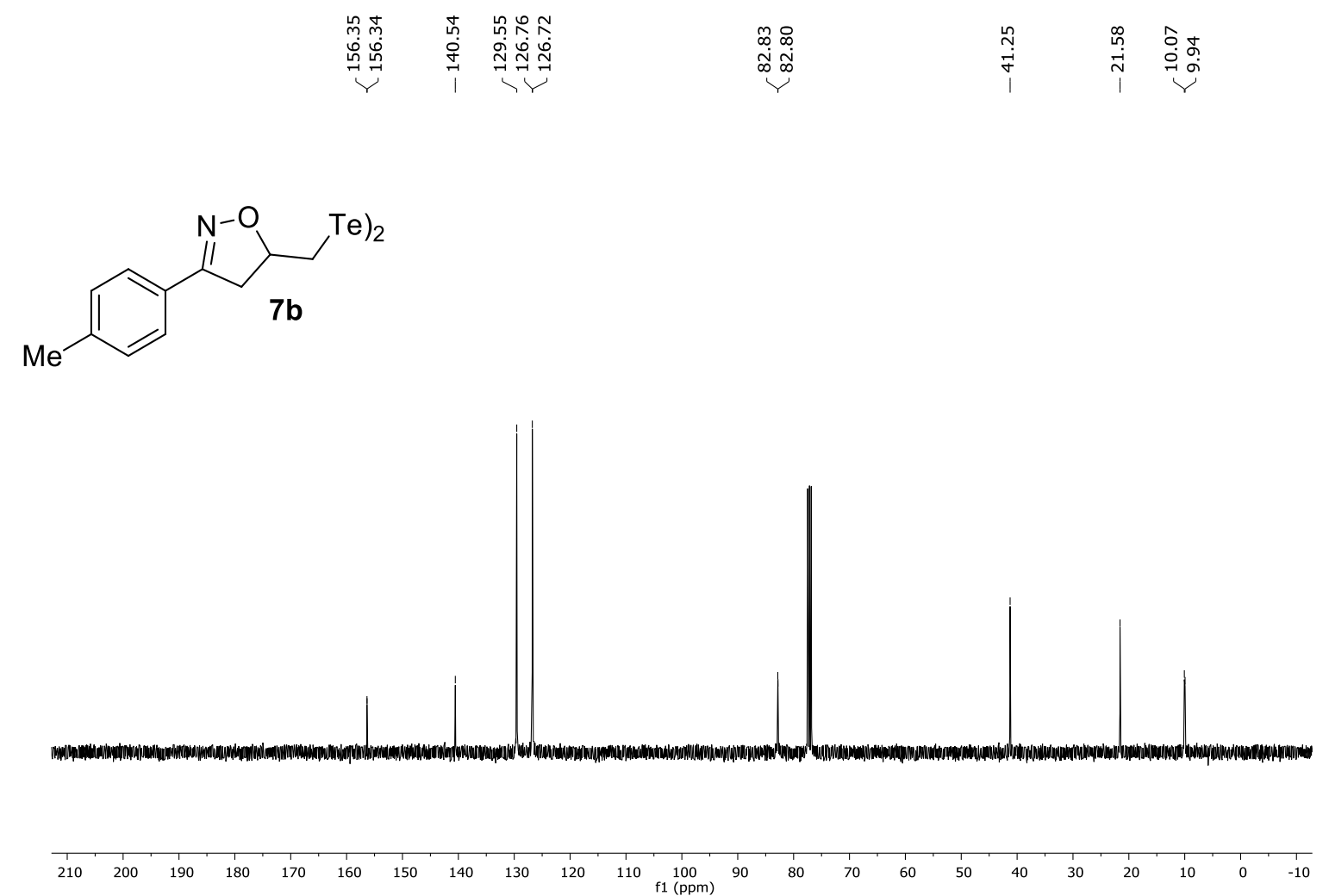

${ }^{13} \mathrm{C}$ NMR $\left(100 \mathrm{MHz}, \mathrm{CDCl}_{3}\right)$ spectrum of $\mathbf{7 b}$.

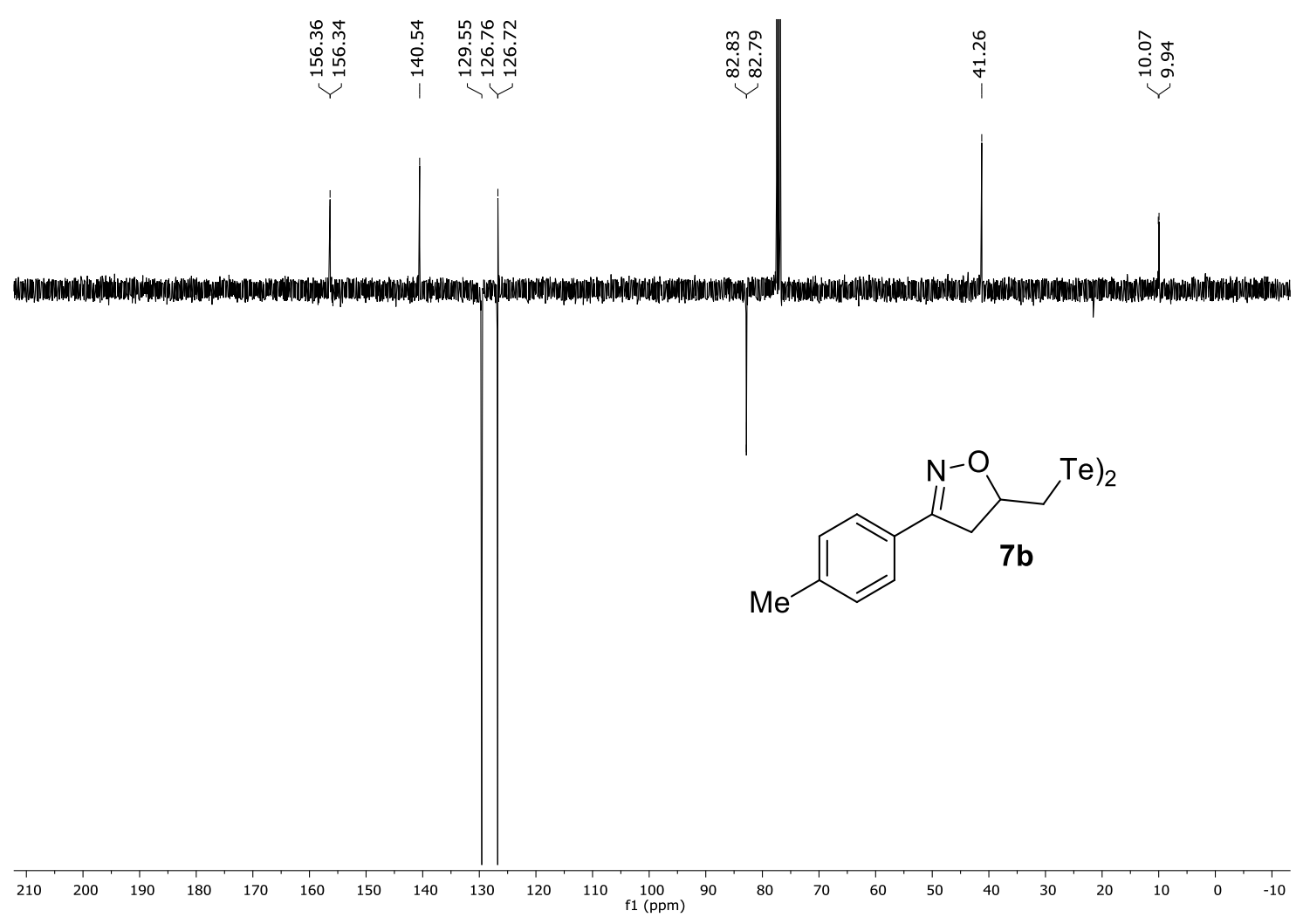

${ }^{13} \mathrm{C}$ APT NMR $\left(100 \mathrm{MHz}, \mathrm{CDCl}_{3}\right)$ spectrum of $\mathbf{7 b}$. 
<smiles>Cc1ccc(C2=NOC(C[Te+2])C2)cc1</smiles>

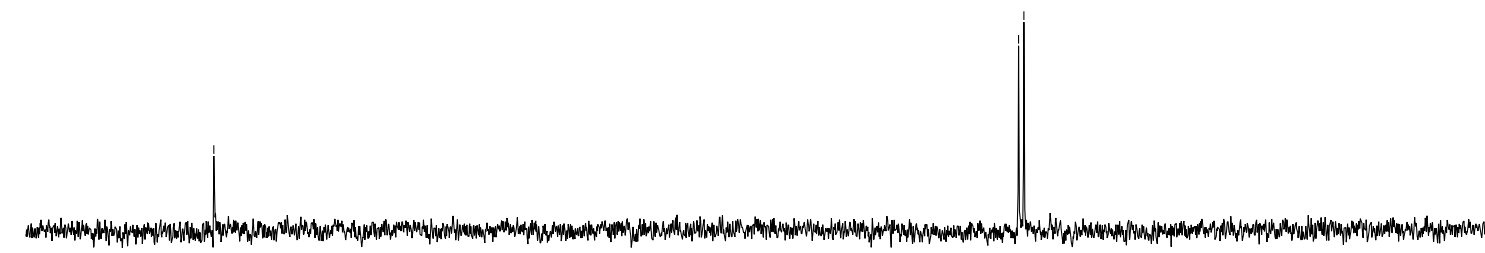
${ }^{125} \mathrm{Te}$ NMR (126 MHz, $\mathrm{CDCl}_{3},(\mathrm{PhTe})_{2}$ as internal standard) spectrum of $\mathbf{7 b}$.

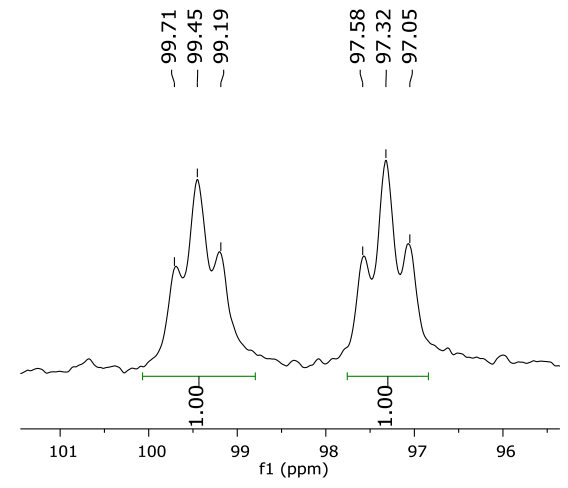<smiles>Cc1ccc(C2=NOC(C[TeH2])C2)cc1</smiles>

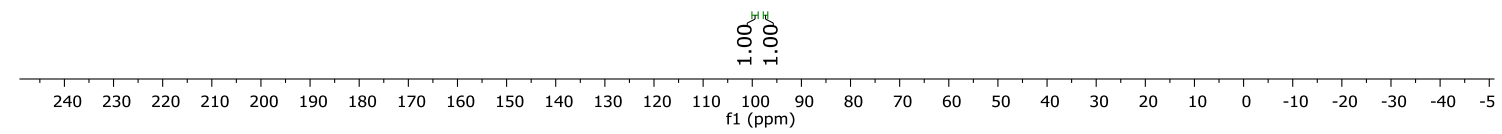

Decoupled ${ }^{125} \mathrm{Te} \mathrm{NMR}\left(126 \mathrm{MHz}, \mathrm{CDCl}_{3}\right)$ spectrum of $\mathbf{7 b}$. 


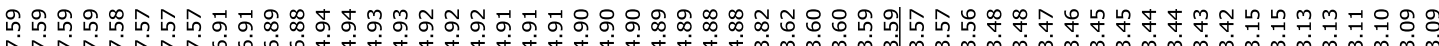

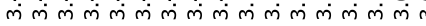

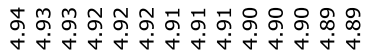

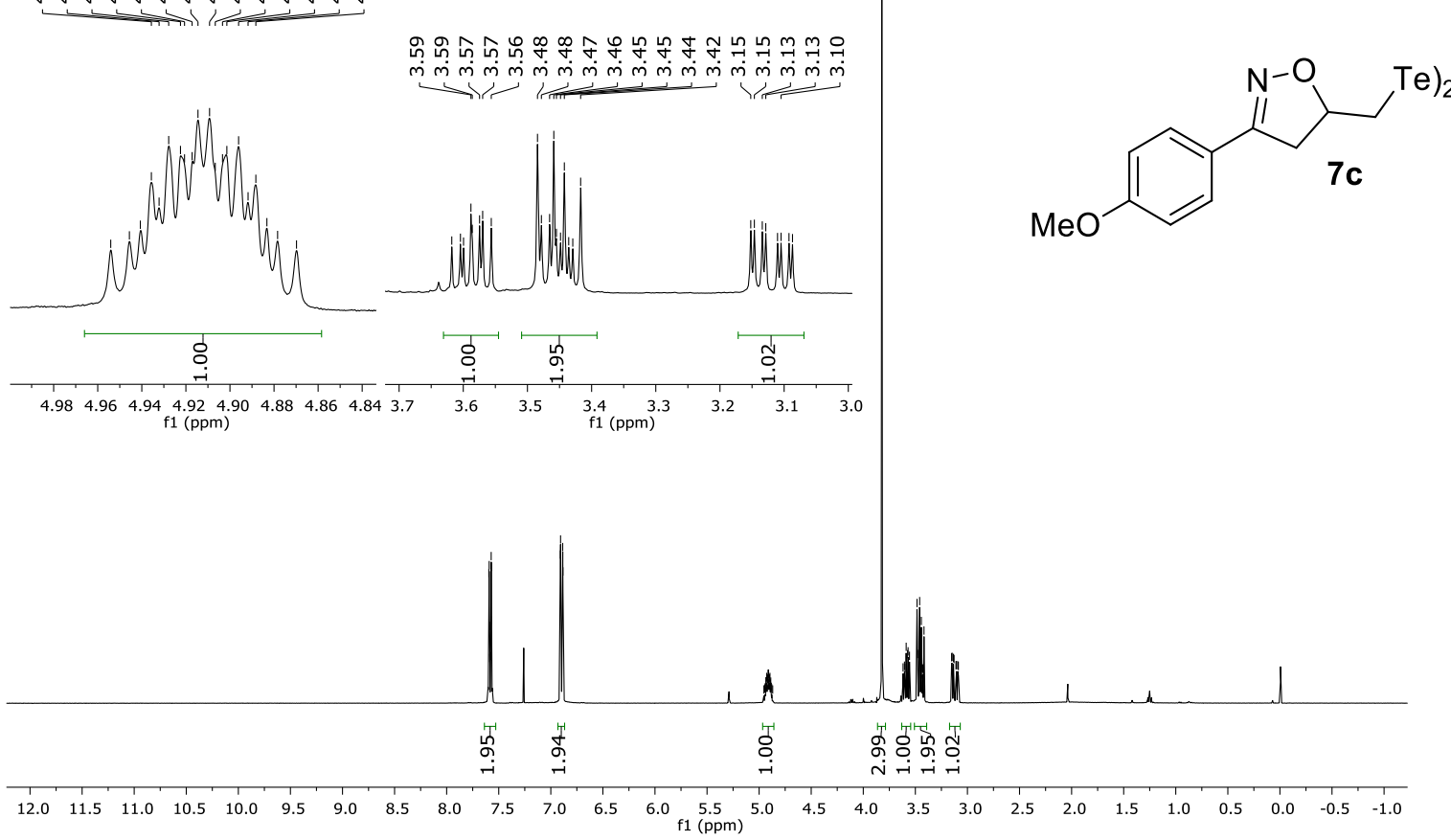

${ }^{1} \mathrm{H}$ NMR $\left(400 \mathrm{MHz}, \mathrm{CDCl}_{3}\right)$ spectrum of $7 \mathrm{c}$.

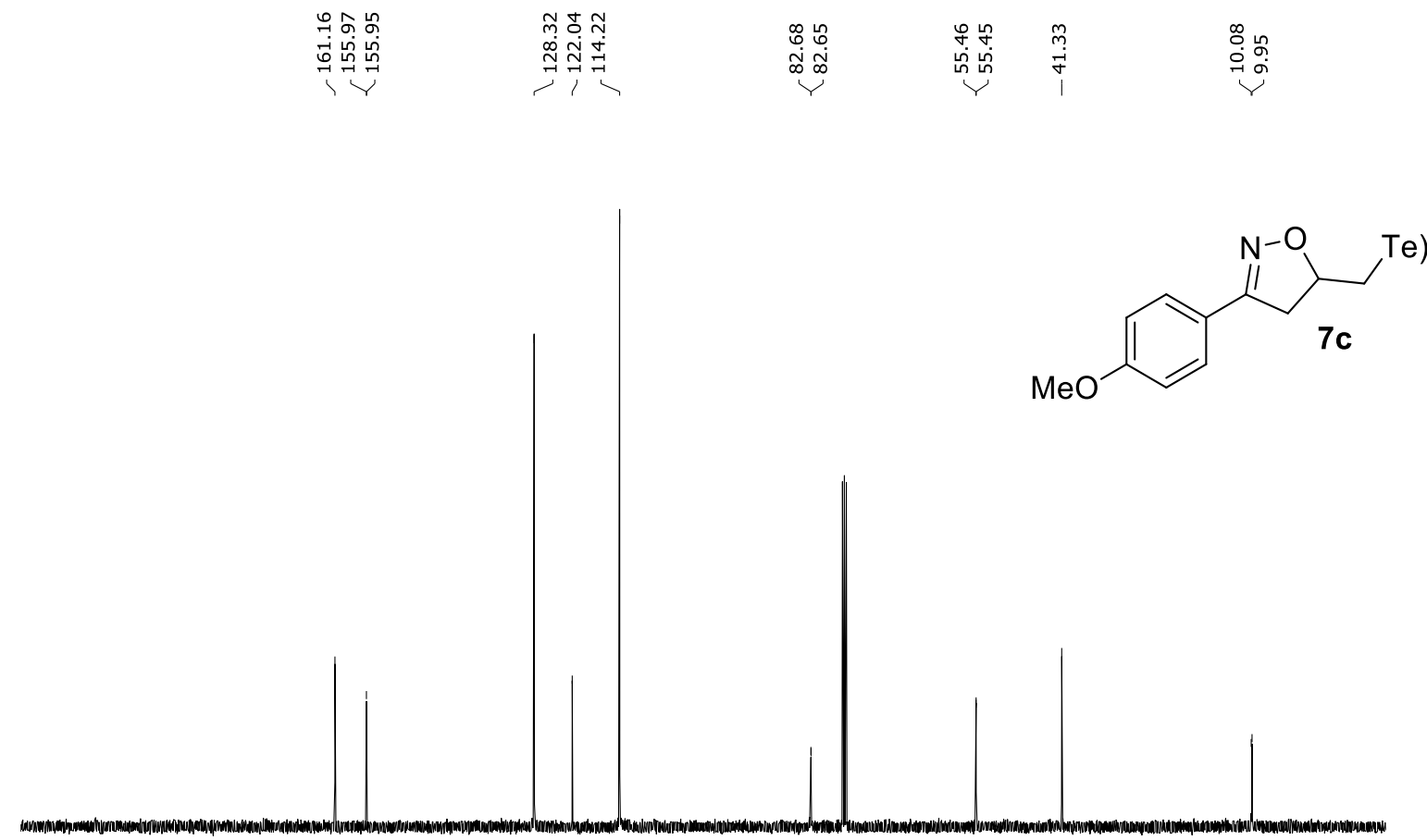

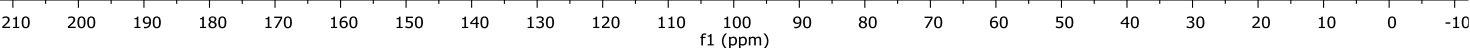

${ }^{13} \mathrm{C}$ NMR $\left(100 \mathrm{MHz}, \mathrm{CDCl}_{3}\right)$ spectrum of $7 \mathrm{c}$. 
<smiles>COc1ccc(C2=NOC(C[TeH2])C2)cc1</smiles>

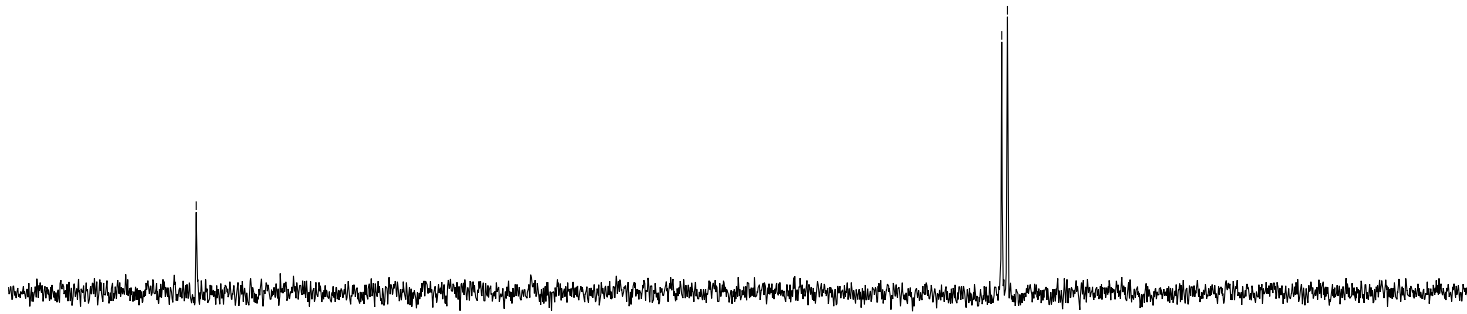

$\begin{array}{llllllllllllllllllllllllllllllllll}480 & 460 & 440 & 420 & 400 & 380 & 360 & 340 & 320 & 300 & 280 & 260 & 240 & 220 & 200 & 180 & 160 & 140 & 120 & 100 & 80 & 60 & 40 & 20 & 0 & -20 & -40 & -60 & -80 & 125 \\ \mathrm{fppm}) & & & & & & & & & & & & & & & \end{array}$ (126 MHz, $\mathrm{CDCl}_{3},(\mathrm{PhTe})_{2}$ as internal standard) spectrum of 7c.

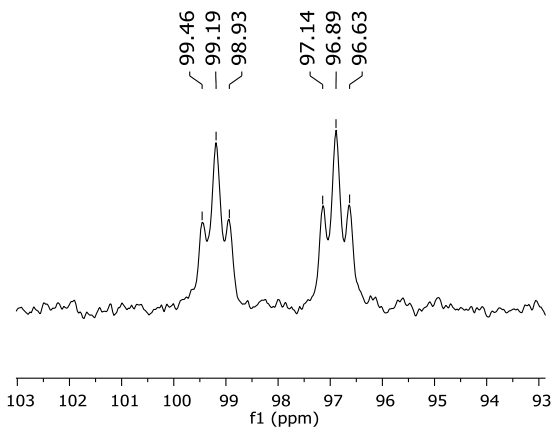<smiles>COc1ccc(C2=NOC(C[Te+2])C2)cc1</smiles>

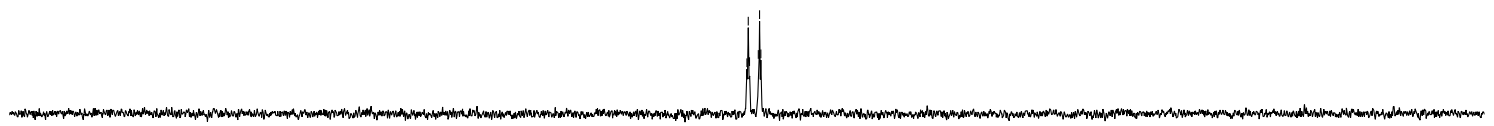

$\begin{array}{lllllllllllllllllllllllllllllllllllllllllllllll}240 & 230 & 220 & 210 & 200 & 190 & 180 & 170 & 160 & 150 & 140 & 130 & 120 & 110 & 100 & 90 & 80 & 70 & 60 & 50 & 40 & 30 & 20 & 10 & 0 & -10 & -20 & -30 & -40 & -5\end{array}$

Decoupled ${ }^{125} \mathrm{Te} \mathrm{NMR}\left(126 \mathrm{MHz}, \mathrm{CDCl}_{3}\right)$ spectrum of $7 \mathrm{c}$. 

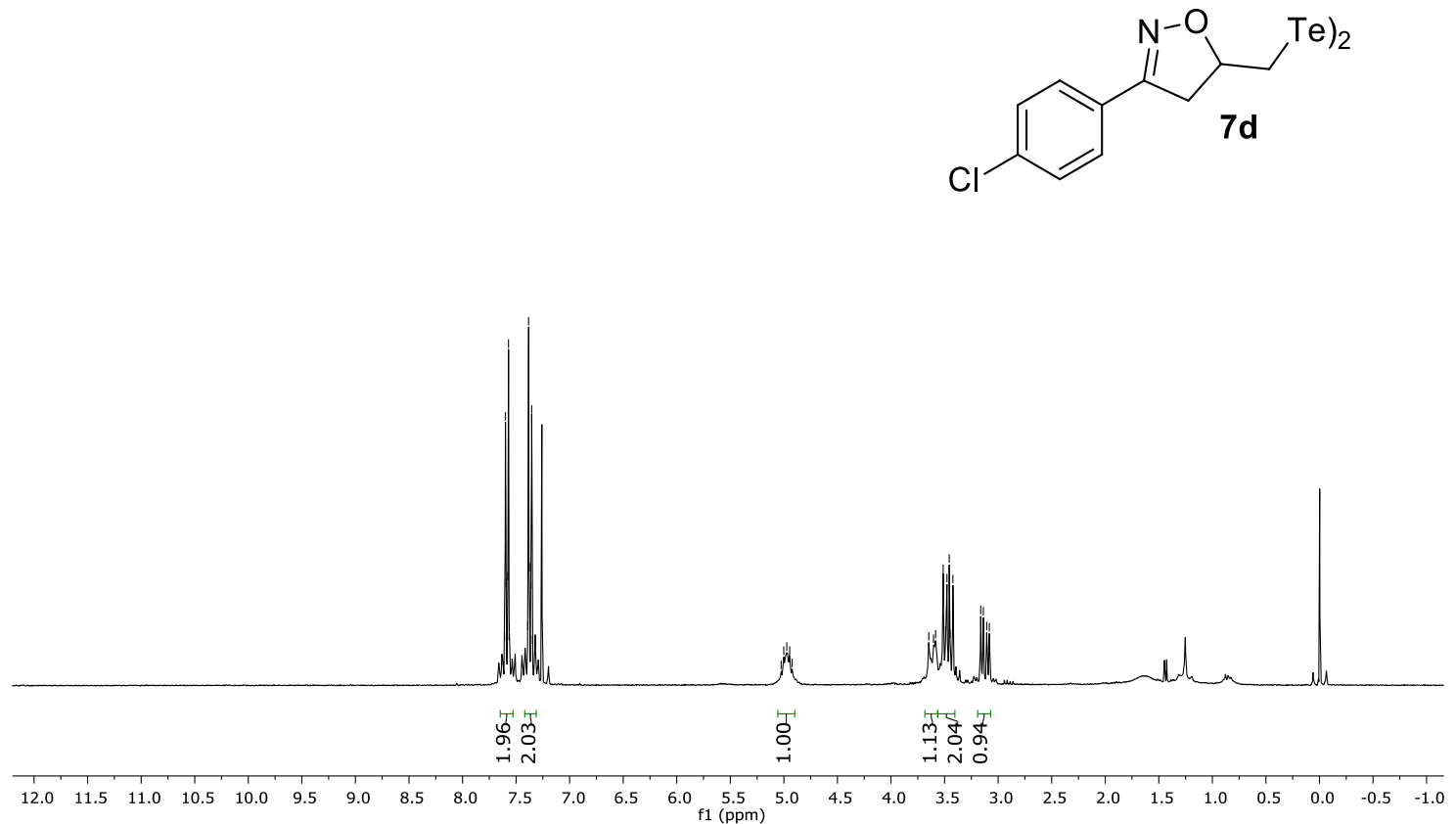

${ }^{1} \mathrm{H}$ NMR (400 MHz, $\mathrm{CDCl}_{3}$ ) spectrum of $7 \mathrm{~d}$.

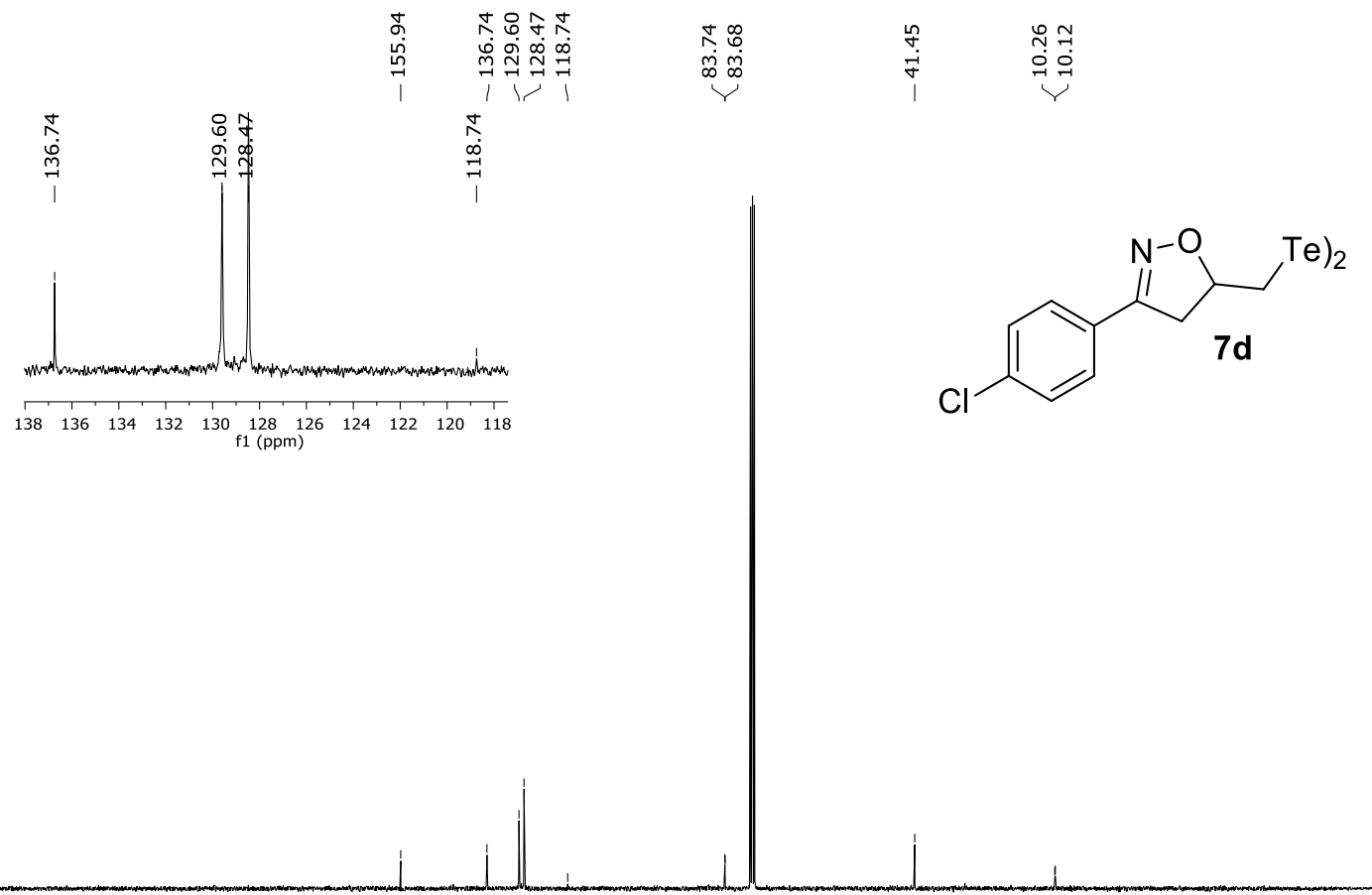

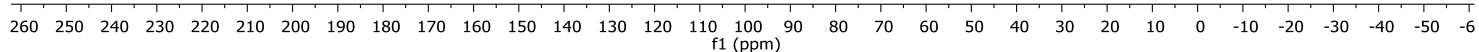

${ }^{13} \mathrm{C}$ NMR $\left(100 \mathrm{MHz}, \mathrm{CDCl}_{3}\right)$ spectrum of $\mathbf{7 d}$. 


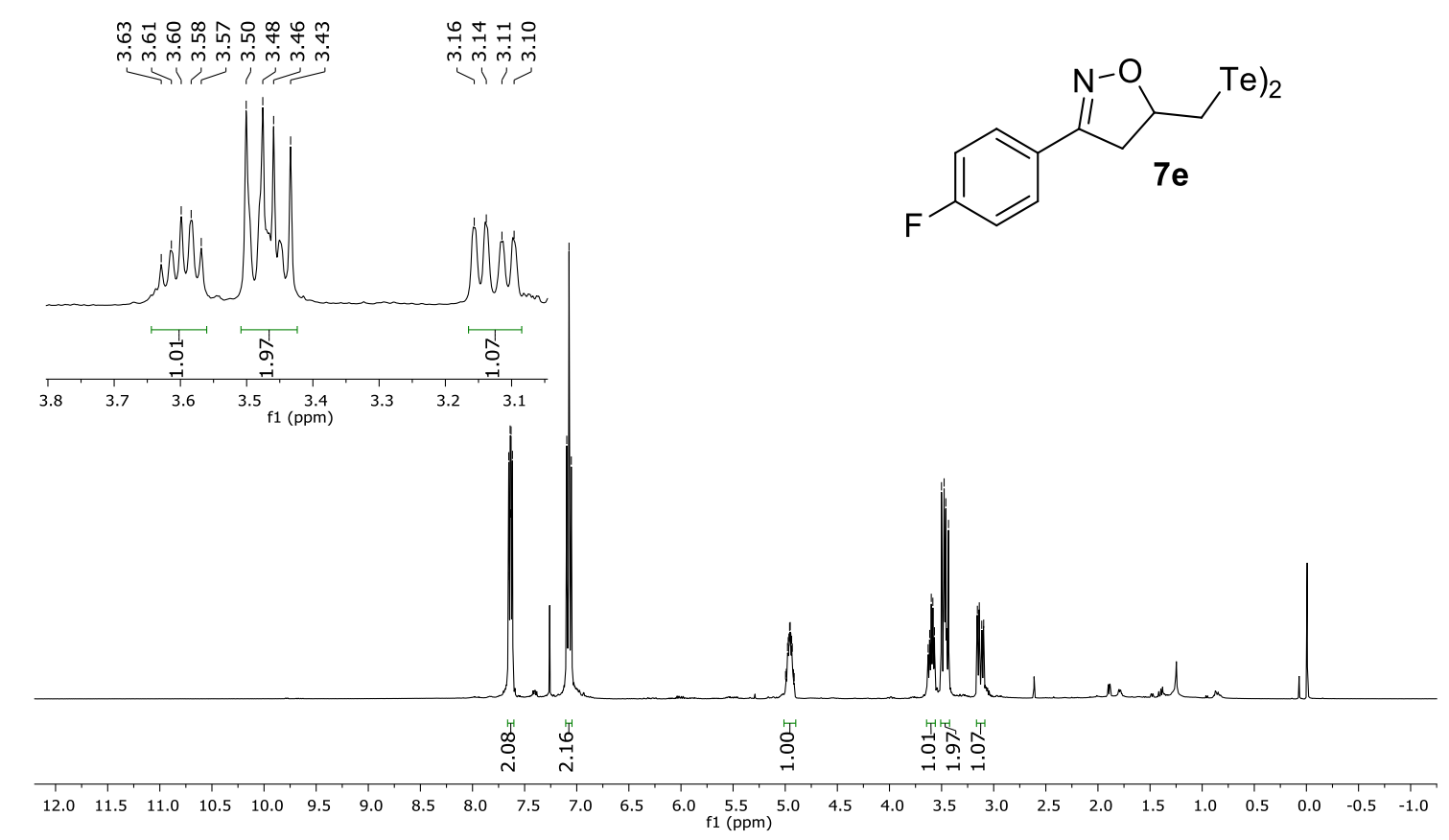

${ }^{1} \mathrm{H}$ NMR $\left(400 \mathrm{MHz}, \mathrm{CDCl}_{3}\right)$ spectrum of $7 \mathbf{e}$.

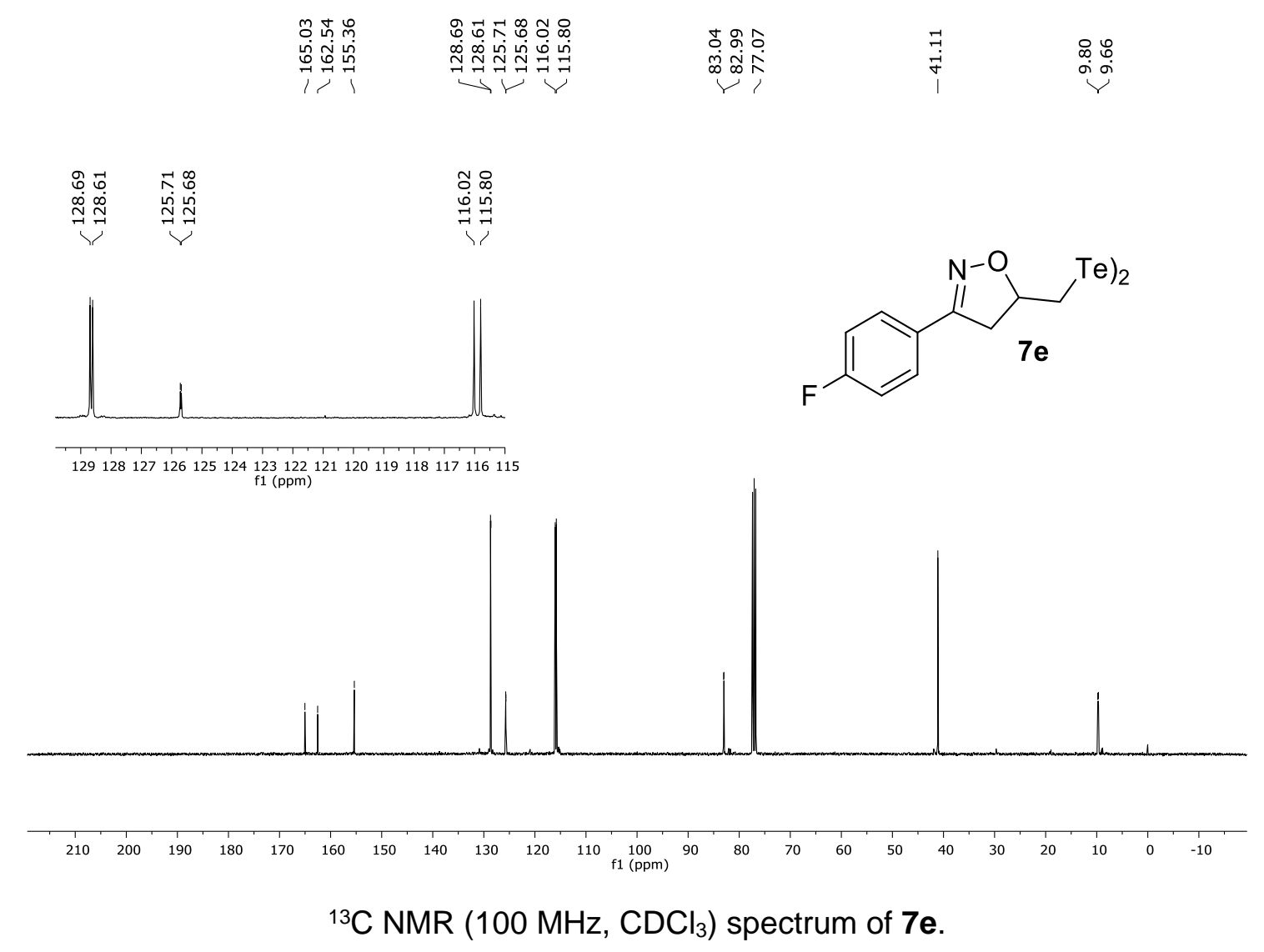



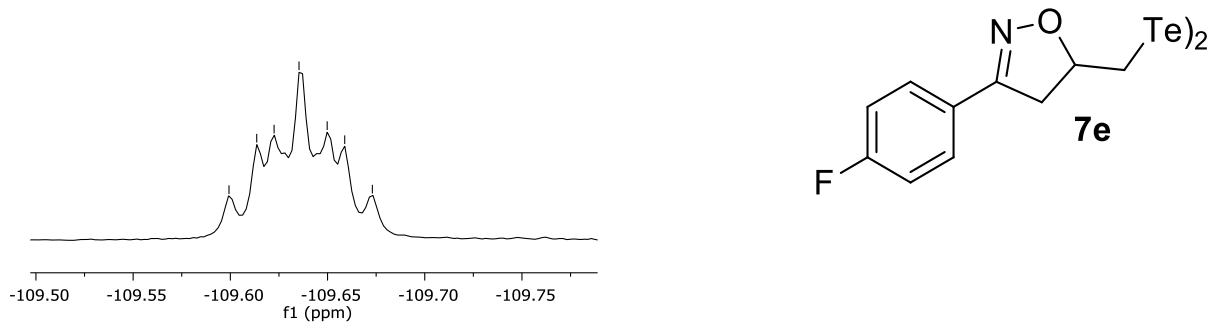

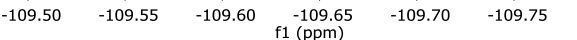
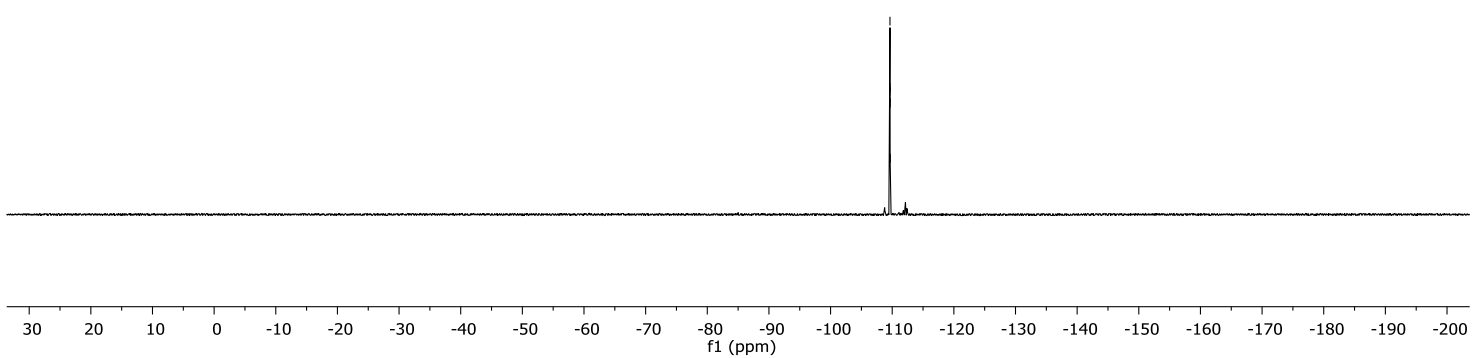

${ }^{19} \mathrm{~F} \mathrm{NMR}\left(376 \mathrm{MHz}, \mathrm{CDCl}_{3}\right)$ spectrum of $7 \mathbf{e}$.

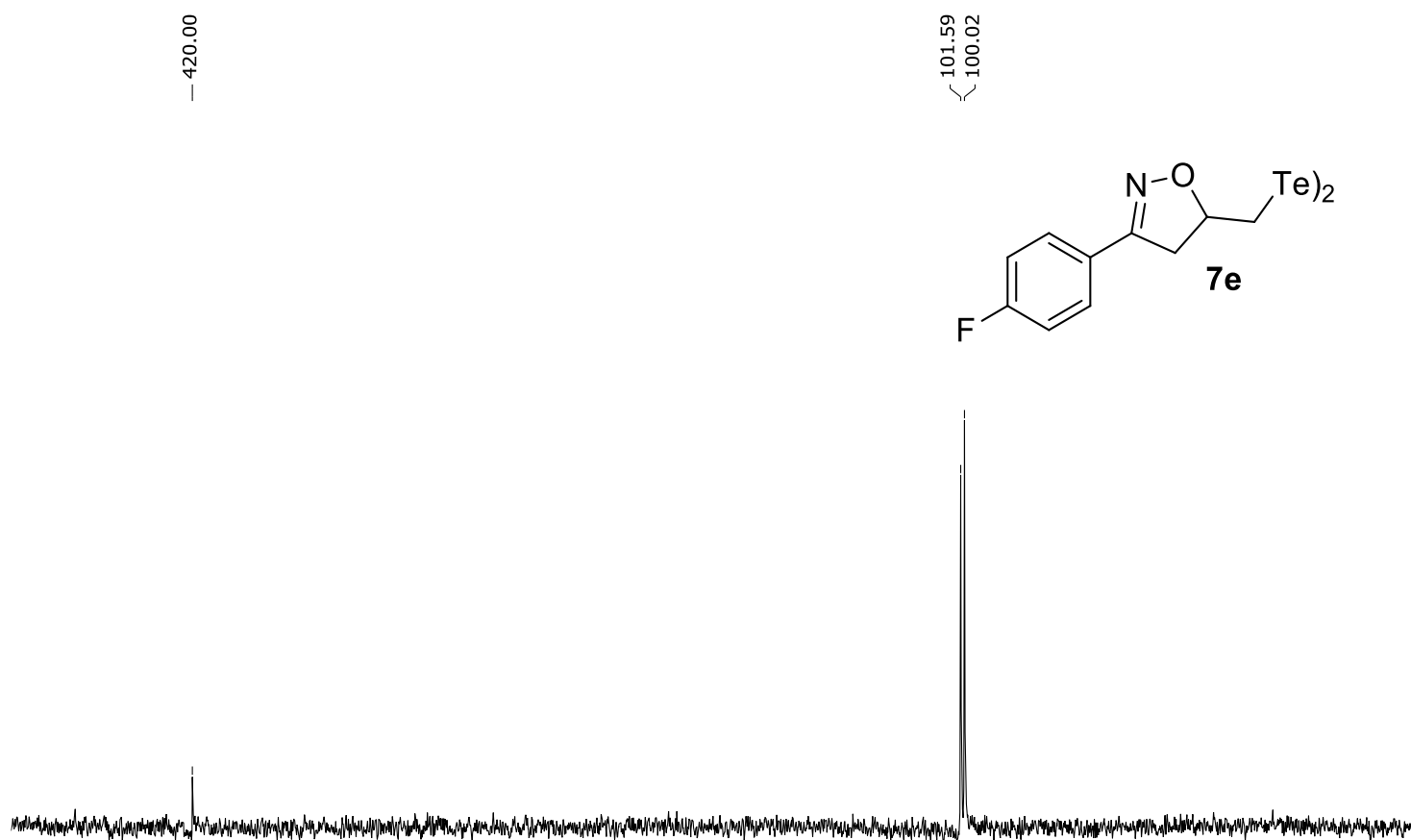

$\begin{array}{llllllllllllllllllllllllllllllllllll}480 & 460 & 440 & 420 & 400 & 380 & 360 & 340 & 320 & 300 & 280 & 260 & 240 & 220 & 200 & 180 & 160 & 140 & 120 & 100 & 80 & 60 & 40 & 20 & 0 & -20 & -40 & -60 & -80\end{array}$ ${ }^{125} \mathrm{Te} \mathrm{NMR}\left(126 \mathrm{MHz}, \mathrm{CDCl}_{3},(\mathrm{PhTe})_{2}\right.$ as internal standard) spectrum of $7 \mathrm{e}$. 


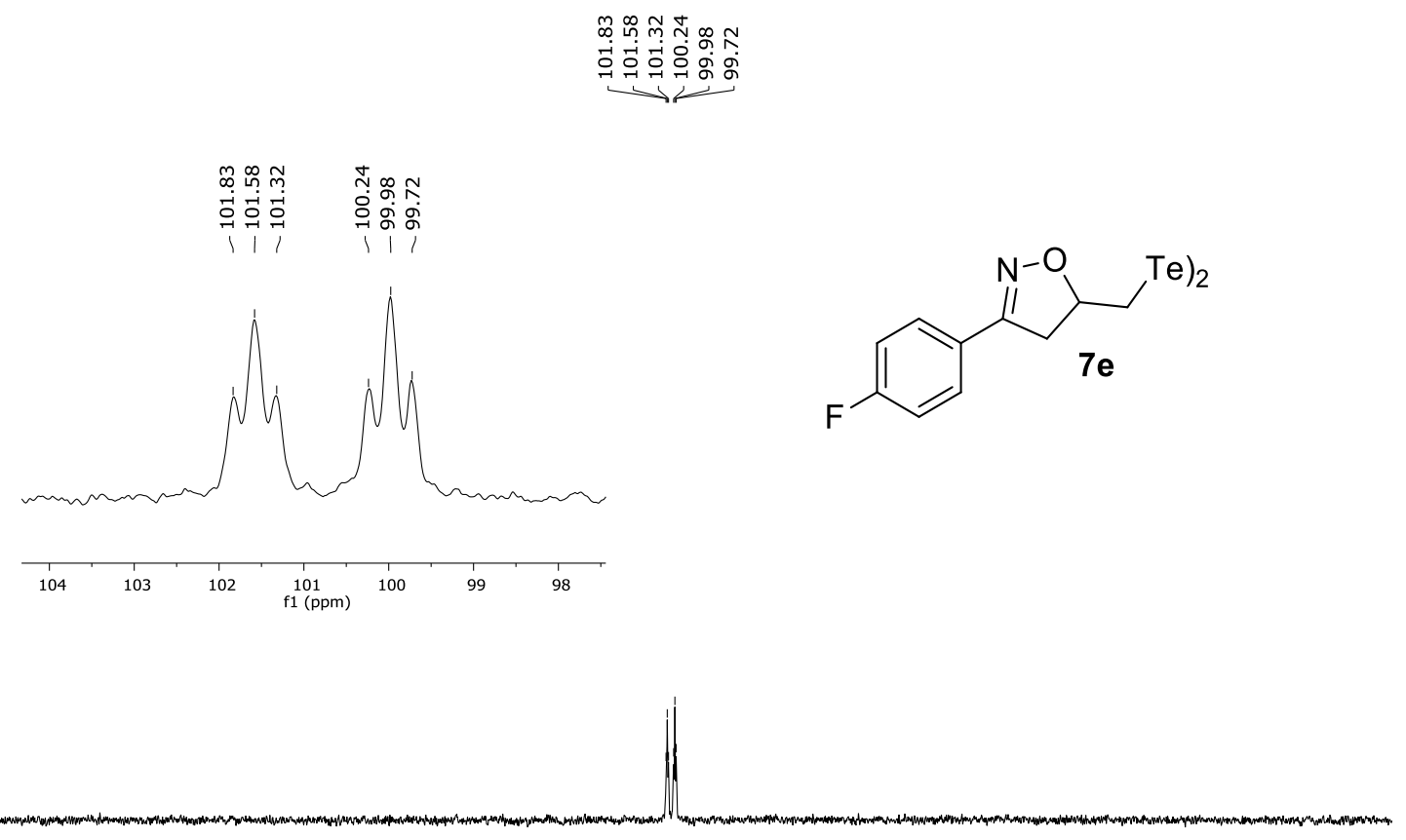

$\begin{array}{lllllllllllllllllllllllllllllllllllll}240 & 230 & 220 & 210 & 200 & 190 & 180 & 170 & 160 & 150 & 140 & 130 & 120 & 110 & 100 & 90 & 80 & 70 & 60 & 50 & 40 & 30 & 20 & 10 & 0 & -10 & -20 & -30 & -40 & -5\end{array}$

Decoupled ${ }^{125} \mathrm{Te} \mathrm{NMR}\left(126 \mathrm{MHz}, \mathrm{CDCl}_{3}\right)$ spectrum of $7 \mathrm{e}$.

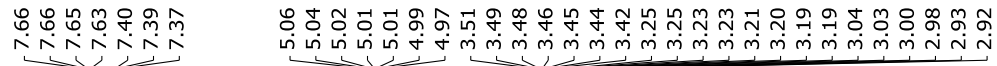
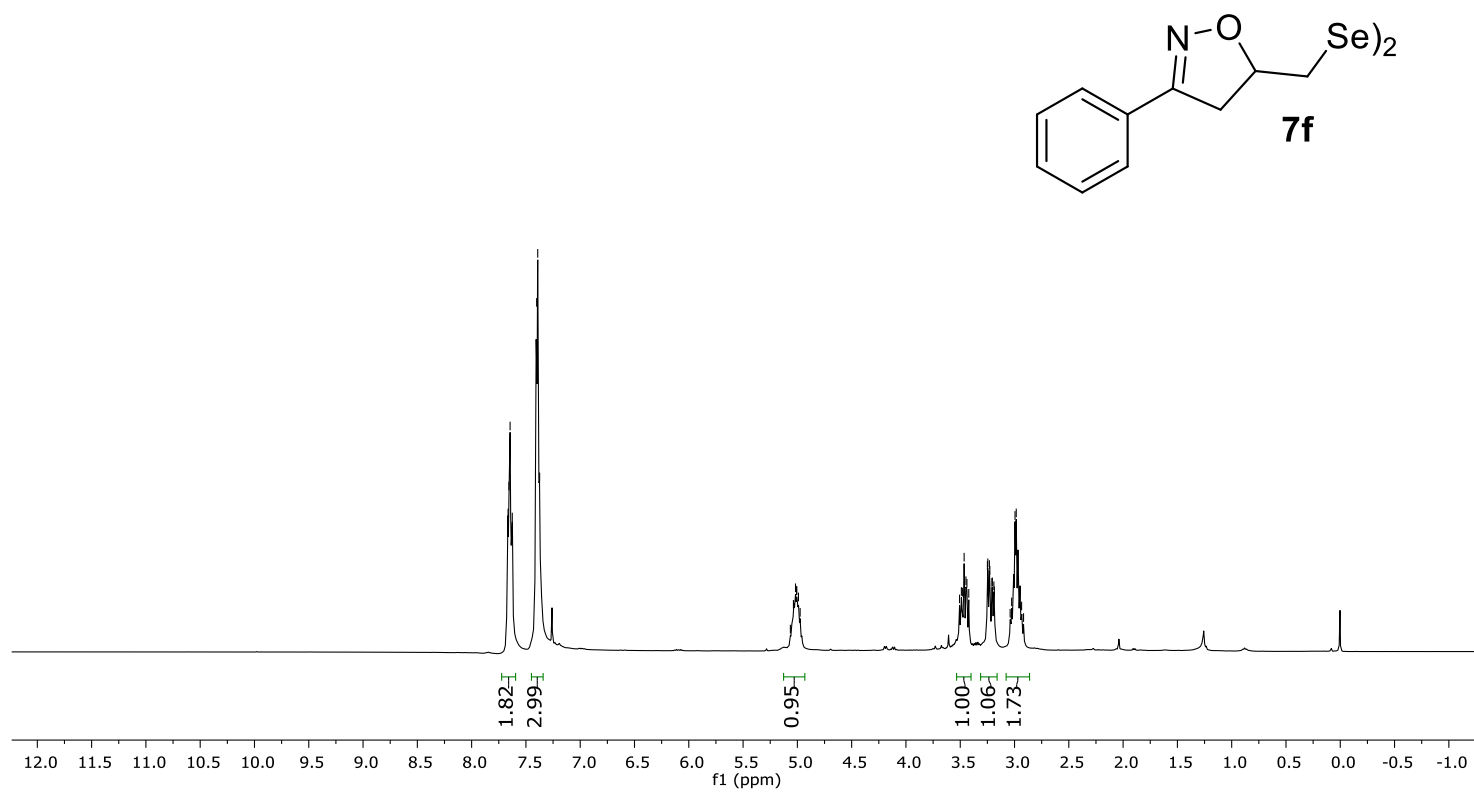

${ }^{1} \mathrm{H}$ NMR $\left(400 \mathrm{MHz}, \mathrm{CDCl}_{3}\right)$ spectrum of $7 \mathrm{f}$. 


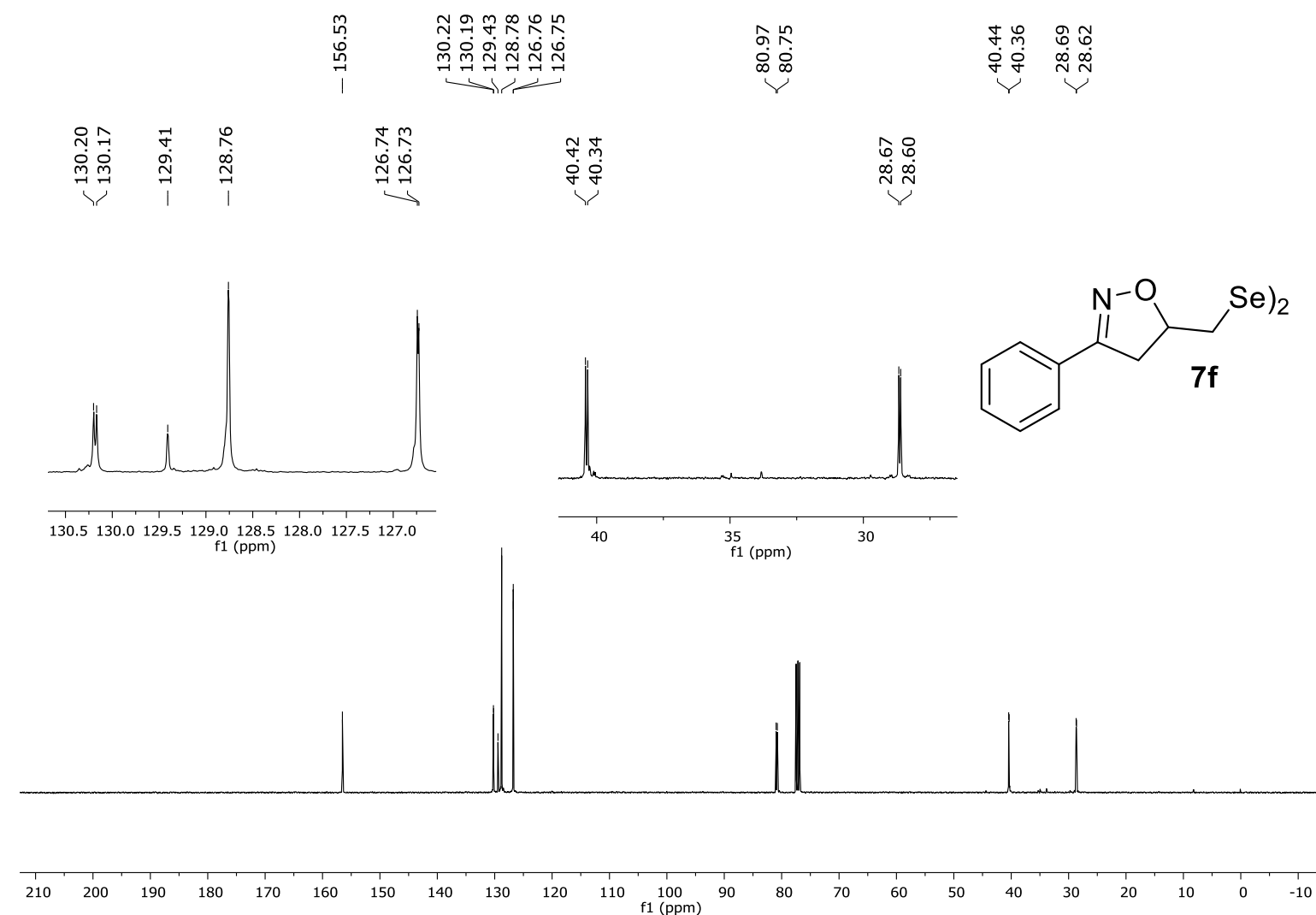

${ }^{13} \mathrm{C} \mathrm{NMR}\left(100 \mathrm{MHz}, \mathrm{CDCl}_{3}\right)$ spectrum of $\mathbf{7 f}$. 